University of Louisville

ThinkIR: The University of Louisville's Institutional Repository

Electronic Theses and Dissertations

$5-2018$

\title{
A 3D numerical analysis of the railway to compare the performance of the granular and asphalt trackbeds.
}

Thammapot Wattanapanalai

University of Louisville

Follow this and additional works at: https://ir.library.louisville.edu/etd

Part of the Transportation Engineering Commons

\section{Recommended Citation}

Wattanapanalai, Thammapot, "A 3D numerical analysis of the railway to compare the performance of the granular and asphalt trackbeds." (2018). Electronic Theses and Dissertations. Paper 2923.

https://doi.org/10.18297/etd/2923

This Master's Thesis is brought to you for free and open access by ThinkIR: The University of Louisville's Institutional Repository. It has been accepted for inclusion in Electronic Theses and Dissertations by an authorized administrator of ThinkIR: The University of Louisville's Institutional Repository. This title appears here courtesy of the author, who has retained all other copyrights. For more information, please contact thinkir@louisville.edu. 


\title{
A 3D N8 $0(5, \& \$ /$ A1 $\$ /<6,62) 7+(\mathrm{R} \$, /: \$<$ $72 \mathrm{CC} 203 \$ 5(7+(\mathrm{P}(5) 250 \$ 1 \&(2) 7+($

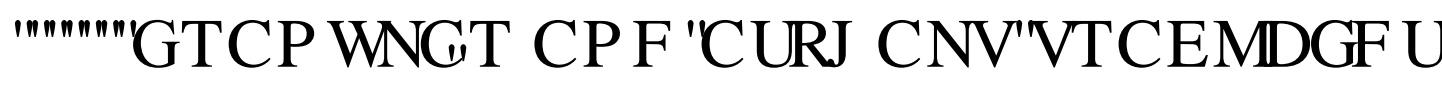

\author{
By
}

Thammapot Wattanapanalai

\section{A Thesis}

Submitted to the Faculty of the

J.B. Speed School of Engineering of University of Louisville In Partial Fulfillment of the Requirements for the Degree of

\author{
Master of Science \\ in Civil Engineering
}

Department of Civil and Environmental Engineering

University of Louisville

Louisville, Kentucky

May 2018 
Copyright 2018 by Thammapot Wattanapanalai

All rights reserved 



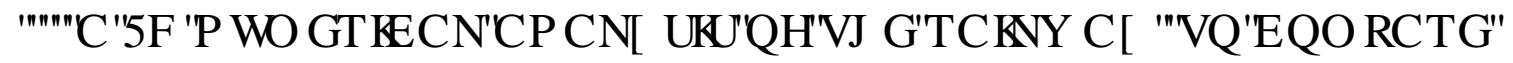

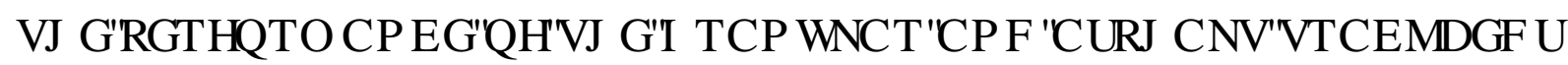
By

Thammapot Wattanapanalai

A Thesis Approved on

April 26, 2018

by the following Thesis Committee:

Dr. Omid Ghasemi-Fare

Dr. JP Mohsen

Dr. Young Hoon Kim

Dr. James E. Lewis 


\section{ACKNOWLEDGEMENTS}

The following research, whereas an independent study, benefited from the comprehension of our society. Firstly, I would like to greatly appreciate my enthusiastic advisor, Dr. Omid Ghasemi Fare, who always welcomed me for discussion about my research. I also would like to thank Dr. Jerry Rose for kindly sharing the experimental results. And also, I would like to extend gratitude to Dr. JP Mohsen for his encouragement and supporte, while I was a graduate student at University of Louisville. Secondly, I would like to thank my committee members, Dr. JP Mohsen, Dr. Young Hoon Kim, and Dr. James E. Lewis, for the motivation, invaluable feedback, and friendly support that each of them offered to me during the completion of this dissertation.

Finally, I would like to thank my mother, "Soawarot Wattanapanalai", who is unconditional support and sacrifice. Thus, this is my absolute honor to dedicate this dissertation to her. 


\begin{abstract}

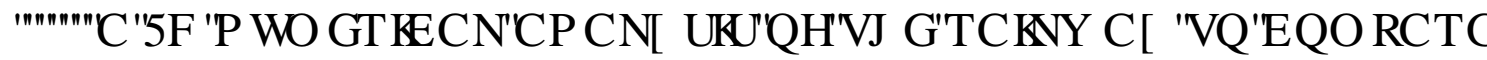

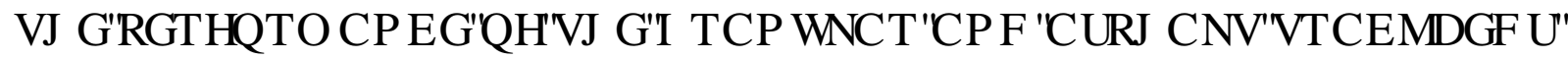
Thammapot Wattanapanalai
\end{abstract}

April 26, 2018

In the last two decades, trains have been developed either to carry heavy weight of cargo or for high-speed rail transport. Nonetheless, track structure, have not been improved adequate to support the extra loads or dynamic vibrations of high-speed trains. As a result, the performance of track will be affected from heavy freight or highspeed trains. In the long term it results in trackbed damage by increasing the subgrade and ballast displacement. Besides, it negatively affects the performance of the locomotives. Therefore, alternative subballast, should be introduced to reduce the stress and deformation of the track under dynamic or heavy loads. Asphalt underlayment trackbed is an alternative solution, which has been applied in many countries. The 
thickness of the asphalt layer varies from $10 \mathrm{~cm}$ to $20 \mathrm{~cm}$, depends on the regulation of each country.

In this study Finite Element (FE) Program, ABAQUS, is used to simulate a threedimensional railway track to predict the trackbed performance. The model is validated through an analytical model and experimental. The validated model then used to determine the effect of different parameters on the stress and displacement increments on the subgrade under a static load. In the next step, the comparison of the granular and asphalt trackbeds displacement has been studied. The numerical model is used to predict the stress-strain and displacement variations on the subgrade while the thickness of the asphalt layer is varied. Results show increasing the asphalt layer from $15 \mathrm{~cm}$ to $18 \mathrm{~cm}$ significantly reduces the stress and displacement of the subgrade and results in uniform displacement. Furthermore, results show placing the asphalt layer below the subballast is more efficient than above it. And using the theory of Winkley to determine the track modulus, which is one of the important indicator to determine the track performance. 
ACKNOWLEDGEMENTS .........................................................................

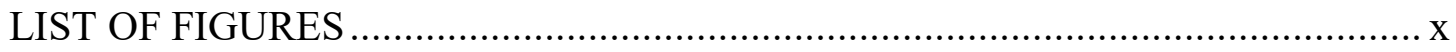

LIST OF TABLES …...............................................................................

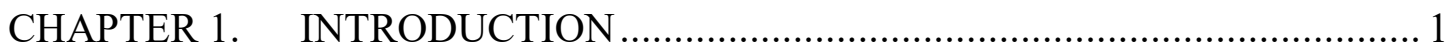

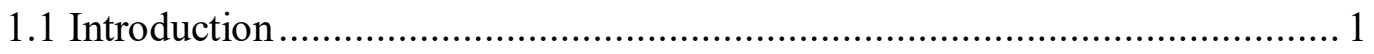

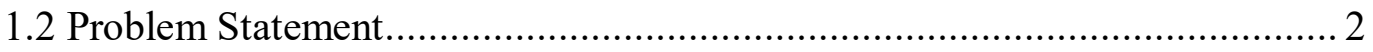

CHAPTER 2. LITERATURE REVIEW ....................................................... 4

2.1 Track Structure Components ............................................................ 4

2.1.1 Superstructure........................................................... 5

2.1.2. Substructure ............................................................... 7

2.2 Capacity of Modern Train.................................................................... 9

2.3 Track Structure Failure …..................................................................... 10

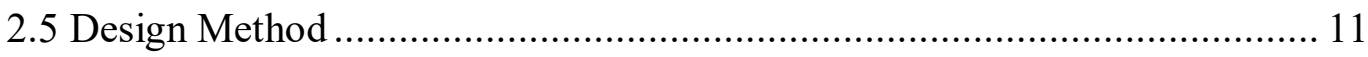

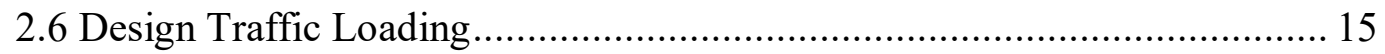

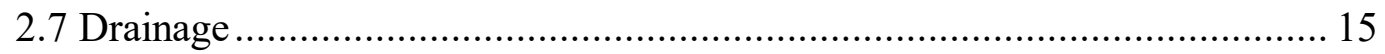

2.8 Hot Mixed Asphalt as Alternative Subballast ........................................... 18

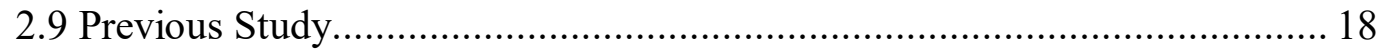

2.9.1 Experimental Methodology ................................................ 20 


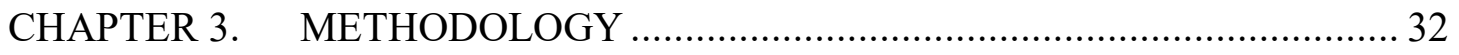

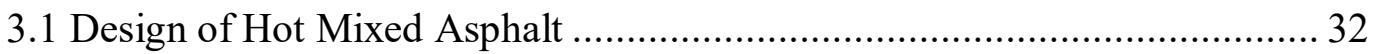

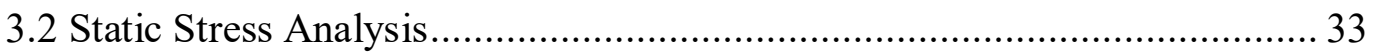

3.3 Methods for Determining Track Modulus ............................................... 34

3.4 Finite Element Expression of Static stress analysis............................... 36

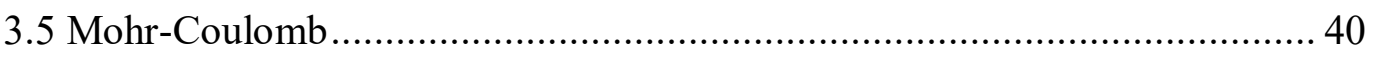

CHAPTER 4. Validation of the Model .............................................................. 43

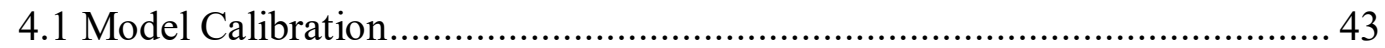

4.1.1 Bearing Capacity Evaluation of Footing on a Layered-Soil ...... 43

4.1.2 Railway Trackbed Modeling ................................................. 47

4.1.3 Stress Below a Rectangular Area .......................................... 48

4.1.4 Comparison Modeling and Experiment .................................. 51

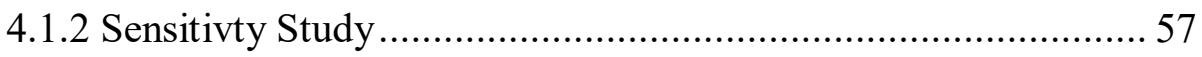

CHAPTER 5. Sensitivity Study of 3-D Trackbed Performance .......................... 62

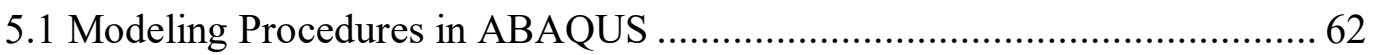

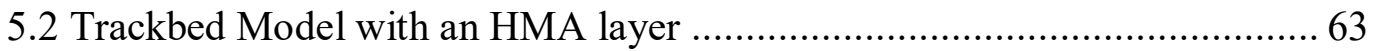

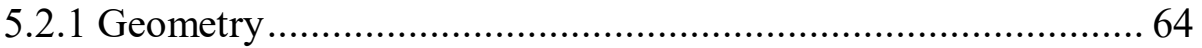

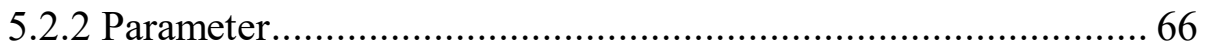

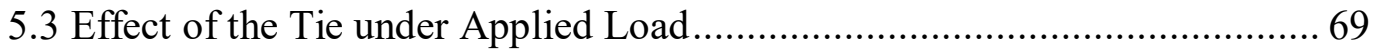

5.4 Effect of the static load on the surface of subgrade................................... 72 
5.4.1 Increasing the Thickness of the Subballast

5.4.2 Comparison Using Asphalt Layer and Conventional Track. .... 74

5.4.3 Comparison Using Combination Design and Conventional Track

5.5 Track Modulus

80

CHAPTER 6. CONCLUSION AND FUTURE STUDY …............................... 84

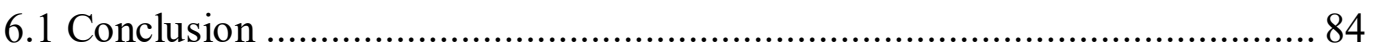

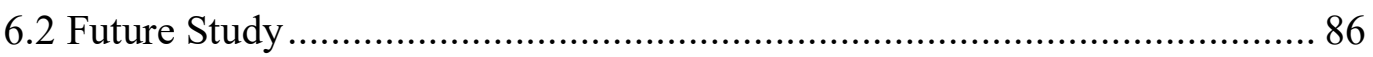

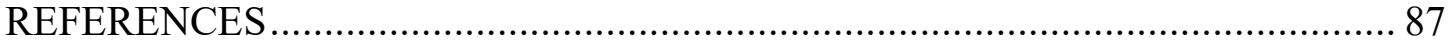

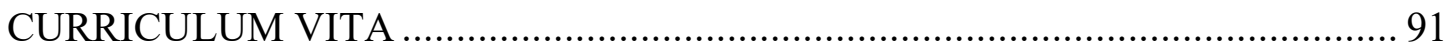




\section{LIST OF FIGURES}

Figure 2-1 Different rail cross-section (Coenrad, 2001).... 5

Figure 2-2 Types of rail-pad, which are single-shoulder, double-shoulder, and pandrol (A\&K Railroad Material, Inc, 2013) 6

Figure 2-3 Profile and cross-section of ballast layer (Li et al, 2010) .............. 8

Figure 2-4 Progressive shear failure develops on the subgrade surface (Li and Selig, 1998).

Figure 2-5 Subgrade is excessive plastic deformation (Li and Selig, 1998) .. 11

Figure 2-6 Raymond design chart (Li et al, 2016) .................................. 13

Figure 2-7 British Design chart that based on axle load and soil threshold (Li and Selig, 1998)

Figure 2-8 Example design chart after analyzed by using GEOTRACK (Li et al., 2016)

Figure 2-9 Diagram of three major sources (Li et al., 2016) ...................... 16

Figure 2-10 Impact of poor drainage system effect to the track geometry (Li et al., 1995) 17

Figure 2-11 the simulation of fluctuate of ground water impact to the railway track (Ferreira et al., 2011)

Figure 2-12 Comparison of subgrade Stress (Li, 2000) ............................. 22

Figure 2-13 Stiffness of three different materials under low frequency (Lee et al, 2014)

Figure 2-14 Modulus stiffness versus frequency under different temperatures, $10^{\circ} \mathrm{C}, 17^{\circ} \mathrm{C}$, and $25^{\circ} \mathrm{C}$. DARC 1 , DARC 2, and DARC 3 are indicated as $1 \%, 2 \%$, and $3.5 \%$ of crumb rubber, respectively (Mino et al, 2015) 24

Figure 2-15 Comparison between granular layer and three different thickness of asphalt layer (Lei and Rose, 2009).... 26

Figure 2-16 Comparison between granular layer and $20 \mathrm{~cm}$ of HMA with $0 \%$, $10 \%$, and $20 \%$ of crumb rubber (Lei and Rose, 2009). 26

Figure 2-17 Deflection of asphalt layer profiles between $10 \mathrm{~cm}$ and $20 \mathrm{~cm}$ under train speed at $20 \mathrm{~m} / \mathrm{s}$ (Left) and train speed at $50 \mathrm{~m} / \mathrm{s}$ (Right) (Huang et al, 2010).

Figure 2-18 Frequency content of the vertical velocity at the sleeper (Left) and $8 \mathrm{~m}$ from the track (Right) under the passage train (Galvin et al, 2010).... 28

Figure 2-19 Ballast displacement due to a freight traffic and mixed traffic (Huang, 2012) 
Figure 2-20 Pressure on subgrade between three different subballast (Mino et al, 2012) 30

Figure 2-21 Vertical displacement (Left) and horizontal strain (Right) (Fang et al, 2013) 31

Figure 2-22 Vertical displacement under three different loaded (Fu and Zheng, 2014). 31

Figure 3-1 Cross-section of underlayment ............................................ 33

Figure 3-2 Cross-section of overlayement............................................... 33

Figure 3-3 Winkler track foundation model (Cai et al. 1994) ..................... 35

Figure 3-4 Rectangular on xy-plane, that displacement $u$ on $x$-axis and ....... 37

Figure 3-5 Brick element, which has eight-node element (Cook et al, 2002) 38

Figure 3-6 Eight-nodes hexahedral as nonrectangular shape (Cook et al, 2002)

Figure 3-7 Mohr's circle at failure (ABAQUS 6.14, 2014) ........................ 41

Figure 3-8 Mohr-Coulomb surface in deviatoric plane (ABQUS 6.14, 2014) 41

Figure 4-1 Model simulation and boundary condition, that a model of 510 elements (Mosadegh and Nikraz, 2015)

Figure 4-2 Assumption of soil failure in Terzaghi model (Mosadegh and Nikraz, 2015)....

Figure 4-3 Soil failure from finite element analysis (Mosadegh and Nikraz, 2015)

Figure 4-4 Comparison bearing capacity, with dilation, without dilation, and calculated value by using Terzaghi's equation (Mosadegh and Nikraz, 2015)...... 45

Figure 4-5 Comparison of soil failure between present study, other FEM results and theoretical model.

Figure 4-10 Stress increase at depth $\mathrm{z}$ under the shallow foundation (Das, 2015)

Figure 4-11 Example of rectangular loaded area (Das, 2015) 48

Figure 4-12 Result of vertical stress in the simulation, the green area presents the high concentrated vertical stress at the middle of the rectangular place................50

Figure 4-13 Full-scale of half-track at University of Kentucky ................... 51

Figure 4-14 Cross-section of half-track structure .................................... 52

Figure 4-15 The result of vertical stress is applied various loads (Rose et al. 2018)

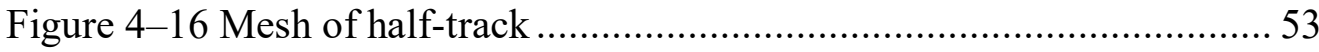

Figure 4-17 Dimension of rail type $136 \mathrm{lbs} / \mathrm{yd}$......................................... 54

Figure 4-18 Consideration path of half-track structure ............................... 55

Figure 4-19 The vertical stress of half-track structure under applied load.... 55

Figure 4-20 Comparison stress between experiment and analytical model. .. 56

Figure 4-6 Mesh of simulation model in case of parametric study ............... 57 
Figure 4-7 the range of track modulus due to various properties of track components

Figure 4-8 The range of track modulus due to change in the train's velocities.

Figure 4-9 The vertical stress distribution at train's speed equal to $235 \mathrm{~km} / \mathrm{h} 61$

Figure 5-1 Cross-section of conventional track ....................................... 63

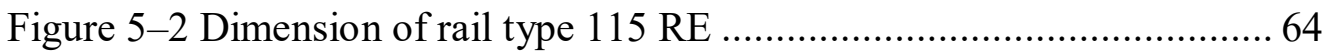

Figure 5-3 Cross-section of combination track design .............................. 65

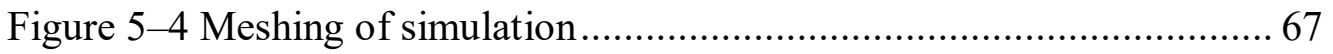

Figure 5-5 Consideration path of the model ............................................. 68

Figure 5-6 The vertical stress of tie under applied load ............................. 69

Figure 5-7 The vertical displacement of tie structure under applied load ...... 70

Figure 5-8 Comparison of vertical deflection of the tie ............................. 71

Figure 5-9 The vertical stress and the vertical displacement on subgrade's surface

Figure 5-10 The result of vertical stress on subgrade's surface under applied load 74

Figure 5-11 The result of vertical displacement on subgrade's surface under applied load 74

Figure 5-12 Effect of subgrade's surface under applied static ................... 76

Figure 5-13 The vertical stress and vertical displacement under the tie ....... 78

Figure 5-14 The vertical stress and the vertical displacement on subgrade's surface

Figure 5-15 Comparison of track modulus between $15 \mathrm{~cm}$ of granular suballast and various asphalt layers

Figure 5-16 Comparison of track modulus between $30 \mathrm{~cm}$ of granular suballast and various asphalt layers 


\section{LIST OF TABLES}

Table 2- 1 Summary of the previous study on track performance................. 19

Table 2- 2 Location of HAM testing (Rose and Hensley, 1991) ................... 20

Table 2- 3 Summary of testing location (Rose and Bryson 2009) ................ 22

Table 4- 1 Dimension and parameter of half-track structure....................... 54

Table 4- 2 Percent different between experiment and simulation ................. 56

Table 4- 3 Parameter and dimension..................................................... 58

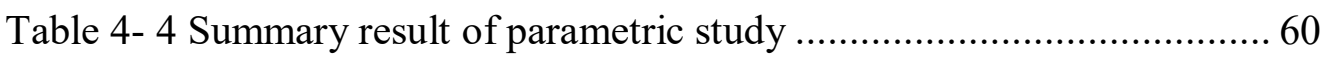

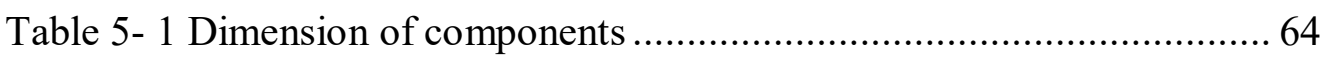

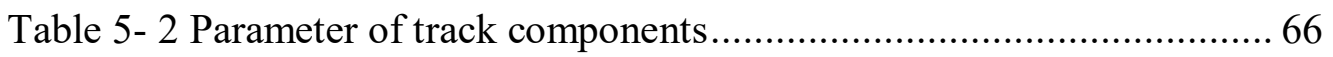

Table 5- 3 Summarized Percent of Protection ............................................... 71

Table 5- 4 Summary of percent improving ............................................... 82

Table 5- 5 Comparison the track modulus ............................................... 83 


\section{CHAPTER 1 INTRODUCTION}

\subsection{Introduction}

Railway affects our society in some way such as shipping cargo or providing fast and safe travels across the country. Railway industry has been developing a locomotive from steam locomotives to modern locomotives, like diesel or electric locomotive, with the purpose of serve customers with sufficient time and cost. Occasionally, a train can run on schedule, so it is impact to trust of train service. Therefore, a delay in railway industry results in the loss of millions of dollars on the trip.

It is well-known fact that modern locomotive's speed recently is reaching to the maximum speed of $300 \mathrm{~km} / \mathrm{hr}$ for a passage train and a freight train contains doublestack with weigh around 100 tons. Either high speed trains or freight trains will generate a massive impact to conventional track. In order to keep the high performance of train's speed, the track has to be smooth. However, the increasing of speed and train load cause deformation, pumping, and attrition track. As a result, all train has to be stop to repair the track and this can cause the delay and maintenance cost. 
Although increasing granular thickness is one of the regular method to improve the track performance, this technique is not economical. Therefore, many researches have been developing some new methods, like reinforcing subballast or using alternative material as subballast, to solve the failure in subgrade from major causes such as repeated load, soil condition, and environmental issues. As a result, the track performance is developed by increasing the strength of the track structure, extending the service life, and reducing the maintenance cost.

Installing an asphalt layer as subballast or adding an asphalt layer above or below the subballast has been applied recently in many countries; however, the effective thickness of asphalt layer has not been identified yet. For example, in the U.S. the thickness of the asphalt layer varies from $15.0 \mathrm{~cm}$ to $20.0 \mathrm{~cm}$. While, European countries, like France, Italy, Spain, and Germany use $8.0-\mathrm{cm}$ to $14-\mathrm{cm}$-thick asphalt layers.

\subsection{Problem Statement}

The thickness of granular layer, combining with ballast layer and subballast layer, is from $450 \mathrm{~mm}$ to $600 \mathrm{~mm}$ for the conventional track design. However, to maintain the track performance and preparing for future development that could increases capacity and speed, the frequent maintenance is required with short period of time. Although alternative subballast, like asphalt or bitumen, is installed to improve the track performance and reduce the maintenance cost, the design of asphalt layer as subballast provides various thickness from $10 \mathrm{~cm}$ to $20 \mathrm{~cm}$. 
Therefore, in this study the optimum thickness of the asphalt layer will be proposed. A three-dimensional track structure will be simulated using finite element program, ABAQUS. A finite element model firstly will be validated using analytical and experimental data. The validated model will be used to investigate the track performance under loading with different thickness of asphalt layer, which are 10, 12, $14,15,18,20$, and $25 \mathrm{~cm}$. Furthermore, this study will simulate the combination design, that use asphalt layer and granular subballast, to compare the sufficiency between installing asphalt layer above subballast and installing asphalt layer below subballast by fixing the thickness of asphalt layer at $15 \mathrm{~cm}$. The result of this study will present stress and displacement under the sleeper and on the surface of subgrade comparing with the conventional track design that uses $15 \mathrm{~cm}$ of granular subballast. Chapter 2 of this thesis presents the brief literature review. In Chapter 3 the methodology and background of the numerical model are presented. In Chapter 4, a 2 D numerical model is discussed and then it provides the validation steps. Chapter 5 presents the 3D numerical model and sensitivity study. At the end, the conclusion and suggested future studies will be presented in Chapter 6 . 


\section{CHAPTER 2 LITERATURE REVIEW}

\subsection{Track Structure Components}

Over a century, track structure has been developing to support either high speed trains or locomotive freight trains. It is a quest for many researchers to design a reliable track with lower cost.

A rail track should provide a durable, and smooth surface. It also needs to reduce the pressure from wheel loads to the subgrade.

Railway tracks structure can be divided into superstructure and substructure. Superstructure combines rail, fastening system, and sleeper. The rail contacts directly with the train wheel and generates dynamic load with the joint connection of the rail, which transmits to other parts until it reaches the substructure. Substructure is constructed as layers, which is ballast, subballast, and subgrade. The significant function of each layer is to distribute stress and provide adequate vertical, lateral, and longitude resistance. 


\subsubsection{Superstructure}

\subsubsection{Rail}

A design of rail cross sections has been developed over a century. Figure 2-1 shows different cross sections of the rail. Nowadays, with new technology, a rail cross section is produced from high carbon steel to become durable and prevent maintenance. The connection between rails or rail joints creates dynamic load (Chandra and Agarwal, 2007) that affects the whole track structure; therefore, many companies produce a very long rail to eliminate dynamic load. Other techniques, like continuous welded rail, are applied to improve the quality of service. However, a stronger and stiffer rail will not provide a better performance; in contrast, the stiffer rail will reduce service life of the track because of the deterioration.
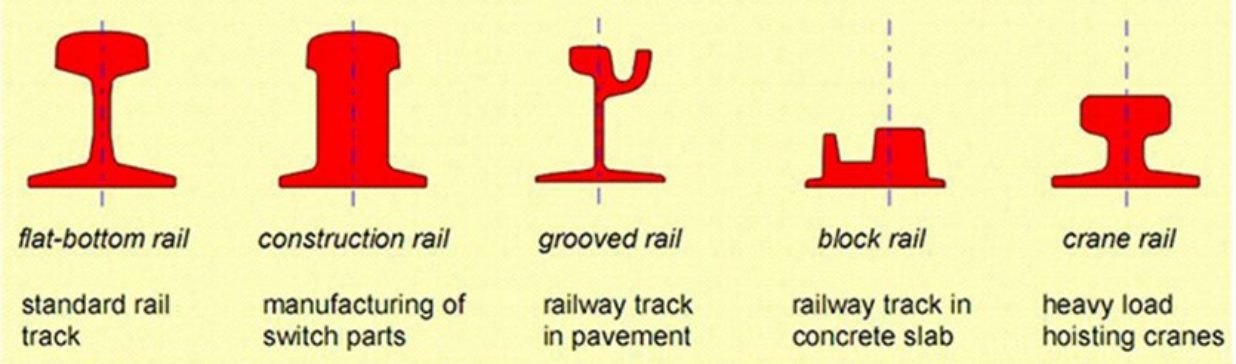

Figure 2-1 Different rail cross-section (Coenrad, 2001) 


\subsubsection{Fastening}

Rail Fastening not only fixes rails and sleepers but also attenuates dynamic load transferring from rail to the sleepers.

In addition, installing fastening will increase service lift of rail and sleeper, since fastening reduces abrasion and corrosion between those two components. Single, double shoulder, and pandrol plate are commonly installed with wood sleeper, as shown Figure 2-2.
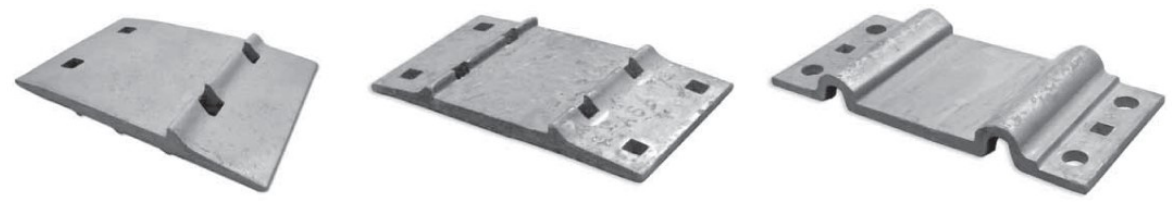

Figure 2-2 Types of rail-pad, which are single-shoulder, double-shoulder, and pandrol (A\&K Railroad Material, Inc, 2013)

\subsubsection{Sleepers}

Although sleepers (tie) can be produced from wood, concrete, steel, and composite/plastic, wood sleepers and concrete sleepers are common worldwide. For example, wood sleepers are the most commonly used in the United States because they are cheap can provide high flexibility and will reduce interaction between the train wheel and track structure. Unfortunately, wood sleepers are sensitive to water rot and decay. Unlike wood sleepers, concrete sleepers, which have a very high stiffness, provide some advantages such as resisting higher load, improving ballast life and longer 
service life. However, production processes should meet the qualification of design and quality control, which includes the installation process of concrete sleepers. Although concrete sleepers have such strict instructions, Europe and Britain commonly use this type of sleeper.

\subsubsection{Substructure}

As the interdependent structure, a quality of the track performance depends on the substructure, thus a degradation of foundation will decrease the performance of the train such as reducing speed of the train, and creating pumping mud. The substructure of the track combines three main layers (ballast, subballast, and subgrade) to support and arrange drainage of the superstructure.

\subsubsection{Ballast}

Ballasts have a large grain size and uniform granular particle, made from crushed hard stone, like granite and basalt. The ballast layer should have enough void spacing to drain water from the track and accumulate small material, like abraded and broken ballast, known as fouling material; therefore, the average standard size of ballast is around $35 \mathrm{~mm}$. Providing a thickness of the ballast layer increases resilience and damping to attenuate vibration transmission to the subgrade.

Ballast layer, which has thickness around $300 \mathrm{~mm}$, is divided into different zones that are upper ballast, lower ballast, and tamping zone. The upper ballast is the zone that 
usually disturbs from track maintenance, whereas lower ballast is not disturbed from tamping maintenance. Tamping zone is located at the upper ballast supports the sleeper directly under the rail, so this zone carries usually effect from the traffic load as shown in Figure 2-3.
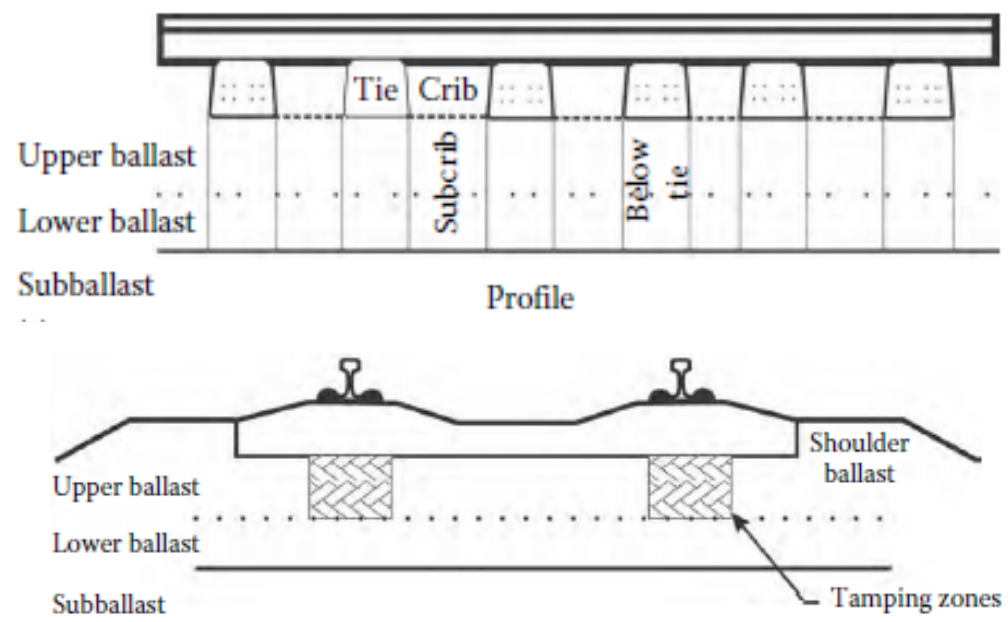

Figure 2-3 Profile and cross-section of ballast layer ( $\mathrm{Li}$ et al, 2010)

\subsubsection{Subballast}

Only the ballast layer cannot prevent progressive shear failure in the subgrade, so another layer known as subballast layer is placed between the ballast layer and the subgrade. The subballast layer is constructed with various sizes of gravel and sand with high compaction, thus this layer requires drainage freely and prevent the migration of subgrade particle. The other purpose of subballast layer is reducing the stress o the subgrade, so this layer should not plastically deform under cyclic load. Both function, separation and drainage, performances are influenced by grain size of the subballast. For example, constructed subballast with low fines grain provides a good drainage but 
it will not achieve the function of separation between ballast and subgrade. Therefore, the subballast thickness is constructed with low fines content and thickness should not exceed more than $300 \mathrm{~mm}$.

\subsubsection{Subgrade}

Subgrade is the foundation of the track structure that supports dead load (track structure) and live load (train load) without any deteriorated consolidation. Unfortunately, subgrade is considered as the weakest component of the track, because it is difficult to detect a failure condition as well as to remediate it. Subgrade is consisted of either the placed soil (fill) or the natural soil (formation). However, the construction process usually lies a thin lay of place soil over the formation to provide a smooth surface in various elevation. In addition, Soil condition of subgrade should be considered whether coarse grained or fine grained. That is because subgrade should provide a stable foundation, which is not sensitive with environment damage.

\subsection{Capacity of Modern Train}

Increasing of car capacities, like higher horsepower and heavier locomotives, are accompanied by large track forces. According to CSX's railroad equipment, capacity of freight trains is around 70 to 100 tons with the maximum speed around $129 \mathrm{~km} / \mathrm{hr}$, 
whereas the weight of passage train is around 65 tons with the maximum speed up to $350 \mathrm{~km} / \mathrm{hr}$.

\subsection{Track Structure Failure}

Serval design methods have been developing to prevent the most common cases of failures, which are progressive shear failure and excessive plastic deformation or ballast pocket. Progressive shear failure, is the first case of failure, occurred under repetitive stress on the surface of fine-grain soil, like clay. In this case, the surface subgrade under rails slowly squeezes outward and upward push to a shoulder of the track (Li and Selig, 1998) as shown in Figure 2-4.

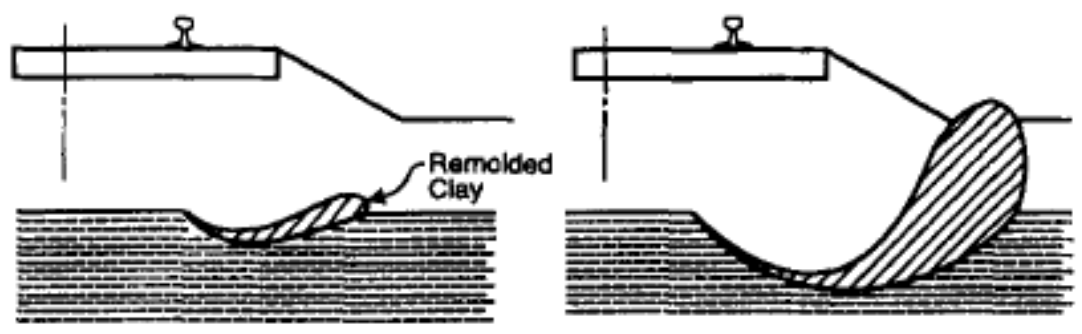

Figure 2-4 Progressive shear failure develops on the subgrade surface (Li and Selig, 1998)

The second case of failure happens when the subgrade is under repetitive stress which results in excessive plastic deformation. This creates ballast pocket as shown in Figure 2-5. This type of failure is a result of vertical deformation that causes by a progressive compaction which will affect a substantial depth of subgrade. 


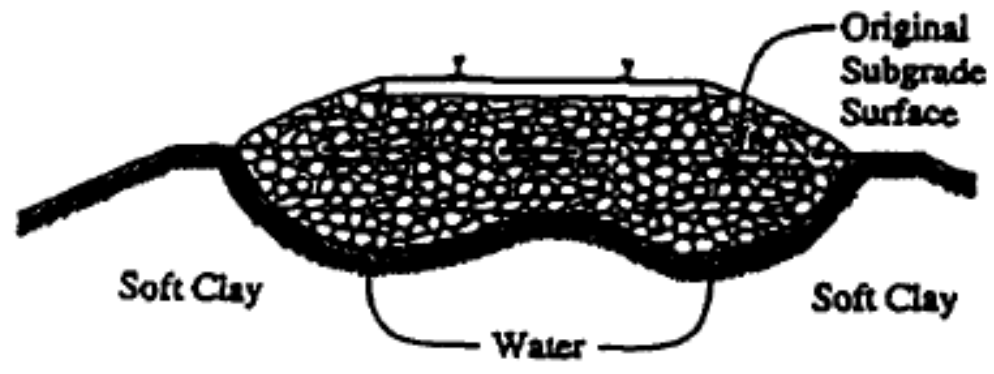

Figure 2-5 Subgrade is excessive plastic deformation ( $\mathrm{Li}$ and Selig, 1998)

Both cases of failure are not completely independent because these two cases are occurred with the similar condition. Designing an optimum granular thickness is essential to provide a subgrade protection. However, the granular layer might not be good for other type of failures that reduces the ability to carry traffic load such as mud pumping, slope erosion, and swelling shrinkage. Furthermore, modifying the subgrade in case of "fix as needed" may be very expensive because of the delays in train operation and cost opportunity loss. To avoid subgrade problems, contractors need to determine subgrade soil characteristics that include soil type, physical state, and mechanistic properties.

\subsection{Design Method}

Granular layer, is combined with Ballast and subballast layer, locates between sleepers and subgrade layer. Designing an effective granular thickness should be economical and achieve the function of reducing stress in subgrade. Thus, in several design codes, the thickness of the granular layer is selected to limit the traffic load-induced stress in the track subgrade (Li and Selig, 1998). 
American Railway Engineering Association (AREA) recommends Talbot's equation that is based on field tests over many years, to determine the efficient granular thickness, $\mathrm{H}$, and also recommends using $138 \mathrm{kPa}$ for the allowable subgrade, $P_{c}$. However, this equation is not simplified in soft soil condition and soil condition becomes too conservative.

$$
H=0.24\left(\frac{P_{m}}{P_{c}}\right)^{0.8}
$$

Where $\quad P_{m} \quad$ is vertical stress applied on the ballast surface.

$P_{c} \quad$ is $138 \mathrm{kPa}$ for the allowable subgrade.

Raymond (1985) developed a design chart for vehicles weighing from 70 to 125 tons from the design AREMA by assuming ballast, subballast, and subgrade are homogeneous half-space. This design defines allowable bearing capacity subgrade from soil classification. Figure 2-6 shows the design chart that provides three different vehicle weights, which are 70-tons, 100-tons, and 125-tons. The granular thickness is defined by using correlation between vertical stress and the allowable bearing capacity of subgrade. 


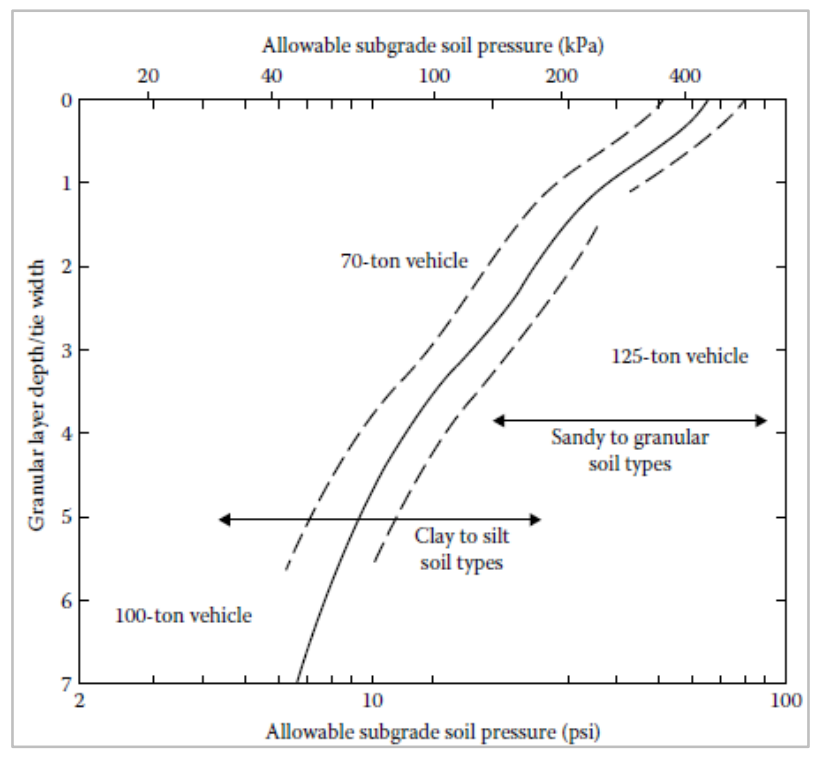

Figure 2-6 Raymond design chart (Li et al, 2016)

British railway introduces a design method to select a granular thickness to prevent progressive subgrade shear failure by comparing subgrade stress with threshold stress, which is a testing result of determining soil cumulative strain under repeated loading. If the stress reaches to the threshold stress level, the subgrade would certainly at plastic deformation state. On other hand if the applied stress is lower than the threshold stress level, the deformation of subgrade would be small. However, this method has a limitation in terms of the amount of cumulative tonnage. For example, designing a railway track with the same axle loads for 10 MGT and 100 MGT, both track design would have a similar design granular thickness. 

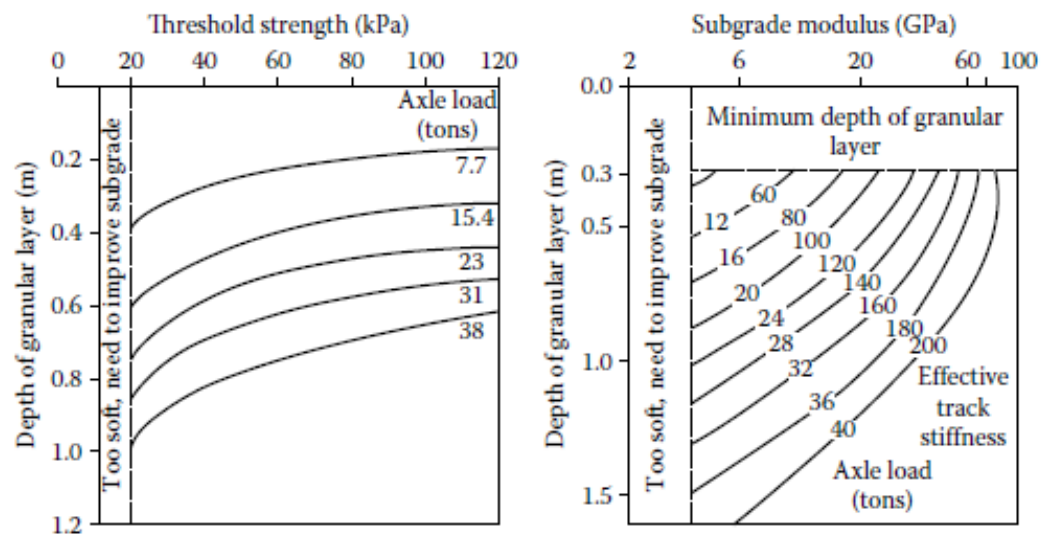

Figure 2-7 British Design chart that based on axle load and soil threshold (Li and Selig, 1998)

Li-Selig (1998) suggested a design method to prevent the common subgrade failure types that are progressive shear failure and excessive plastic deformation by determining an effect of train induced stresses to the subgrade, and using as analytical program, known as GEOTRACK, to predict the expected cumulative permanent settlement of the subgrade.

The theoretical granular thickness for variety subgrade condition is defined by input the limit of settlement and comparing influence settlement from the train induced stress into GEOTRACK program. Then, the program will provide two design charts which gives the minimum thickness of the trackbed layers and a function of subgrade depth as shown in Figure 2-8.

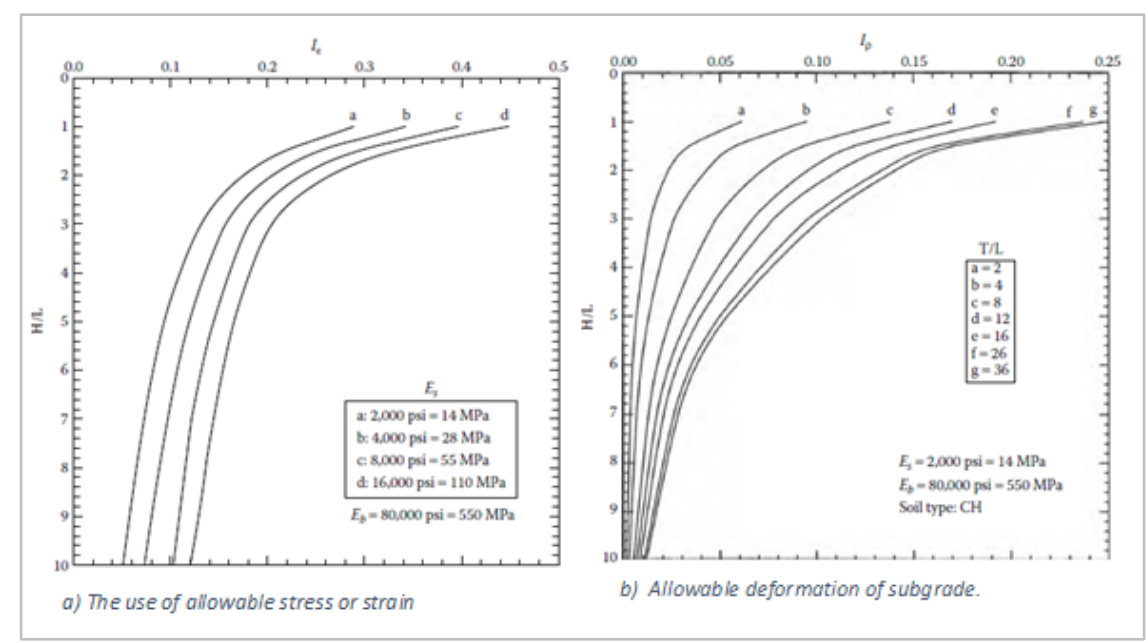

Figure 2-8 Example design chart after analyzed by using GEOTRACK (Li et al., 2016) 


\subsection{Design Traffic Loading}

To design the railway track, it is important to understand amount of stress at the foundation due to variation of the axle load and wheel spacing. AREMA has been using a design live loads by developed cooper E series configuration.

Between heavy haul freight and a high-speed passenger train, both types of train apply different load characteristic to the track foundation. Several researchers show that increasing a train speed will increase of the dynamic load to the track vibration (Fu and Zheng, 2014, Li et al., 2017). Consequently, the induced stress distribution varies with the weight and speed of the train. American Railway Engineering Association (AREA) provides an equation converting from a static wheel load, $P_{s}$ to a dynamic wheel load, $P_{d}$ by determining the impact factor used in the calculation of the design wheel load is a function of the vehicle speed and the wheel diameter.

$$
P_{d}=\left(1+\frac{0.0052 V}{D}\right) \cdot P_{s}
$$

\subsection{Drainage}

Many types of track failure are associated with the inadequate drainage system (Burrow et al., 2017), although it is the most crucial to reduce maintenance cost. The track drainage control has access from three major sources, direct water, runoff water, and ground water. 


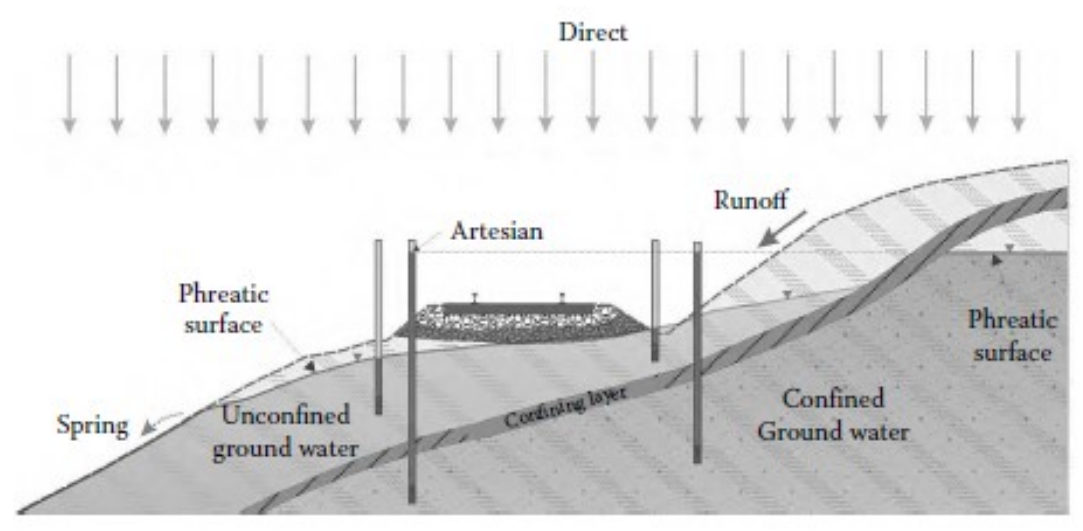

Figure 2-9 Diagram of three major sources (Li et al., 2016)

Figure 2-9 presents the track structure will get wet from water from various sources such as rain, surface water, and confined ground water. Various location will have a different precipitation, so designing the drainage system should consider the magnitude and duration for a certain area. In case of water remaining excessive in the substructure for over periods of time, it will be increasing the magnitude of deformation, and decreasing resilient modulus. In the other words, the ballast layer has a higher plastic strain and lower shear strength (Li et al., 2016).

Li et al., (1995) presents a study that the granular layer losses ability of carrying heavy axle load after a heavy rain, so the train operation is cancelled because of the track geometry has a large deformation. This situation can be explained that the granular layer is contaminated with foul ballast and water creating weak spot inside the track; consequently, the track losses a strength to carry a heavy load and will start the degradation. The track that has a problem with mud pumping perform poorly and will have a deformation along the wet bed and this problem will influence ride quality and restrictions of train speed (Hudson et al, 2016). 


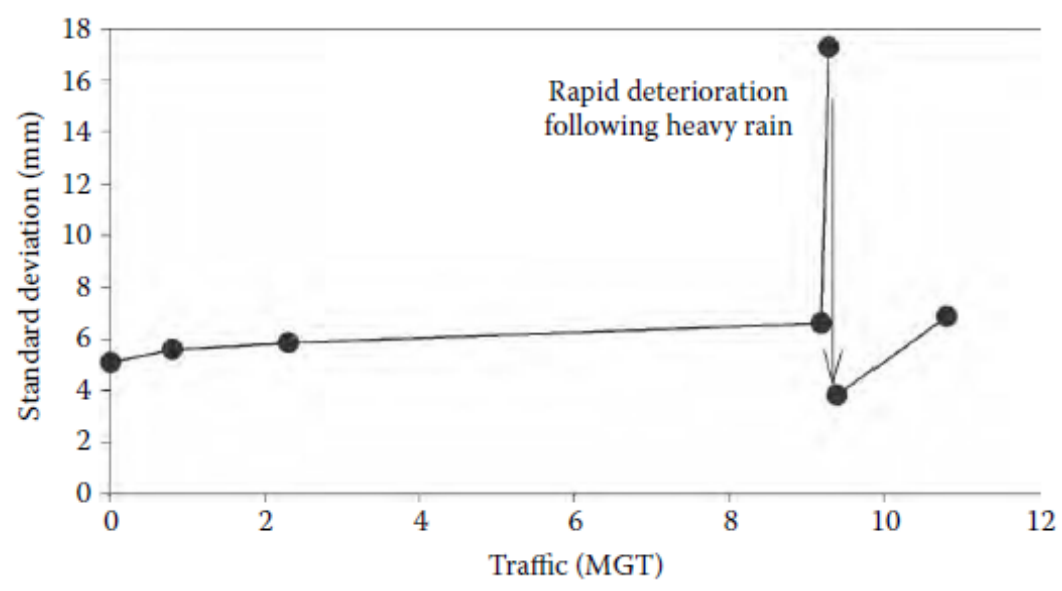

Figure 2-10 Impact of poor drainage system effect to the track geometry (Li et al., 1995)

The track geometry degradation is not only from the direct water but also comes from fluctuate of ground water. Variation of the groundwater table at different weather condition makes a negative impact to the long-term track performance. As a result, this problem leads to shrink-swell of soil and created uneven track settlement. Ferreira et al., (2011) conduct a simulation a changing of ground water level over 5 years. The result shows that the evolution of vertical displacement over 5 years highly impact at the middle of the track when comparing with other positions.

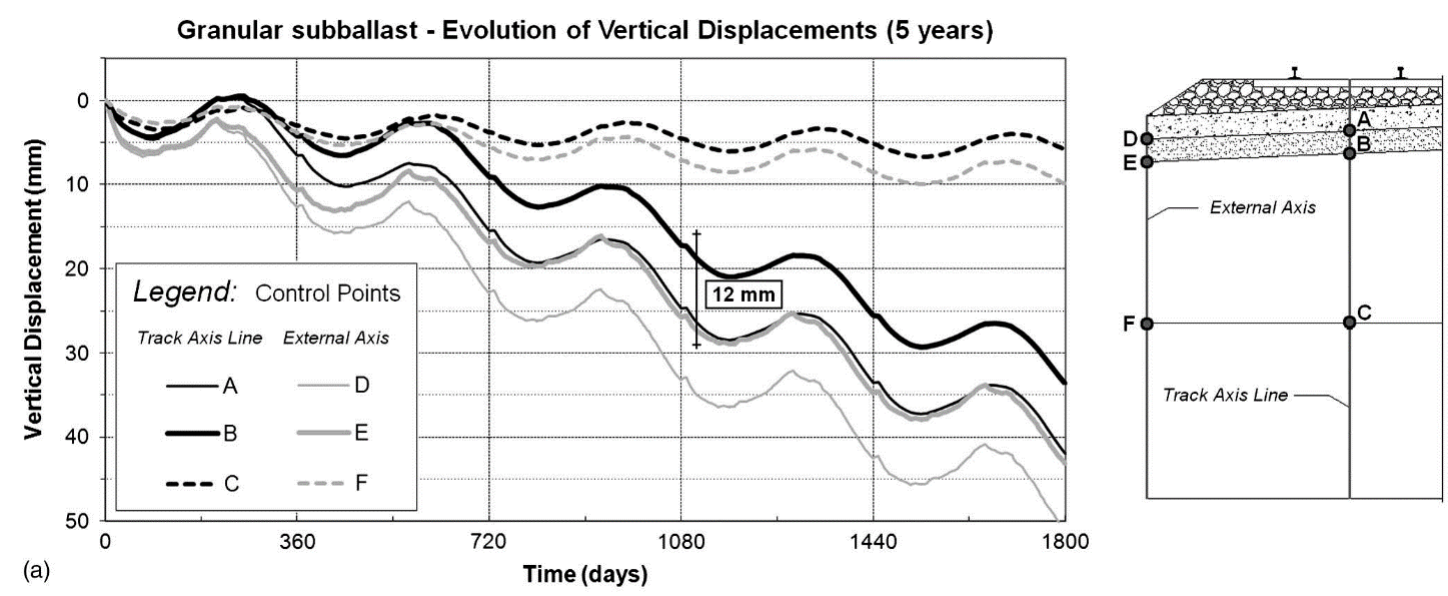

Figure 2-11 the simulation of fluctuate of ground water impact to the railway track (Ferreira et al., 2011) 


\subsection{Hot Mixed Asphalt as Alternative Subballast}

Installing Hot Mix Asphalt (HMA) as subballlast provides to improve the performance of track structure in term of protect water penetrating into subgrade and increasing track stiffness. Two applications of installing HMA, are underlayment and overlayment, are dependent on the subgrade soil condition. Therefore, before installing asphalt layer should provide subgrade treatment to become more economical.

\subsection{Previous Study}

Over a decade, several researchers perform either an experiments or simulation models to determine the strength and deflection of a railway track. Results from both methods show some agreement that the degradation of track structure happens because of either a freight train or a passenger train. Occasionally, the railway track was constructed on poor subgrade, like fines grain soil with lower bearing capacity. Some of researchers show a method of track improve, like installing asphalt layer, while other introduce a new material that is only increasing the strength but also increasing ability of attenuation vibration. 
Table 2-1 presents a summary of the research has been performed in two decades.

Table 2- 1 Summary of the previous study on track performance

\begin{tabular}{|l|l|l|}
\hline \multicolumn{1}{|c|}{ Author } & Year & Methodology \\
\hline Rose and Hensley & 1991 & Experiment \\
Buonanno and Raffaele & 2000 & Experiment \\
Li & 2000 & Experiment \\
Rose and Bryson & 2009 & Experiment \\
Lee et al & 2014 & Experiment \\
Mino et al & 2015 & Experiment \\
Wang et al & 2005 & Simulation model \\
Lei and Rose & 2008 & Simulation model \\
Yang et al & 2009 & Simulation model \\
Huang et al & 2010 & Simulation model \\
Galvin et al & 2010 & Simulation model \\
Huang et al & 2012 & Simulation model \\
Mino et al & 2012 & Simulation model \\
Fang et al & 2013 & Simulation model \\
Fu and Zhen & 2014 & Simulation model \\
\hline
\end{tabular}




\subsubsection{Experimental Methodology}

Rose and Hensley (1991) presented long-term testing to investigate the track modulus of asphalt subballast under traffic condition and climate condition. In this case, all location used the similar structural design and quality of hot mixed asphalt (HMA) as summary in Table 2-2.

Table 2- 2 Location of HAM testing (Rose and Hensley, 1991)

\begin{tabular}{|l|c|c|c|c|}
\hline Location (Railroad) & $\begin{array}{c}\text { Cleveland } \\
\text { (RTA) }\end{array}$ & $\begin{array}{c}\text { New Mexico } \\
\text { (ATSF) }\end{array}$ & $\begin{array}{c}\text { Oklahoma City } \\
\text { (ATSF) }\end{array}$ & $\begin{array}{c}\text { Conway, KY } \\
\text { (CSX) }\end{array}$ \\
\hline Traffic (MGT) & 3 & 3 & 10 & 40 \\
Year Constructed & 1968 & 1969 & 1982 & 1983 \\
HMA Width (m) & 3 & 5 & 3.5 & 3.5 \\
HMA Thickness (m.) & $0.1 \sim 0.12$ & $0.065 \sim 0.19$ & 0.2 & $0.12 \sim 0.20$ \\
Ballast Thickness (m.) & 0.3 & 0.25 & 0.2 & 0.12 \\
\hline
\end{tabular}

Table 2-3 shows that in all locations HMA layer is was provided underlayment with a various thickness of asphalt and ballast layer due to different traffic loads. For example, the railway track at Oklahoma City was constructed by ATSF, installed $20 \mathrm{~cm}$ thickness of asphalt to serve a freight train, whereas RTA constructed railway track at Cleveland to serve a passenger train, uses asphalt thickness from 10 to $12 \mathrm{~cm}$.

Results show that the track geometry of several mainline HMA trackbeds have no detectable deformations at 6-month intervals, although that all those mainline have a drainage and highly required for maintenance. Furthermore, the study chooses the accumulated date of track deflection from Conway, KY to calculate the track modulus by using correlation between stiffness of the track structure and static loading, known as Beam-On-Elastic Foundation method. The record from both locations show that 
deflections of track under freight trains (100 ton) is around $4.6 \mathrm{~mm}$, which presents 170 $\mathrm{MN} / \mathrm{m} / \mathrm{m}$ of the track modulus.

Buonanno and Raffaele, (2000) studies an alternative subballast for high speed train by using ultrasound speed test to evaluate energy absorption and vibration attenuation of four difference materials, which are bituminous grade 50/70, modified bituminous, bituminous with crumb rubber $4 \%$, and bituminous with crumb rubber $8 \%$. The result shows that modified bituminous with crumb rubber have the ability of energy absorption and vibration attenuation, and it is better than bituminous grade 50/70.

Li, (2000) conducts a field test to investigate three different improving track designs under poor subgrade condition. Increasing granular thickness, reinforce with geocell, and installing asphalt lay are a method of improving the conventional trach on Clayhighly plasticity. The initial track was constructed from $0.46 \mathrm{~m}$ of ballast thickness, and $0.15 \mathrm{~m}$ of subballast thickness.

From the investigation shows that all those three applications with extend service life of the track under freight train. However, increasing granular thickness around $0.2 \mathrm{~m}$ is not economical and the track will rapid deterioration after heavy rain. Reinforcement by geocell and installing asphalt layer significantly improve the strength of the track structure, but the track modulus of installing asphalt is around $25000 \mathrm{kPa}$, whereas the track modulus of reinforcing by geocell is $17200 \mathrm{kPa}$. In addition, installing asphalt layer reduces stress of the subgrade layer as show in Figure 2-12. 


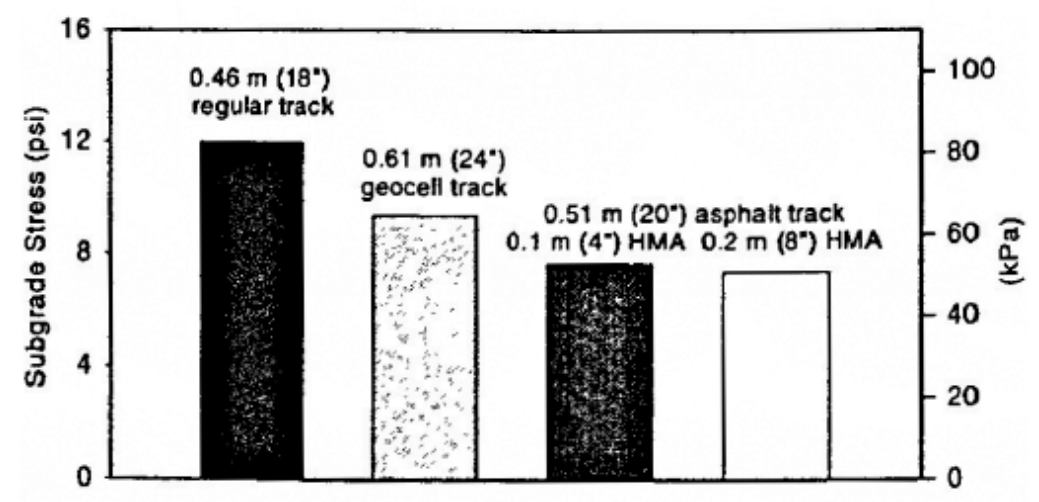

Figure 2-12 Comparison of subgrade Stress ( $\mathrm{Li}, 2000)$

Rose and Bryson, (2009) conduct the following study to evaluated qualities of asphalt after service as the track layer for a several years from seven different locations as shown in Table 2-3.

Table 2- 3 Summary of testing location (Rose and Bryson 2009)

\begin{tabular}{|l|c|c|}
\hline \multicolumn{1}{|c|}{ Location } & $\begin{array}{c}\text { Year Asphalt } \\
\text { Track Installed }\end{array}$ & $\begin{array}{c}\text { Age of Asphalt at } \\
\text { Time of Testing }\end{array}$ \\
\hline Conway, KY & 1983 & 15 and 24 \\
Cynthiana, KY & 1984 & 14 and 23 \\
Deepwater, WV & 1984 & 14 and23 \\
Guthrie, OK & 1989 & 9 and 18 \\
Oklahoma City, OK & 1982 & 16 and 25 \\
Quinlan, OK & 1995 & 3 and 12 \\
Hoover, TX & 1994 & 4 and 13 \\
\hline
\end{tabular}

A sample of asphalt layers from seven locations were constructed as underlayment with a various thickness, which is from $12 \mathrm{~cm}$ to $20 \mathrm{~cm}$. The sample of asphalt is tested with in-situ moisture contents, standard proctor moisture contents, and California Bearing Ratio (CBR). And then they compared the result with the previous measurement in 1998. 
After tested, the result showed that the average of in-situ moisture is decreased around 0.1 percent and the optimum moisture content changed less than 1 percent and still achieved the maximum density. As a result, the qualities of the asphalt layer serving as subballast is not reducing over time, in the other words, the test result does not detect any deterioration or cracking of the asphalt.

Lee et al, (2014) conducts an experiment to compare three different asphalt binders, which those are PG 64-22, asphalt mixed with crumb rubber (CRM), and styreneasphalt mixed with butadiene styrene (SBS), with regard to the strength and deformation for railway substructure. All three samples are tested by using dynamic modulus test, uniaxial creep test, indirect tensile test, and Flow number.

The result shows that the stiffness of SBS is higher than the stiffness of CRM and PG 64-22 at the low frequency, which is equivalence with high temperature. The result also shows that SBS and CRM have some similarity of characteristics, in particular rutting and creep. Therefore, using SBS or CRM as subballast may provide a better track performance.

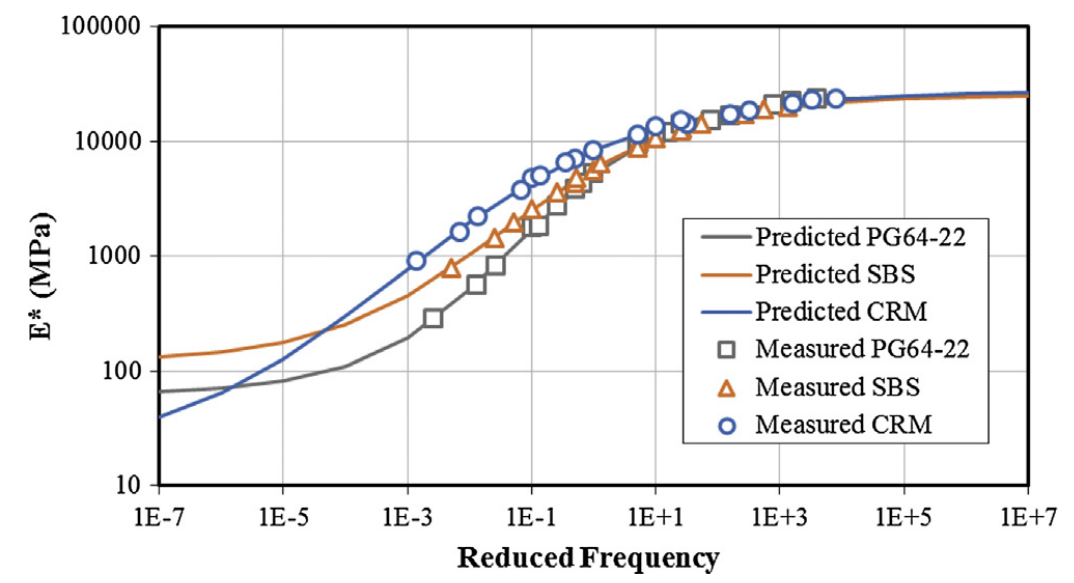

Figure 2-13 Stiffness of three different materials under low frequency (Lee et al, 2014) 
Mino et al, (2015) uses four-point bending test to determine the stiffness modulus of Hot Mixed Asphalt combining with various percentages of dry crumb rubber (DARC), which are $1 \%, 2 \%$, and $3.5 \%$. The result of this study is compared with a general hot mixed asphalt. Applied various temperatures, which are $10^{\circ} \mathrm{C}, 17^{\circ} \mathrm{C}$, and $25^{\circ} \mathrm{C}$, with the constant strain at $30 \mu \mathrm{m} / \mathrm{m}$. Furthermore, various frequencies, which are $0.1 \mathrm{~Hz}$ and 20 $\mathrm{Hz}$, are applied to determine the stiffness modulus.

The result of this study shows that if the percentage of crumb rubber is increased into hot mixed asphalt, the stiffness modulus will be decreased. Similarly, the stiffness modulus of hot mixed asphalt with the same percentage of crumb rubber is also decreased with increasing of temperature as shown in Figure 2-14.
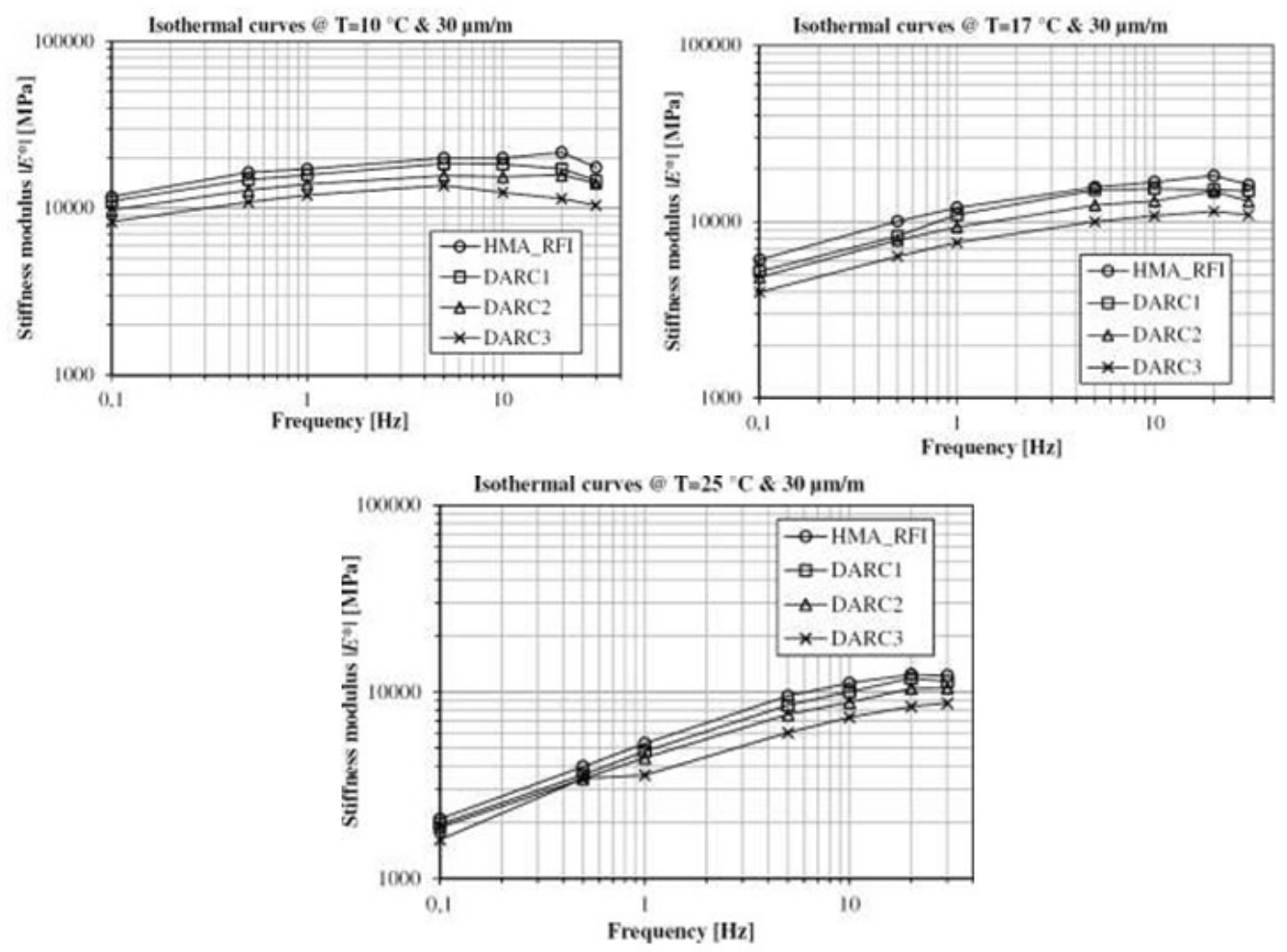

Figure 2-14 Modulus stiffness versus frequency under different temperatures, $10{ }^{\circ} \mathrm{C}, 17^{\circ} \mathrm{C}$, and $25^{\circ} \mathrm{C}$. DARC 1, DARC 2, and DARC 3 are indicated as $1 \%, 2 \%$, and $3.5 \%$ of crumb rubber, respectively (Mino et al, 2015) 


\subsubsection{Simulation by using Finite Element Analysis}

Wang et al, (2005) determined attenuate vibration of four materials used as subballast, which are ballast, concrete, asphalt, and asphalt mixed with $20 \%$ of crumb rubber (RMAC), for a high-speed train by using three-dimensional finite element program, ABAQUS.

All of materials are simulated with the same thickness at $15 \mathrm{~cm}$ and applied linear elastic and 20 node-quadratic with Euler-Bernoulli beam theory to present mesh. And then applied load $37.5 \mathrm{kN}$ to $0.75 \mathrm{~m}^{2}$, that equivalents to the rail supports the train force at $75 \mathrm{kN}$.

The result in this study shows that asphalt and RMAC are able to reduce the ground acceleration around the track significantly but the ground acceleration at the middle increased around $3.5 \%$. Using concrete as subballast shows the ground vibration is increased at middle and around the track, when comparing with other materials.

Lei and Rose, (2008) investigated the deformation of the track by various thickness of asphalt combining with $20 \%$ of crumb rubber due to the load at $142.5 \mathrm{kN}$. Furthermore, the study also determined an impact from changing the percentage of crumb rubber into asphalt. The continuous elastic beam model (Euler-Bernoulli beam) is applied to simulate four layers of the track, including the asphalt layer.

The analytical result shows that increased thickness of the asphalt layer will improve the track performance in term of reduced deflection of the track as shown in Figure 215. 


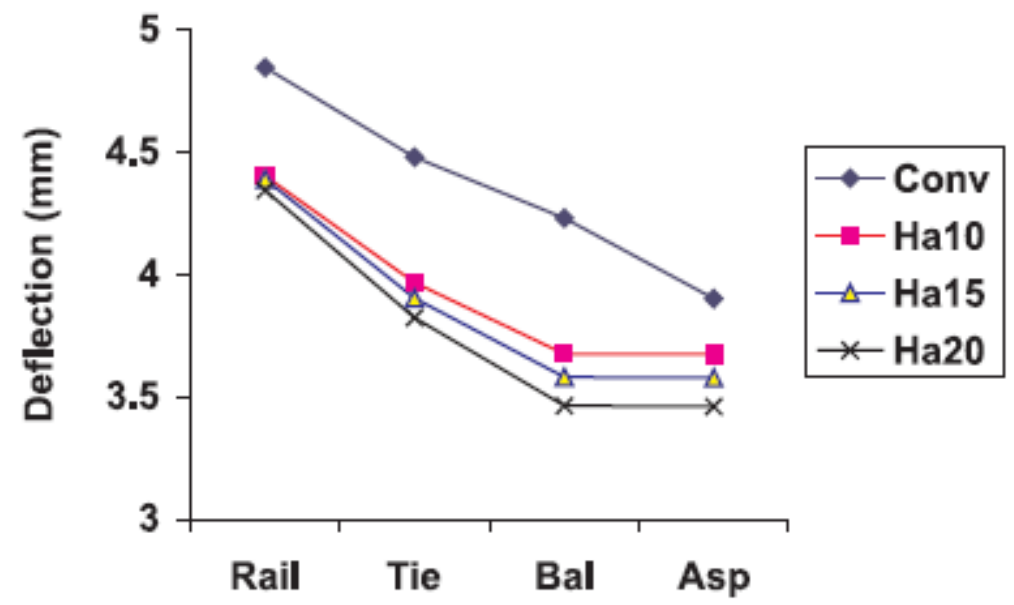

Figure 2-15 Comparison between granular layer and three different thickness of asphalt layer (Lei and Rose, 2009)

The study also shows a comparison of deflection in term of adding various percentages of crumb rubber into hot mixed asphalt, there are not significantly difference as shown in Figure 2-16.

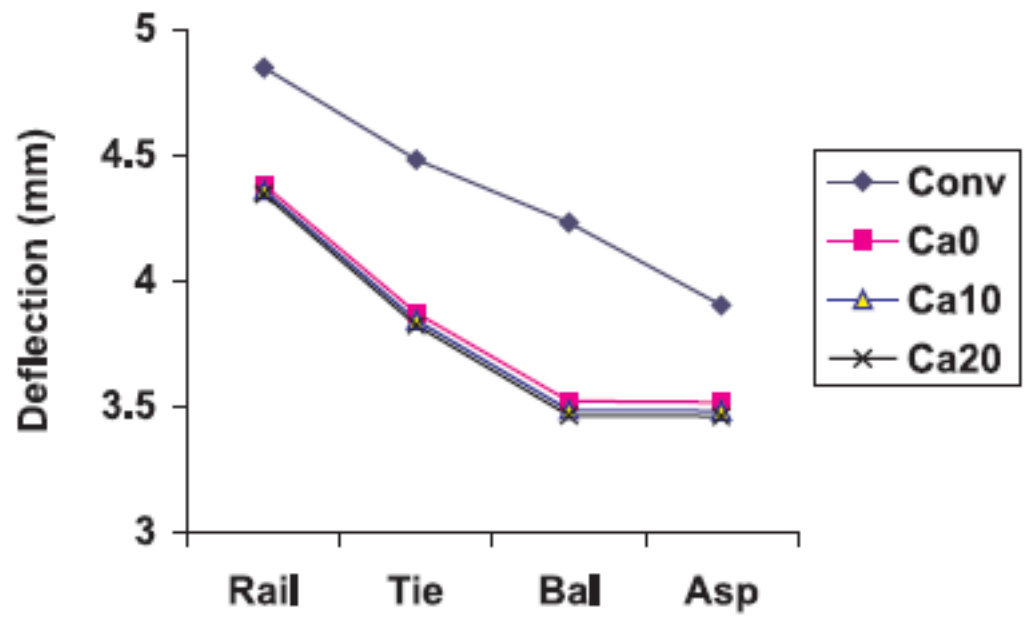

Figure 2-16 Comparison between granular layer and $20 \mathrm{~cm}$ of HMA with $0 \%, 10 \%$, and $20 \%$ of crumb rubber (Lei and Rose, 2009)

Yang et al (2009) simulates two-dimensional conventional track by using ABAQUS program to determine the stress under a freight train's speed at $47.5 \mathrm{~km} / \mathrm{h}$. All components of the track are simulated as solid element with elastic properties. The 
result shows that the shear stress is related with a speed of the train. Thus, increased speed of train also increases the vertical stress and vertical displacement.

Huang et al, (2010) determined discontinuous of track that installed the asphalt layer by modeling a 2-D track structure as Euler-Bernoulli beam. The structure of simulation is called "sandwich type structure" because this simulation modeled beam on discrete support on beam, similar with sandwich. Purposes of this study are to compare the performance of asphalt layer between $10 \mathrm{~cm}$ and $20 \mathrm{~cm}$ under two different speeds of a passage train, which are normal speed $(20 \mathrm{~m} / \mathrm{s})$ and high-speed $(50 \mathrm{~m} / \mathrm{s})$.

The result shows that the deflection of track, that used $20 \mathrm{~cm}$ of asphalt layer, is less impacted under both speeds of the train, even though the track loses one tie support. On the other hand, using $10 \mathrm{~cm}$ of asphalt layer may not impact from the train's normal speed, but the track is highly influenced from the train's high speed as shown in Figure $2-17$.

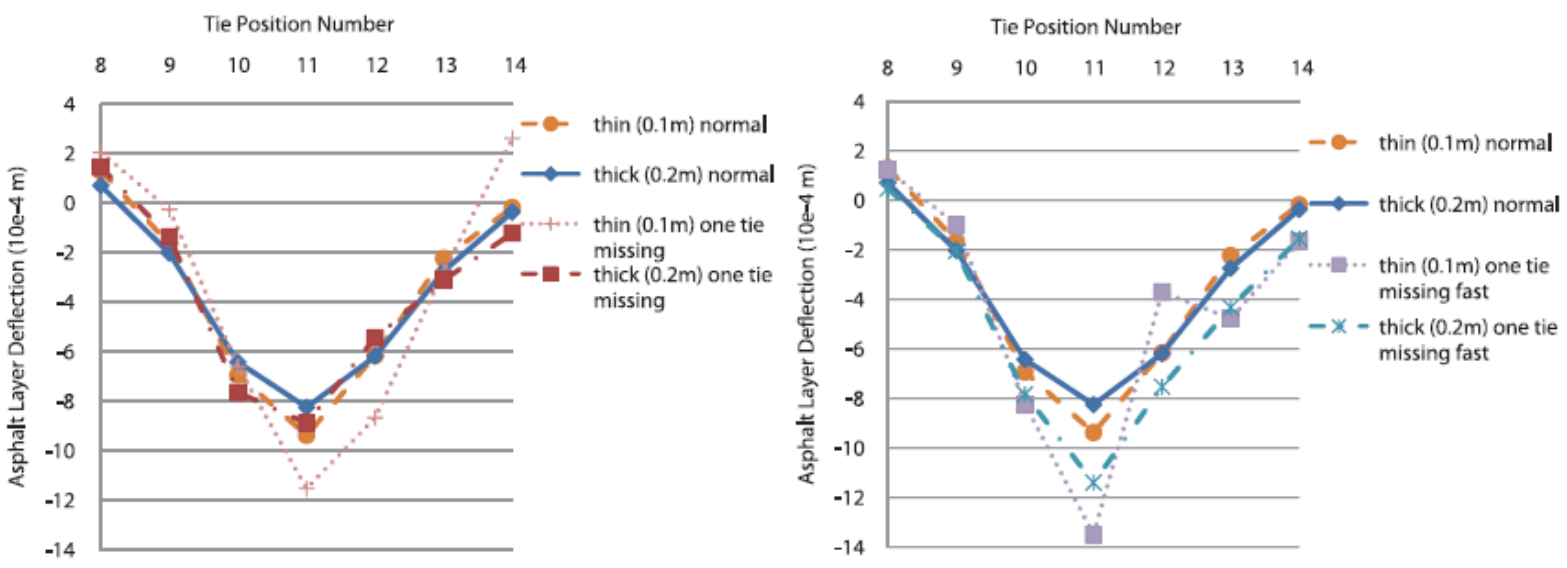

Figure 2-17 Deflection of asphalt layer profiles between $10 \mathrm{~cm}$ and $20 \mathrm{~cm}$ under train speed at $20 \mathrm{~m} / \mathrm{s}$ (Left) and train speed at $50 \mathrm{~m} / \mathrm{s}$ (Right) (Huang et al, 2010) 
Galvin et al, (2010) simulated a conventional track due to a train's speed at $298 \mathrm{~km} / \mathrm{h}$ to predict the ground vibration of the track and surrounding. In this case, a vehicle that has two cars and eight passengers, is represented as a multi-body system, and the track is simulated as a half-space by the boundary element model. The result is displayed by using nine nodes rectangular and six nodes triangular quadratic element and comparing with the experimental.

This analysis shows that the result of analytical model and experimental have the agreement on the frequency at $8 \mathrm{~m}$ from the train's speed at $298 \mathrm{~km} / \mathrm{h}$ as shown in Figure 2-18
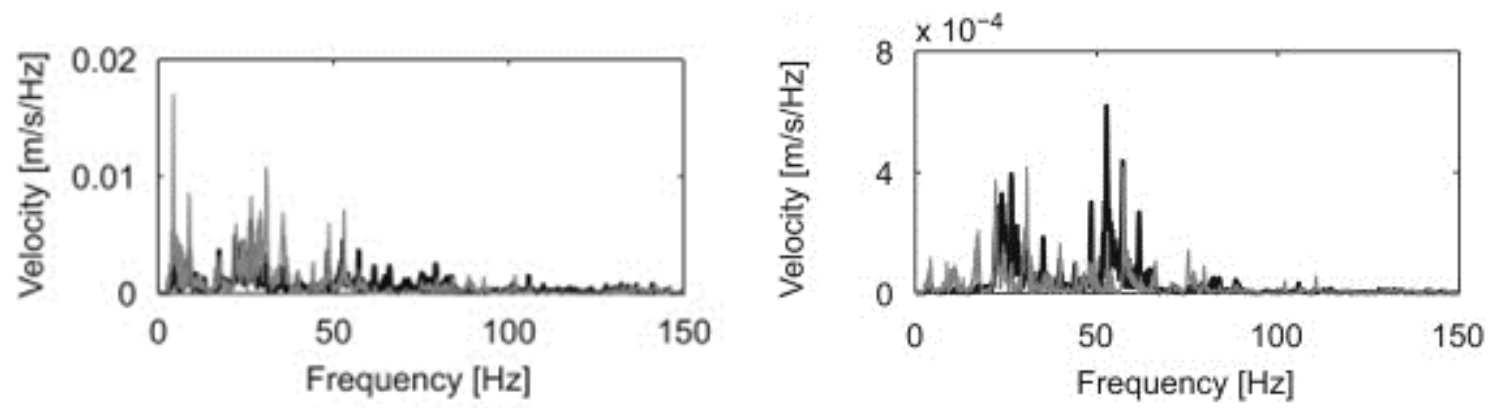

Figure 2-18 Frequency content of the vertical velocity at the sleeper (Left) and $8 \mathrm{~m}$ from the track (Right) under the passage train (Galvin et al, 2010)

Huang, (2012) determined an immediate performance of conventional track under a normal train's speed $(20 \mathrm{~m} / \mathrm{s})$ and a high train's speed at $90 \mathrm{~m} / \mathrm{s}$. This study uses Discrete Element Modelling (DEM) to determine the settlement of ballast under both speeds. The study simulates the track design of AREMA by using three-dimensional sandwich model that adopted from his previous research. Thus, this simulation is similar with 
two-dimensional model, which is beam (rail) on support structure (ballast) on beam (subballast).

After applied load 2,000 cycles, the result shows that the freight train created the settlement around $0.025 \mathrm{~m}$ in ballast layer, while the displacement of ballast under mixed traffic is slightly lower than $0.025 \mathrm{~m}$.

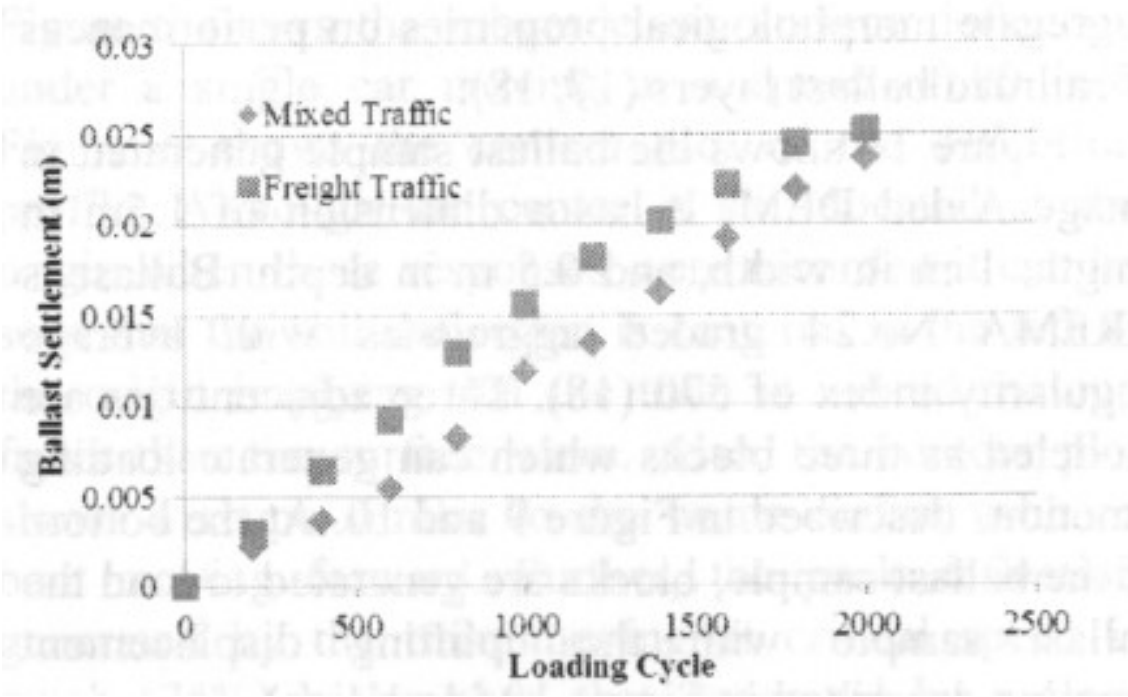

Figure 2-19 Ballast displacement due to a freight traffic and mixed traffic (Huang, 2012)

Mino et al, (2012) simulated a two-dimensional track comparing the performance between asphalt and asphalt combining with various percentages of crumb rubber, which are $1 \%$ and $5 \%$. This research also focuses on the track's performance in typical average temperatures of Southern Italy, which are which are $10^{\circ} \mathrm{C}, 17^{\circ} \mathrm{C}$, and $25^{\circ} \mathrm{C}$. The model simulated four levels of track as Euler Bernoulli beam and thickness of asphalt layer is $12 \mathrm{~cm}$. After analyzed, the result shows that the deflection between using 
asphalt without crumb rubber and using asphalt with crumb rubber is not significantly different due to temperatures.

However, using asphalt combining with crumb rubber shows the pressure of subgrade is slightly higher than using general asphalt as shown in Figure 2-20.

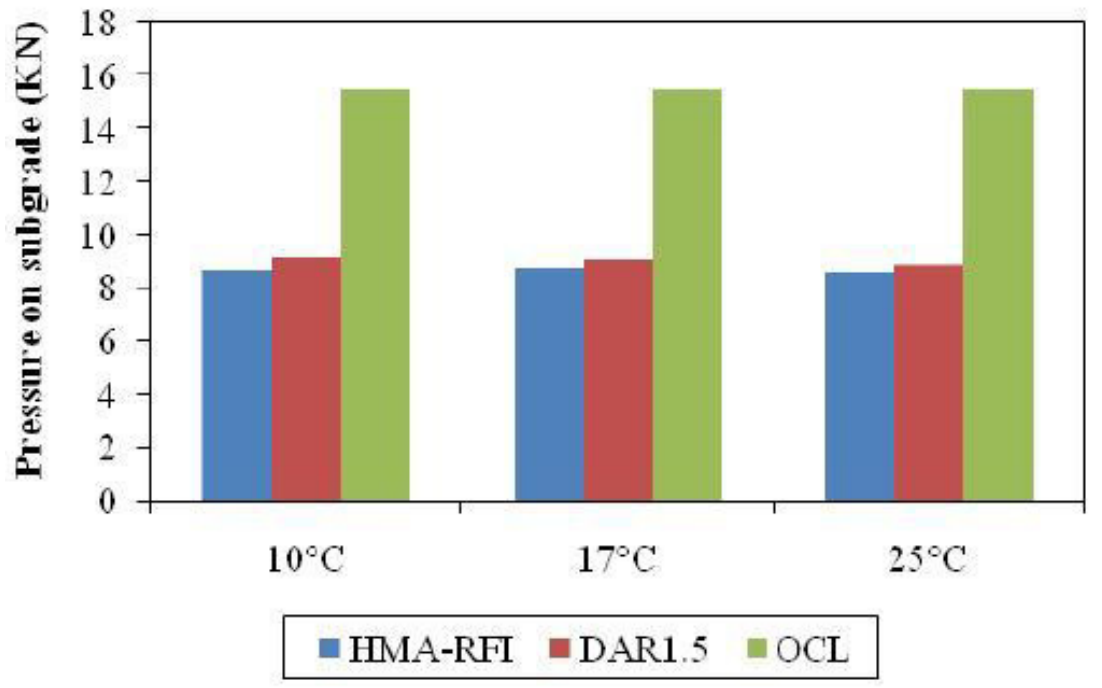

Figure 2-20 Pressure on subgrade between three different subballast (Mino et al, 2012)

Fang et al, (2013) used the finite element program, ABAQUS, to determine the optimal location of $15 \mathrm{~cm}$ of asphalt thickness layer due to $200 \mathrm{~km} / \mathrm{h}$ of high speed train. This model simulated components of the track structure as solid elements. Furthermore, the mesh of hexahedral elements, known as C3D8R, is chose to present the result.

Analytical result shows that the optimal location of using asphalt layer should be located on top of subballast layer. That is because at this location presents the vertical displacement is around $2.093 \mathrm{~mm}$, having less horizontal strain tan other position as shown in Figure 2-21. 

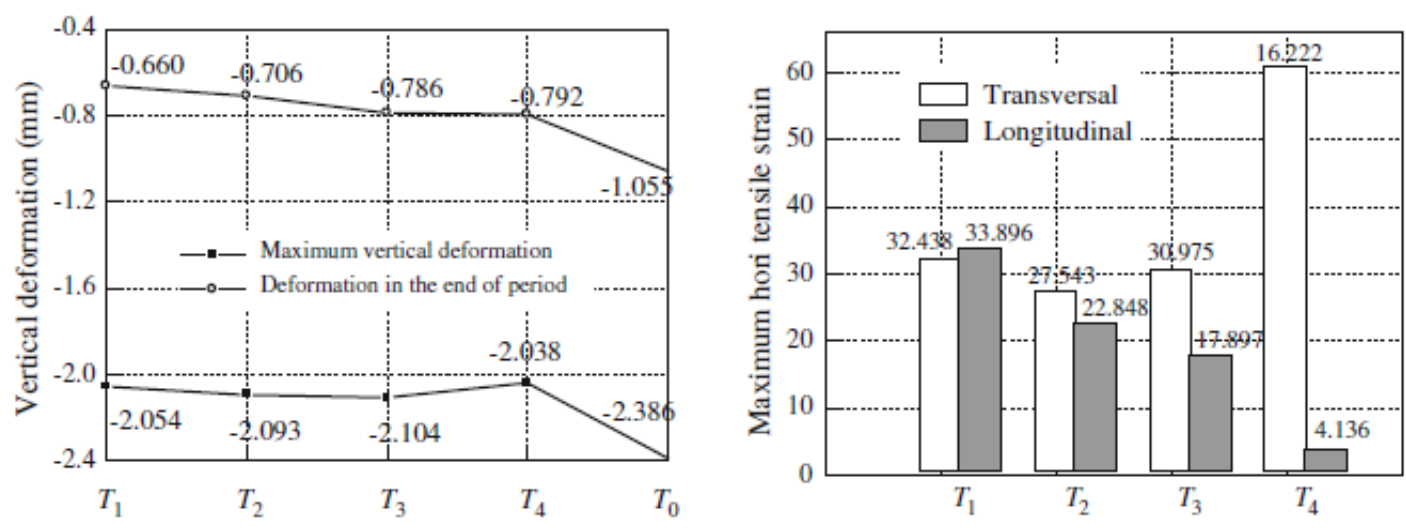

Figure 2-21 Vertical displacement (Left) and horizontal strain (Right) (Fang et al, 2013)

Fu and Zhen, (2014) analyzed a conventional track at four different speeds, which are $60,80,100$, and $120 \mathrm{~km} / \mathrm{h}$, by using ABQUS. This simulation considers components of the track as linear elastic. Bed-rock or bottom of the boundary is fixed in every direction to limit ground movement after being analyzed. Hexahedral element is selected to present the result of this analysis.

Analytical result shows that the vertical displacement is related with the train speed shown in Figure 2-22.

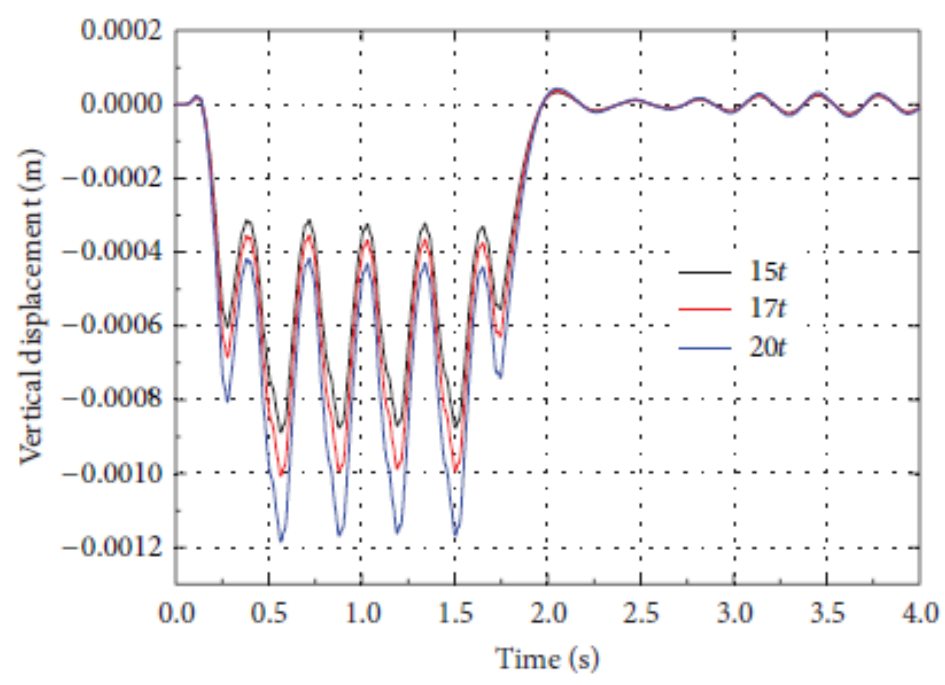

Figure 2-22 Vertical displacement under three different loaded (Fu and Zheng, 2014) 


\section{CHAPTER 3 METHODOLOGY}

\subsection{Design of Hot Mixed Asphalt}

Hot mix asphalt can be placed below the ballast to improve the track's performance. This underlayment method is shown in Figure 3-1. Thickness of the asphalt layer for this method varies from $10 \mathrm{~cm}$ to $20 \mathrm{~cm}$. On the other hand, for the overlayerment or full-depth method the whole ballast and subballast layers will be substitute with the asphalt layer. Thickness of the asphalt in this method should be in the range of $15 \mathrm{~cm}$ to $45 \mathrm{~cm}$ (See Figure 3-2). However, the underlayment design is the most common method, particularly for the freight operation track, because this method is easily adjusted the track geometry.

Furthermore, the ballast layer will protect the asphalt layer from environment condition such as sunlight, rain, and changing in temperature. However, for both methods quality control testing should be done to check temperature, density, and strength, to ensure asphalt reaching to the design specifications (Rose and Hensley, 1991) 


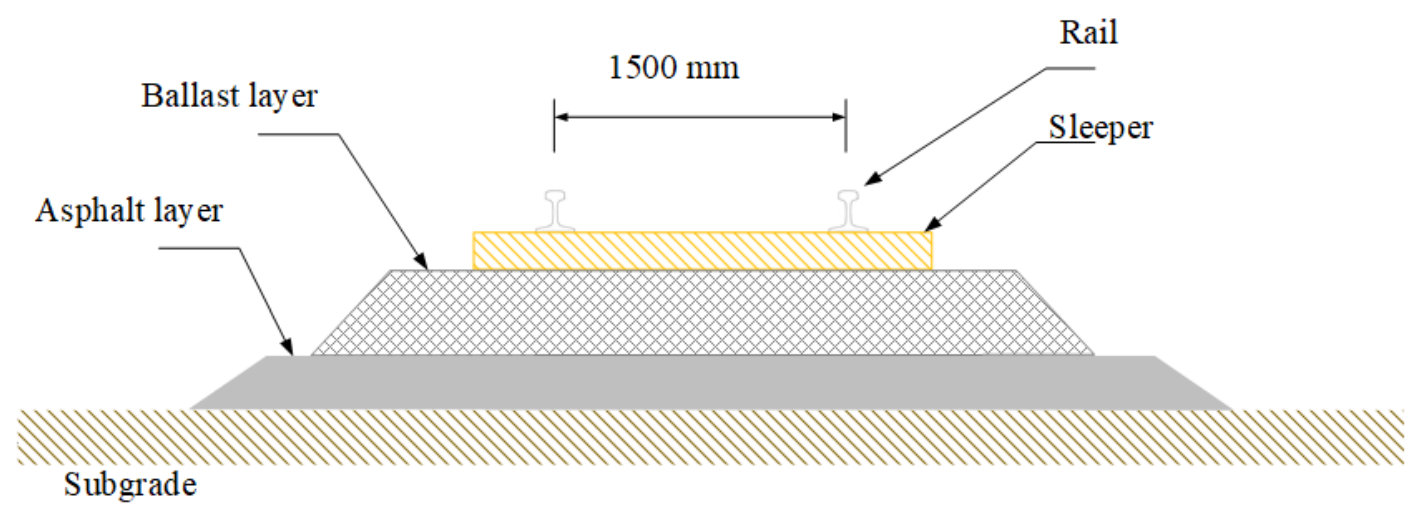

Figure 3-1 Cross-section of underlayment

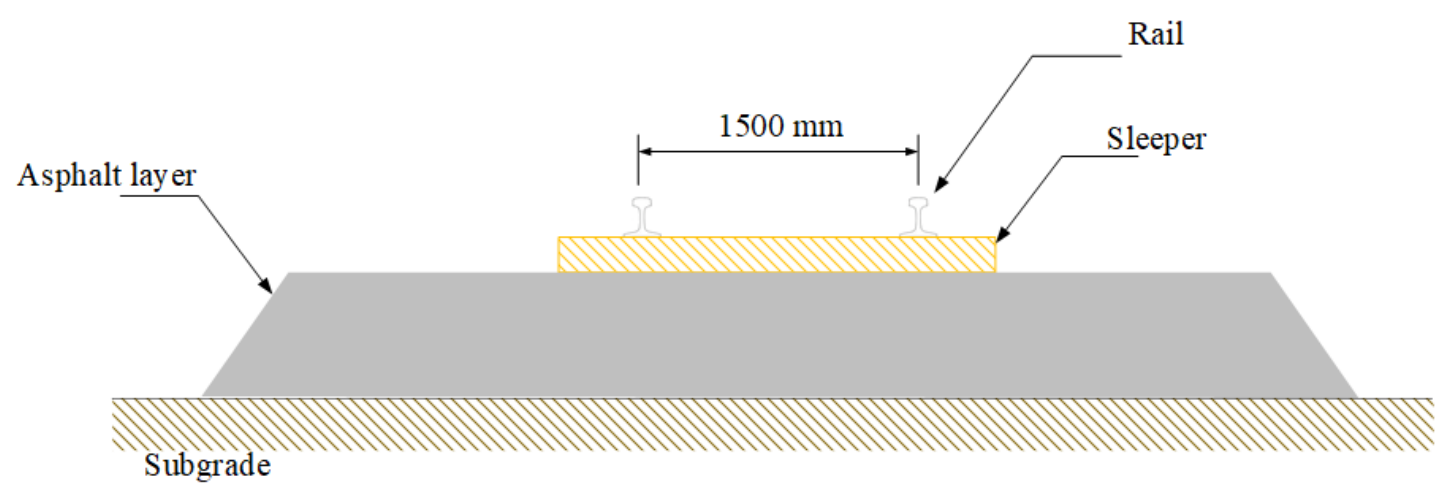

Figure 3-2 Cross-section of overlayement

\subsection{Static Stress Analysis}

Static stress analysis can be applied to determine either linear or nonlinear without an influence from inertia and time-dependent material effects such as creep, swelling and viscoelasticity, including some properties such as pore fluid flow, mass diffusion, and thermal properties. However, Static stress analysis still consider rate-dependent plasticity and hysteresis behavior for hyperelastic materials. 
The bottom boundary considerd to be fixed and all other four boundaries can only have vertical displacement. Stress, strain, and displacement were compared and predicted at different locations such as under the tie, and above the subgrade.

Although linear static analysis reduces the computational analyses, it has a limitation to present some effect such as large displacement, nonlinear material and boundary; therefore, nonlinear static is applied in this study by using Newton's method to calculate nonlinear equilibrium equation. Furthermore, the increment size has some restriction in the algorithmic, so increments selected by using automatic increments scheme to ensure the correct modeling.

\subsection{Methods for Determining Track Modulus}

Track modulus or modulus of elastic of rail support is one of the important parameters that influence the track performance, which is determined from the correlations between deflection of the track and the traffic loading. According to Hooke's law, a concentrated vertical load $(\mathrm{P})$ produces the maximum deflection $(\delta)$, so the spring stiffness, $\mathrm{k}$, is defined as following.

$$
k=\frac{P}{\delta}
$$

With the same theory, assuming that the track structure as a continuous beam support of the rail which is placed above the uniform spring layer. This layer of spring is 
combined with the remainder of the track structure, ballast layer, subballast, and subgrade as shown in Figure 3-3.

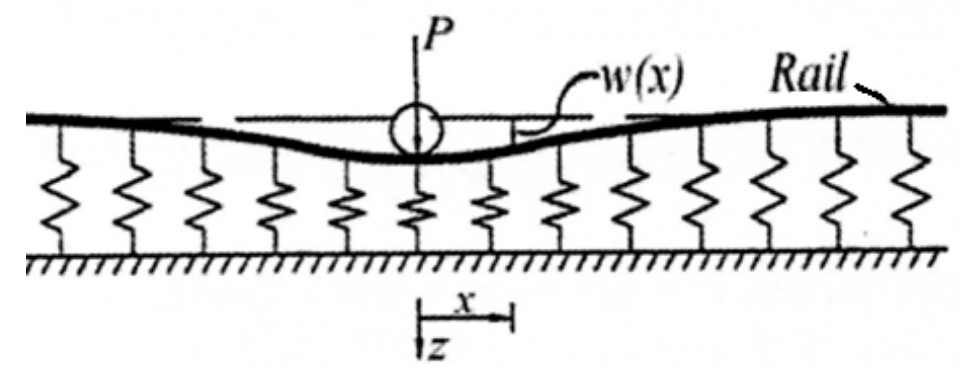

Figure 3-3 Winkler track foundation model (Cai et al. 1994)

Figure 3-3 illustrates the concept of Winkler method (Beam on elastic foundation method) that a concentrated load from the train wheel, $\mathrm{P}$, produces a vertical rail deflection at point $\mathrm{x}, w(x)$. The remaining parts such as sleepers, ballast, subballast will distribute the vertical wheel load, $\mathrm{q}(\mathrm{x})$, which is equal to track modulus, $\mathrm{k}$, multiple with the vertical deflection, $w(x)$.

The difference between applied load and reaction load will lead a curvature in the beam as in Eq.3-2:

$$
E I \frac{d^{4} w(x)}{d x^{4}}+k w(x)=P(x)
$$

Where EI is a flexural rigidity of the rail beam.

Since the train wheel is a single concentrated load applied vertically on the rail, the calculated deflection of the rail from the differential equation yields to:

$$
\begin{gathered}
w(x)=-\frac{p \beta}{2 k} e^{-\beta x}(\cos \beta x-\sin \beta x) \\
\text { where } \beta=\sqrt[4]{\frac{k}{4 E I}}, \text { and } \mathrm{x} \text { is the longitudinal distance. }
\end{gathered}
$$




\subsection{Finite Element Expression of Static stress analysis.}

The principle of virtual work can be applied to define the formula of the element stiffness matrix and a small change of the configuration in a system without requiring much mathematics. In case if the admissible displacement is occurred from applied loads, the equilibrium configuration can be used to explain initial strains, body forces, and surface traction relate with load vector. Results are based on interpolation of displacements from nodal degree of freedom.

In the other words, admissible displacement, $\mathrm{u}$, that stores energy in term of the increment of strain, $\varepsilon$, is equal to the increment of work done by body force, $F$, in volume, $V$, and surface traction, $\phi$, on surface, $S$ as shown in Eq.3-4:

$$
\int(\delta \varepsilon)^{T}\{\sigma\} d V=\int\{\delta u\}^{T}\{F\} d V+\int\{\delta u\}^{T}\{\phi\} d S
$$

From Eq. 3-4, the symbol of differential, $\delta$, uses for virtual displacement.

The displacement, $\mathrm{u}$, transforms to the deformation of element by using the relationship between the nodal displacement of an element, d, and shape function, $N$.

$$
\{u\}=[N]\{d\}
$$

Where $\{u\}$ is transpose matrix of displacement on $\mathrm{x}, \mathrm{y}, \mathrm{z}$-axis.

Furthermore, the strain, $\varepsilon$, is a derivative of displacement, $\partial u$, and the straindisplacement matrix, $[B]$, is equal to the derivative of shape function, $\partial N$. Substituted, strain and strain-displacement matrix into Eq. 3-6 to indicate the element stiffness matrix. 


$$
[k]=\int[B]^{T}[E][B] d V
$$

where $[\mathrm{E}]$ is a constant of elastic modulus.

In case of one-dimensional linear in xy-plane, the shape function contains four-node plane element, known as bilinear rectangle (Q4) as shown Figure 3-4.

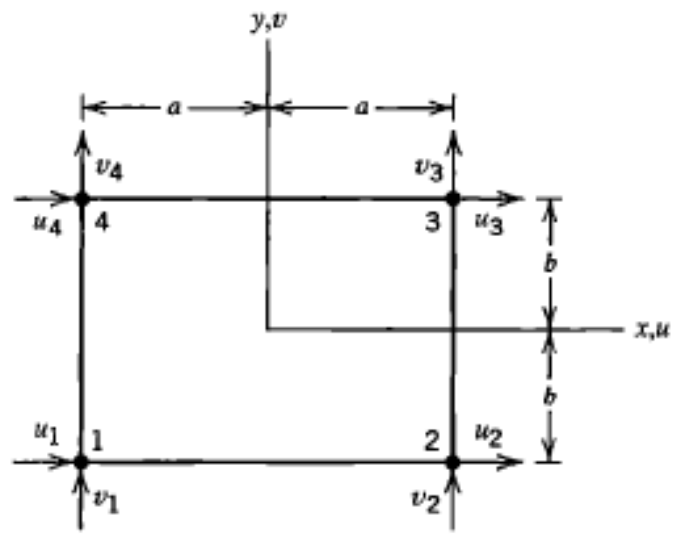

Figure 3-4 Rectangular on xy-plane, that displacement $u$ on $x$-axis and displacement $v$ on y-axis (Cook et al, 2002)

Figure 3-4 shows the rectangular on xy-plane, which has wide from -a to a on $\mathrm{x}$-axis and height is from $-\mathrm{b}$ to $\mathrm{b}$ on $\mathrm{y}$-axis, thus the element displacement field is rearranged into the matric as Eq.3-7

$\left\{\begin{array}{l}u \\ v\end{array}\right\}=\left[\begin{array}{cccccc}N_{1} & 0 & N_{2} & 0 & N_{3} & 0 \\ 0 & N_{1} & 0 & N_{2} & 0 & N_{3}\end{array}\right]\left\{\begin{array}{c}u_{1} \\ v_{1} \\ u_{2} \\ \vdots \\ v_{4}\end{array}\right\}$

Therefore, the element stiffness matrix is determined from bubble integral multiple with the element thickness, $t$, as shown Eq.3-8.

$$
[k]_{8 \times 8}=\int_{-b}^{b} \int_{-a}^{a}[B]_{8 \times 3}^{T}[E]_{3 \times 3}[B]_{3 \times 8} t d x d y
$$


If the thickness, $t$, is expanding on z-axis with 2c (shown Figure 3-5), the rectangular plane will become a rectangular solid element, or called "brick element", which has the displacement, $w$, on z-axis.

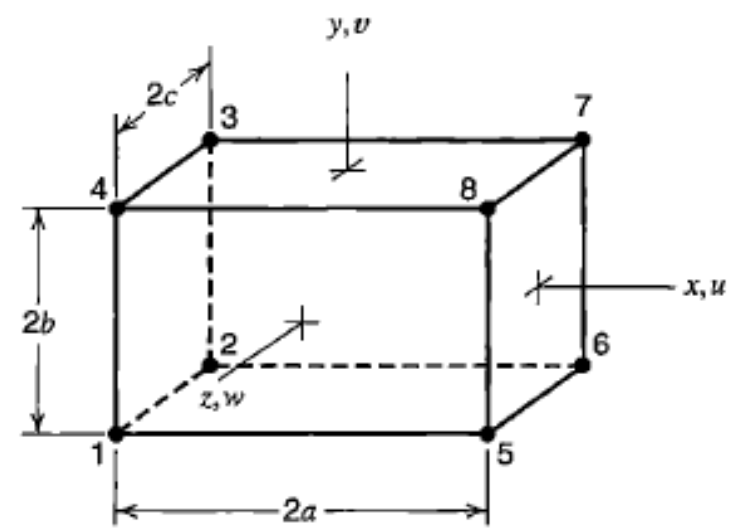

Figure 3-5 Brick element, which has eight-node element (Cook et al, 2002)

Consequently, the shape function becomes three linear functions, namely trilinear, and the relationship of shape function and element displacement is illustrated as Eq.3-9.

$$
\left\{\begin{array}{l}
u \\
v \\
w
\end{array}\right\}=\left[\begin{array}{cccccccccc}
N_{1} & 0 & 0 & N_{2} & 0 & 0 & N_{3} & 0 & 0 & \cdots \\
0 & N_{1} & 0 & 0 & N_{2} & 0 & 0 & N_{3} & 0 & \cdots \\
0 & 0 & N_{1} & 0 & 0 & N_{2} & 0 & 0 & N_{3} & \cdots
\end{array}\right]\left\{\begin{array}{c}
u_{1} \\
v_{1} \\
w_{1} \\
u_{2} \\
\vdots \\
w_{8}
\end{array}\right\}
$$

As a result, the element stiffness matric resembles, that is restricted to rectangular shape, as Eq.3-10.

$$
[k]_{24 \times 24}=\int_{-c}^{c} \int_{-b}^{b} \int_{-a}^{a}[B]_{24 \times 6}^{T}[E]_{6 \times 6}[B]_{6 \times 24} d x d y d z
$$

ABAQUS program uses the hexahedral isoparametric or known as "C3D8R", as a common element type, to do the numerical integration and calculate the stiffness matrix as well as the nodal displacement. In this case, the solid isoparametric elements are not sensitive to distortion and allows a number of nodes, curvatures of edges, or faces of a 
hexahedral lie on the extension axes at $\xi= \pm 1, \eta= \pm 1$, and $\zeta= \pm 1$ as shown in Figure 3-6.

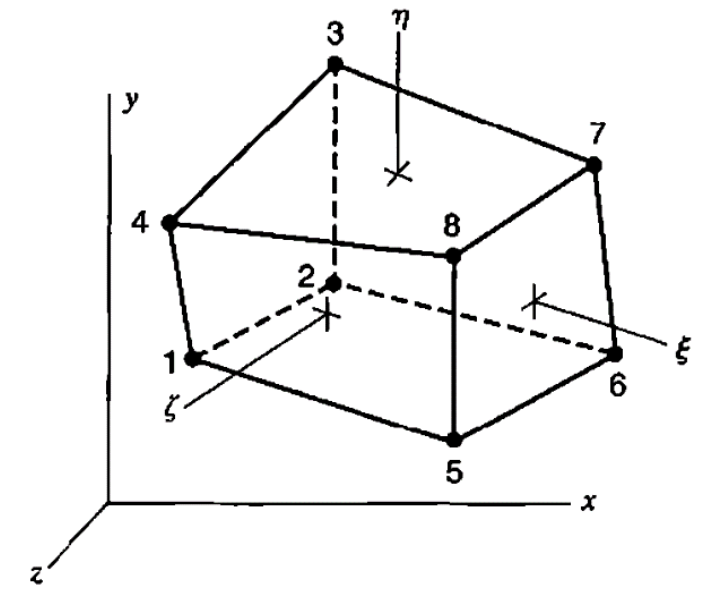

Figure 3-6 Eight-nodes hexahedral as nonrectangular shape (Cook et al, 2002)

From Figure 3-6, the shape of rectangular solid becomes nonrectangular solid, so the shape function is influenced by analogously Jacobian matrix, $[\mathbf{J}]$ as Eq. 3-12

$$
[\mathbf{J}]=\left[\begin{array}{lll}
x, \xi & y_{, \xi} & z, \xi \\
x, \eta & y_{, \eta} & z_{, \eta} \\
x, \zeta & y_{, \zeta} & z_{, \zeta}
\end{array}\right]=\sum_{i}\left[\begin{array}{lll}
N_{i} x, \xi & N_{i} y_{, \xi} & N_{i} z, \xi \\
N_{i} x, \eta & N_{i} y_{, \eta} & N_{i} z_{, \eta} \\
N_{i} x, \zeta & N_{i} y_{, \zeta} & N_{i} z, \zeta
\end{array}\right] \quad 3-12
$$

Furthermore, the shape functions of Eight-nodes hexahedron are defined as Eq. 3-13

$$
\begin{aligned}
N_{1} & =\frac{1}{8}(1-\xi)(1-\eta)(1+\zeta) \\
N_{2} & =\frac{1}{8}(1-\xi)(1-\eta)(1-\zeta) \\
N_{3} & =\frac{1}{8}(1-\xi)(1+\eta)(1-\zeta)
\end{aligned}
$$

Thus, the stiffness matrix for nonrectangular can be resembled by including Jacobian matrix, $J$ as Eq. 3-14

$$
[k]_{24 \times 24}=\int_{-1}^{1} \int_{-1}^{1} \int_{-1}^{1}[B]_{24 \times 6}^{T}[E]_{6 \times 6}[B]_{6 \times 24} J d \xi d \eta d \zeta \quad 3-14
$$




\subsection{Mohr-Coulomb}

Several theories have been developed to explain the time of failure in materials under stress condition. Although some theories are able to describe and satisfy the failure behavior, some of those are very complex to use for practice and need lots of parameters to define the constitutive model. In Geotechnical Engineering, Mohr-coulomb theory is traditionally applied to soil and can appropriately model the soil failure and soil behavior under the normal condition.

This theory is applied to finite element model known as Mohr-coulomb plastic model, that can be used with any stress/displacement element and will allow the potential of materials either harden and/or soften as a hyperbolic shape relating to stress plane, and a piecewise elliptic shape in the deviatoric stress plane.

In Mohr-coulomb model, a linear failure envelope to determine the critical combination of normal stress and shear stress will be considered. In other words, the shear stress and the normal stress produce the friction angle that represents the plane failure (Labuz and Zang, 2012). From the relation between shear strength and normal stress, it can be illustrated by plotting Mohr's circle to present a state of stress with the mathematic function of failure envelop as shown in Figure 3-7.

$$
\tau=c-\sigma \tan \theta
$$

Where $\quad \begin{array}{ll}\tau & \text { is a shear strength of the soil. } \\ C & \text { is a cohesion of the soil. } \\ \sigma & \text { is a compressive stress. } \\ \theta & \text { is friction angle. }\end{array}$




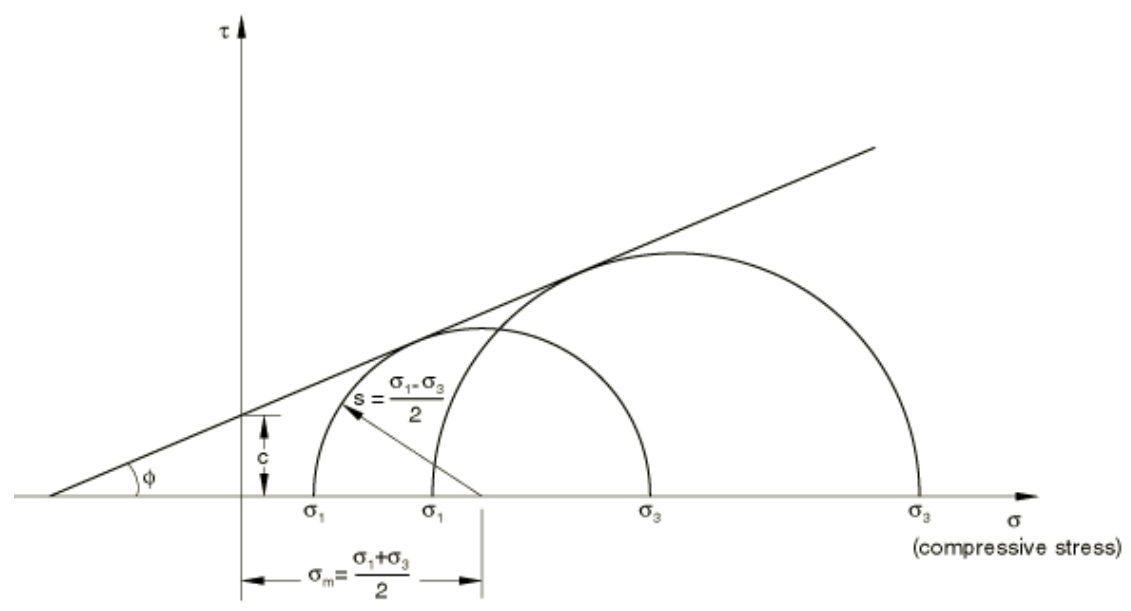

Figure 3-7 Mohr's circle at failure (ABAQUS 6.14, 2014)

Figure 3-7 presents the half of Mohr's circle diagram for a soil element, which compressive stress and shear strength act on to the tangency points between the circle and the failure envelop. At the average of principal stress or the difference between the maximum principal stress and minimum principal stress, the maximum shear stress can be defined.

The shape of yield surface in the deviatoric plane as shown Figure 3-8, which has the rang from $0^{\circ}$ to $90^{\circ}$, is controlled by the friction angle.

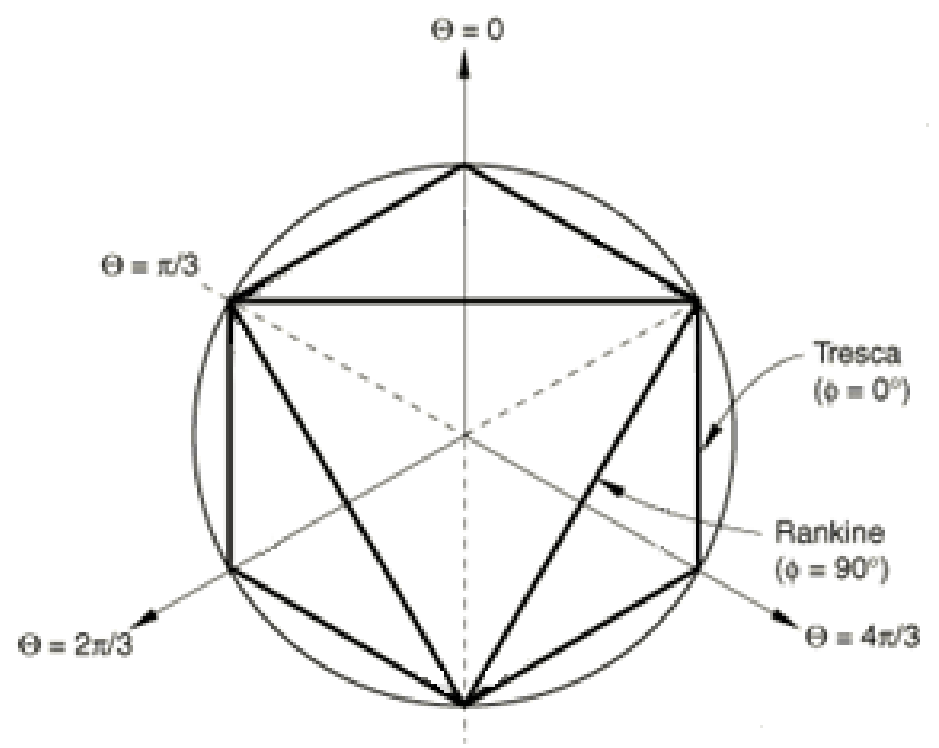

Figure 3-8 Mohr-Coulomb surface in deviatoric plane (ABQUS 6.14, 2014) 
The pressure-independent Tresca model is formed a perfectly hexagonal deviatoric section at friction angle equal to $0^{\circ}$. On other hand, at the maximum friction angle at $90^{\circ}$, the tension cutoff Rankine model is reduced and form a triangular deviatoric section. Mohr-Coulomb plasticity model has been used to define the subgrade. Note, elastic behavior is considered for all other pieces such as, rail, sleeper, asphalt subballast, and ballast behavior. 


\section{CHAPTER 4 VALIDATION OF THE MODEL}

\subsection{Model Calibration}

\subsubsection{Bearing Capacity Evaluation of Footing on a Layered-Soil}

For the first step to develop and validate a numerical model, stress and displacements of the soil blow the shallow foundation was studied. The predicted failure of the shallow foundation either can be compared with a theoretic model or published results. Studying the basic failure mechanism of soil under footing with various types of soil condition is a viable method to validate the railway trackbed model. In general, many researchers are conducting an experiment to investigate influence of various parameters on soil failure under the footing. Finite element method can accurately estimate bearing capacity of a shallow foundation on a layered-soil.

Mosadegh and Nikraz, (2015) conducted two -dimensional model by using commercial program, ABQUS, to compare the failure of one-layer soil. They considered two scenarios (with and without dilation angel). They assumed a 0.5 -m rigid footing placed on top of a one-layer sand. Isotropic Ealsto-plastic material satisfying Drucker-Prager were considered. The overburden pressure was $9.6 \mathrm{kPa}$ and downward 
settlement $(=50 \mathrm{~cm})$ was applied on the foundation for 100 second (See Figure 4.1). The result was validated with Terzaghi's equation.

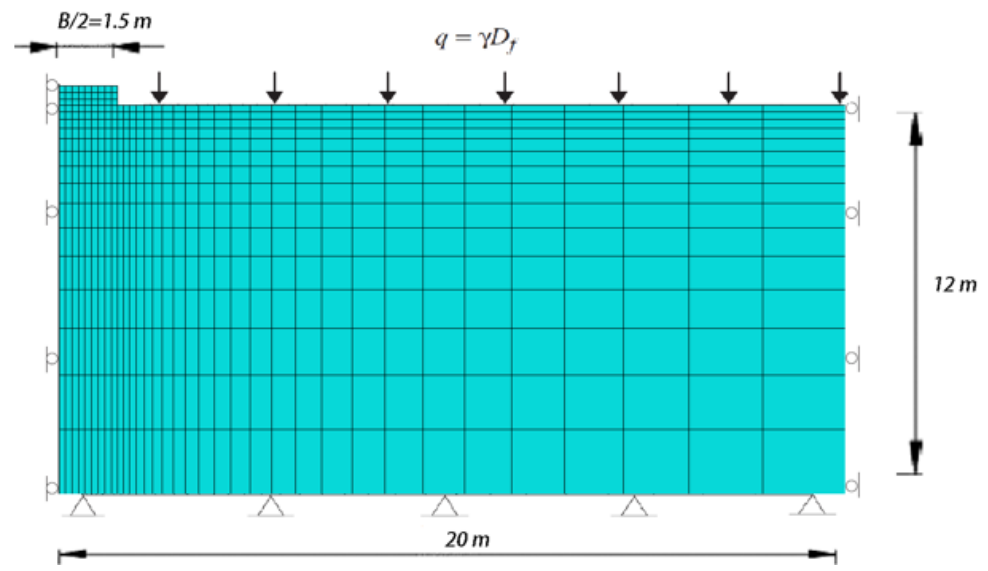

Figure 4-1 Model simulation and boundary condition, that a model of 510 elements (Mosadegh and Nikraz, 2015)

Comparison of soil failure model predicted from Terzaghi with FEM model, illustrates three different zone of plastic shear failure, which are immediately under the footing, two radial zones, and two Rankine passive zones as shown in Figure 4-2 and Figure 43.

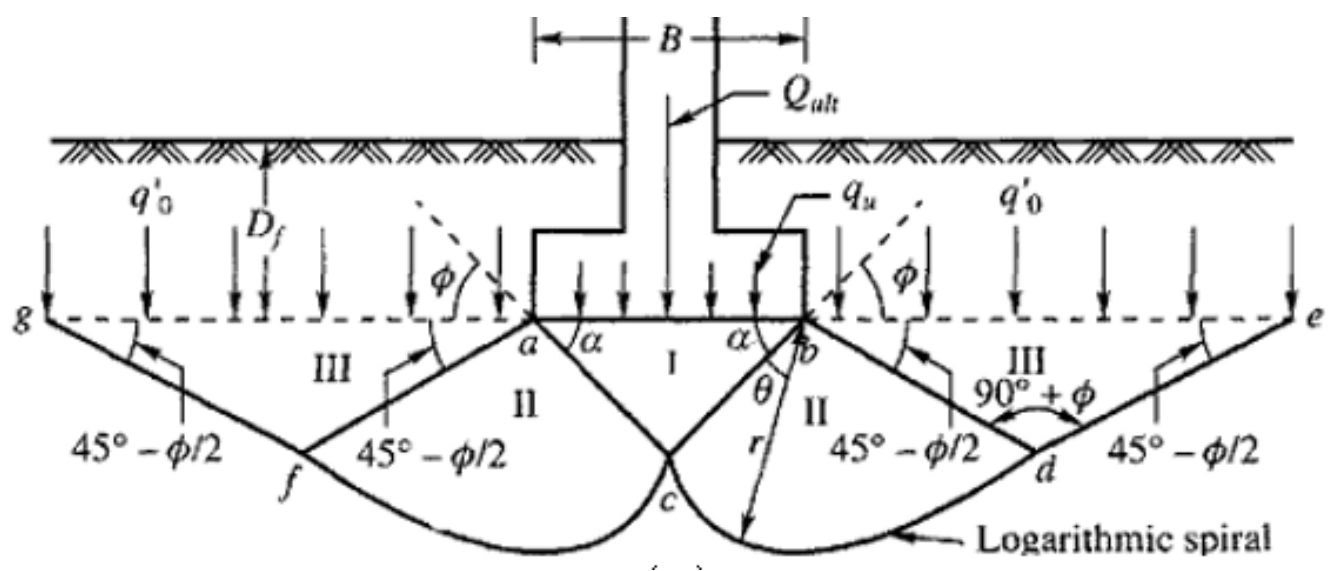

Figure 4-2 Assumption of soil failure in Terzaghi model (Mosadegh and Nikraz, 2015) 


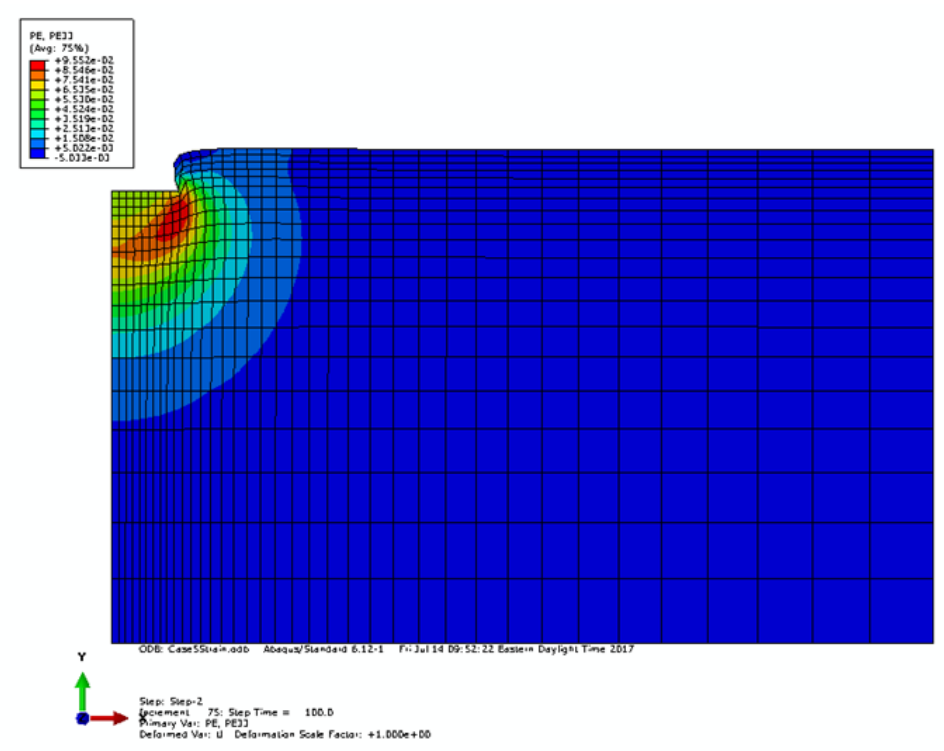

Figure 4-3 Soil failure from finite element analysis (Mosadegh and Nikraz, 2015)

Results show that the bearing capacity of soil considering dilation angel is $13 \%$ higher than bearing capacity of soil $\mathrm{c}$ without dilation. Note the predicted bearing capacity is slightly higher than the value calculating using Terzaghi's equation as shown in Figure 4-4.

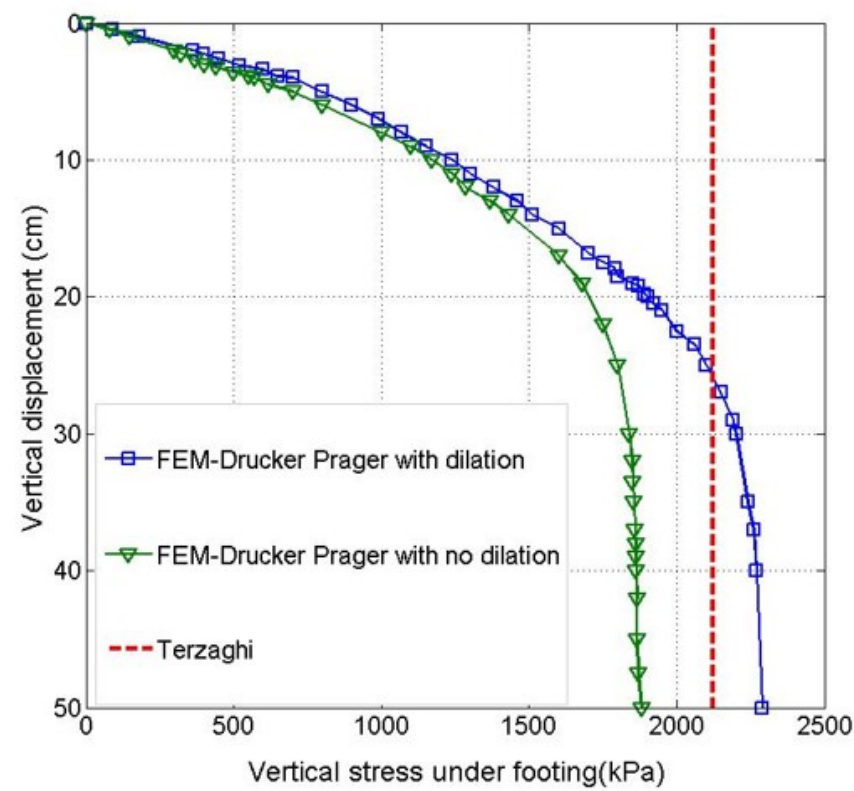

Figure 4-4 Comparison bearing capacity, with dilation, without dilation, and calculated value by using Terzaghi's equation (Mosadegh and Nikraz, 2015) 
The bearing capacity value from Mosadegh and Nikraz, (2015) shows that the vertical stress under the footing equals to $2290 \mathrm{kPa}$ for soil with dilation. Whereas the vertical stress in case of no dilation has the value equals to $1900 \mathrm{kPa}$. Both results match well with the present model. Using the developed model, the value of vertical stress without dilation is equal to $1884 \mathrm{kPa}$, while the value of vertical stress with dilation is equal to $2243 \mathrm{kPa}$. Furthermore, the bearing capacity is calculated by using Terzaghi's equation shows the value of vertical stress is equal to $2124 \mathrm{kPa}$, which slightly lower than the analytical model. The predicted results from present study matches well with empirical model and available published research. However, a slight difference in the results can be because of the different assumptions. The calculated vertical stress by using Terzaghi's equation assumes that the soil behavior is perfectly plastic but the Finite Element Analysis (FEA) model assumes that the soil behavior is elasto-plastic. Furthermore, the sensitive of parameter, like yield stress, and absolute plastic stain, can affect the accuracy of the result. 


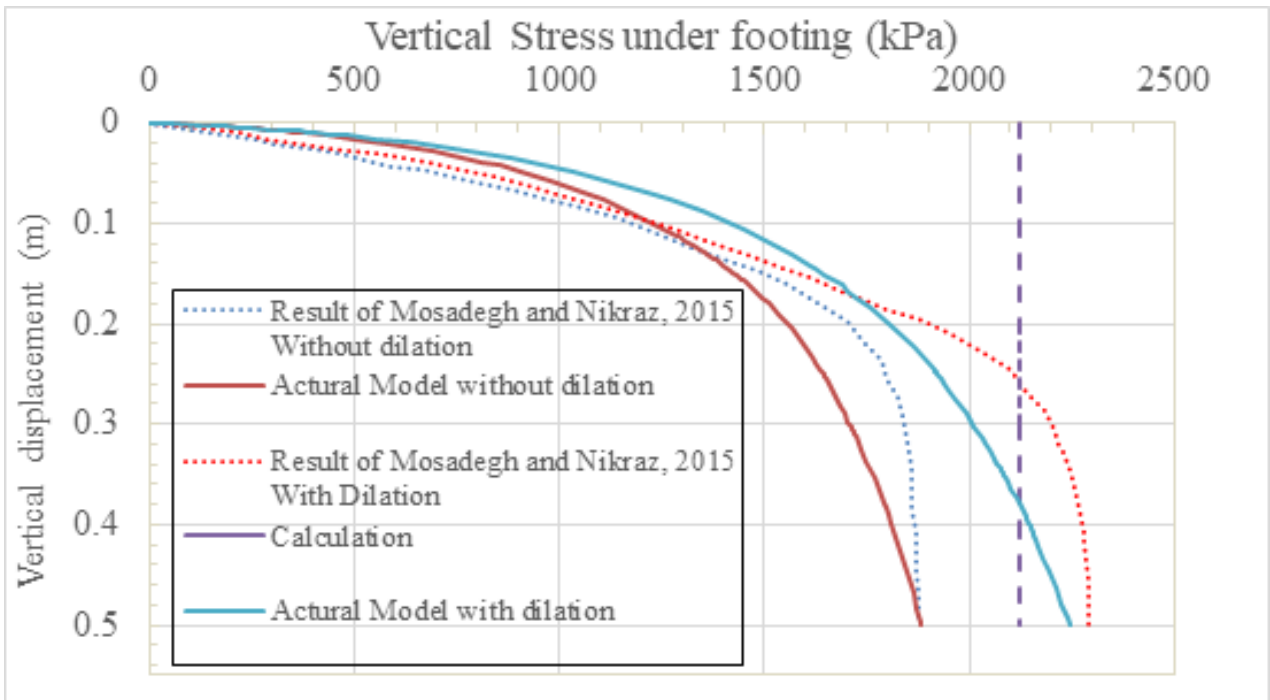

Figure 4-5 Comparison of soil failure between present study, other FEM results and theoretical model

\subsubsection{Railway Trackbed Modeling}

The trackbed geometry is different from the shallow foundation. Therefore, the accurate geometry of the railway trackbed is simulated in this step. The word "track" refers to a combination of all components, such as rail, sleepers, ballast layer, and subballast layer. However, the trackbed FEM should be validated using the Elastic theory and experimental observations. 


\subsubsection{Stress Below a Rectangular Area}

Figure 4-6 presents stress distribution at depth $\mathrm{Z}$ below the loading on the surface of the model using 2:1 method.

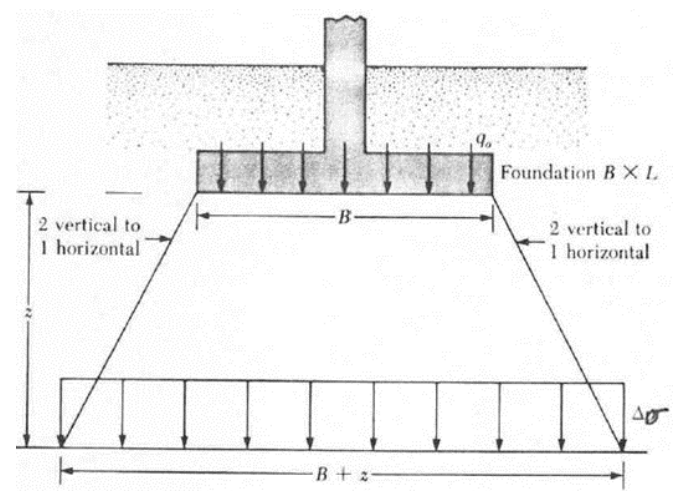

Figure 4-6 Stress increase at depth $\mathrm{z}$ under the shallow foundation (Das, 2015)

The total stress increase, $\Delta \sigma$, at any point under a rectangular area is calculated from the relationship between the applied load, $q_{0}$, and an area, $d$ A to obtain the preceding equation as shown

$$
\Delta \sigma=\int_{y=0}^{L} \int_{x=0}^{B} \frac{3 q_{0}(d x d y) z^{3}}{2 \pi\left(x^{2}+y^{2}+z^{2}\right)^{\frac{5}{2}}}
$$

Alternatively, the increments in total stress, $\Delta \sigma$ is calculated from the applied load, $q_{0}$, multiple with influence factor, I, which is calculated from a ratio of the rectangular area (as shown Figure 4-7) divided with the depth $\mathrm{z}$ substitude into influence factor equation.

$$
\begin{aligned}
& \Delta \sigma=q_{0} I \\
& I=\frac{1}{4 \pi}\left(\frac{2 m n \sqrt{m^{2}+n^{2}+1}}{m^{2}+n^{2}+m^{2} n^{2}+1} \cdot \frac{m^{2}+n^{2}+2}{m^{2}+n^{2}++1}+\tan ^{-1}\left(\frac{2 m n \sqrt{m^{2}+n^{2}+1}}{m^{2}+n^{2}+m^{2} n^{2}-1}\right)\right) \\
& \begin{array}{ll}
\text { Where } & 4-2 \\
\text { and } & m=\frac{B}{z}
\end{array}
\end{aligned}
$$




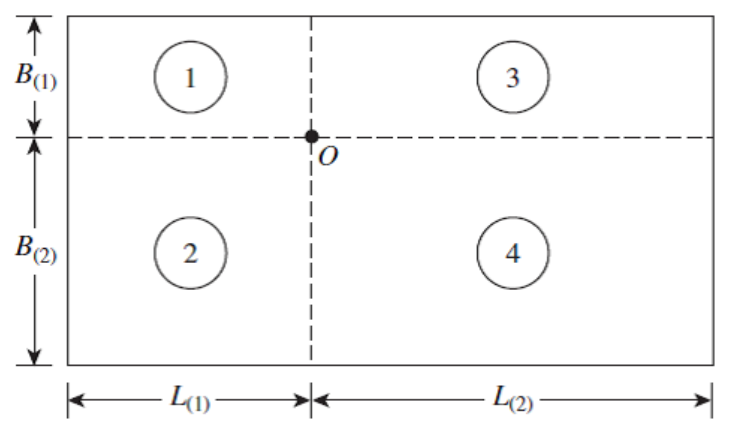

Figure 4-7 Example of rectangular loaded area (Das, 2015)

The stress at a depth $\mathrm{z}$ below point $\mathrm{O}$ or at the intersection of four rectangles is calculated from the summation of influecen values from $I_{1}$ to $I_{4}$ multiple with the applied load.

$\Delta \sigma=q_{0}\left(I_{1}+I_{2}+I_{3}+I_{4}\right)$ $4-3$

However, the center of a rectangular area is the importantce point to show the verticle stress that can be calculated directly by using Eq. $4-4$

$$
\Delta \sigma=q_{0} I_{c}
$$

Where

$$
\begin{gathered}
I_{c}=\frac{2}{\pi}\left[\frac{m_{1} n_{1}}{\sqrt{1+m_{1}^{2}+n_{1}^{2}}} \cdot \frac{1+m_{1}^{2}+n_{1}^{2}}{\left(1+n_{1}^{2}\right)\left(m_{1}^{2}+n_{1}^{2}\right)}+\sin ^{-1}\left(\frac{m_{1}}{\sqrt{m_{1}^{2}+n_{1}^{2}} \sqrt{1+n_{1}^{2}}}\right)\right] \\
m_{1}=\frac{L}{B} \\
n_{1}=\frac{Z}{\left(\frac{B}{2}\right)}
\end{gathered}
$$

In this case, $\mathrm{m}_{1}$ and $\mathrm{n}_{1}$ are defined by using a full dimensional of the rectangular area.

Compasion between the results obtained from the present FEM and elasticity theory (appling the theory of stress below a rectangular area) will help to validate the current model and its accuracy to predict the vertical stress. 
Further in this chapter real geometry is used. However, in this section the rail was replaced with a rectangular area, that has dimension of $7 \times 22.86 \times 2.54 \mathrm{in} \mathrm{cm}$, lie over the half of sleeper. Moreover, this model uses the average property. Applied pressure is $900 \mathrm{kPa}$, which is equivalent to a train with $235 \mathrm{~km} / \mathrm{hr}$ speed. The value of vertical stress is measured at $17.7 \mathrm{~cm}$ depth.

Overall of the result shows the vertical stress spreads similar with 2:1 method. However, the result from vertical stress at the center below the rectangular place in he current model is around $239.26 \mathrm{kPa}$, which is slighly higher $(36.1 \mathrm{kPa})$ than the vertical stress from the equation. This slight reduction in stress can be due to the different assumption in the vertical stress's distribution. The theory of 2:1 method presents the prefectly distribution of vertical stress, whereas the simulation shows the vertical strress highly concentrate at around the center of rectangular place as illstrated Figure 4-8.

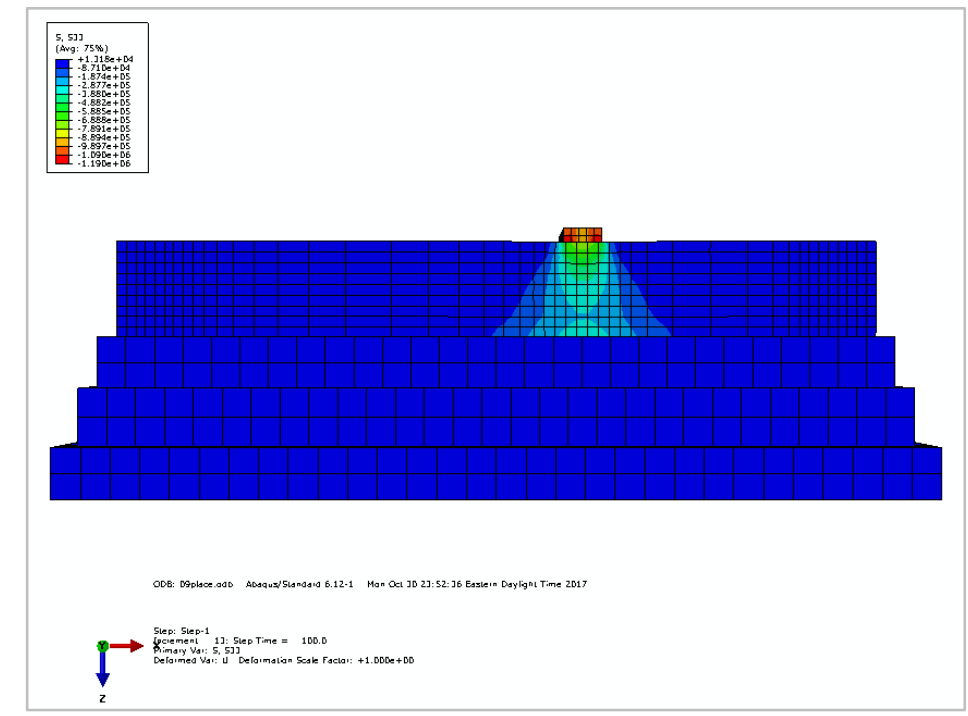

Figure 4-8 Result of vertical stress in the simulation, the green area presents the high concentrated vertical stress at the middle of the rectangular place 


\subsubsection{Comparison Modeling and Experiment}

Jerry Rose from University of Kentucky created a full-scale of half-track structure to determine the vertical stress distribution under the tie due to different static loads. Thus, four load cells, namely $68,69,70$, and 71 , are installed under the tie to measure an impact from different applied static loads, which varies from $1500 \mathrm{lbs}$ to $10500 \mathrm{lbs}$ as shown in Figure 4-9.

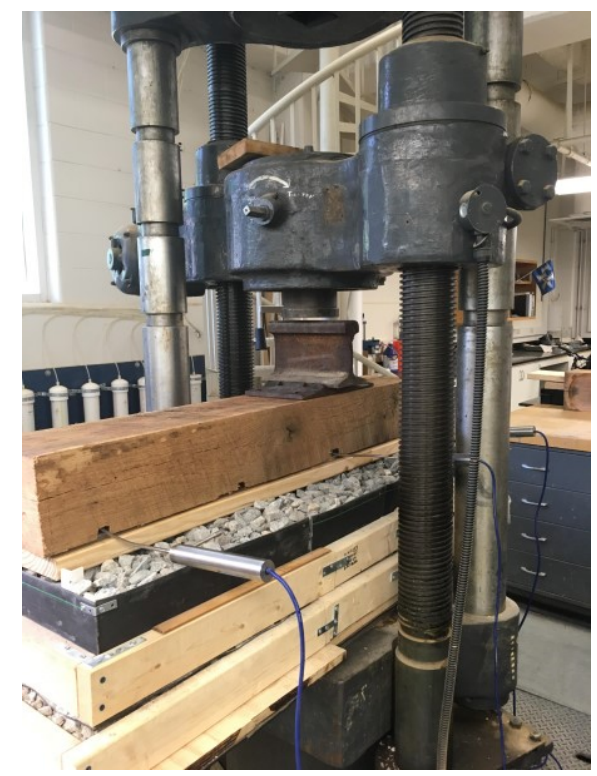

Figure 4-9 Full-scale of half-track at University of Kentucky

The half-track structure is combined with six different components, which are Rail 136 lb/yd, double-should fastening, wooden sleeper, upper-ballast layer, lower-ballast, and subballast layer as shown in Figure 4-10. Thicknesses of upper-ballast, lower-ballast, and subballast are around $9 \mathrm{~cm}, 15 \mathrm{~cm}$, and $9 \mathrm{~cm}$, respectively. This experiment presents the result of stress under applied loading in British-Units. 


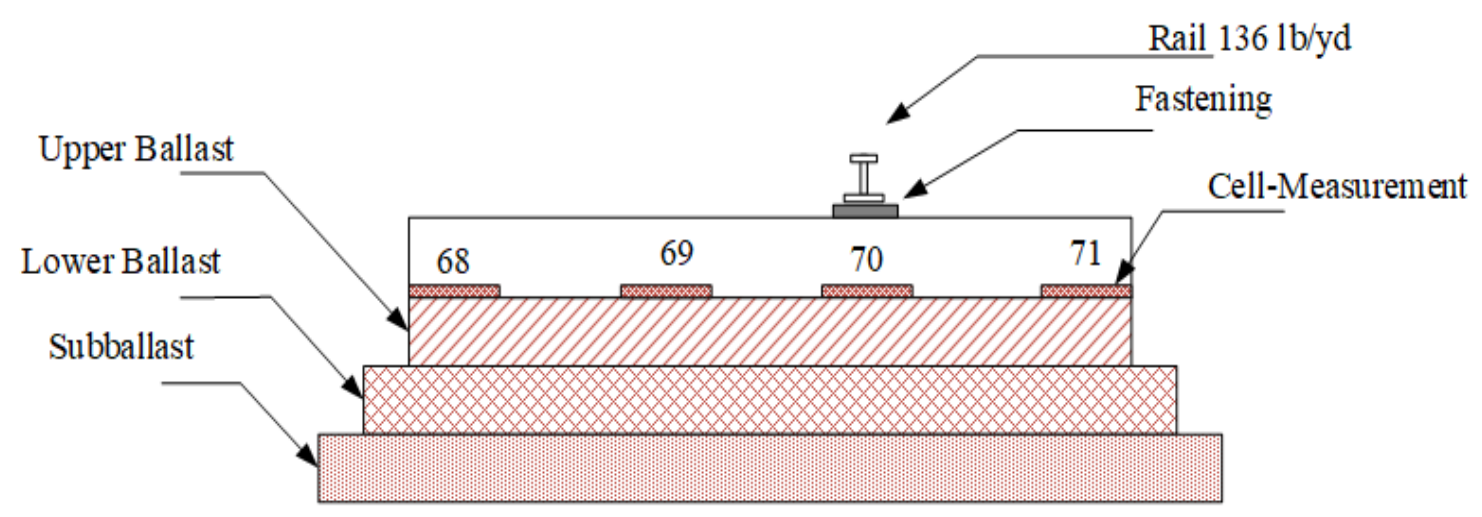

Figure 4-10 Cross-section of half-track structure

After applied various load to the track structure, the result shows that the maximum vertical stress is obviously at cell-number 70 , which locates under the rail, and then spreading to cell-number 69 and 71 as shown in Figure 4-11. For example, the result of the half-track structure under applied load at $3000 \mathrm{lbs}$ shows the cell-number 70 has the vertical stress around 19.18 Psi, whereas the vertical stress at cell-number 69 and cellnumber 71 are around 9.11 Psi and 5.6 Psi, respectively.

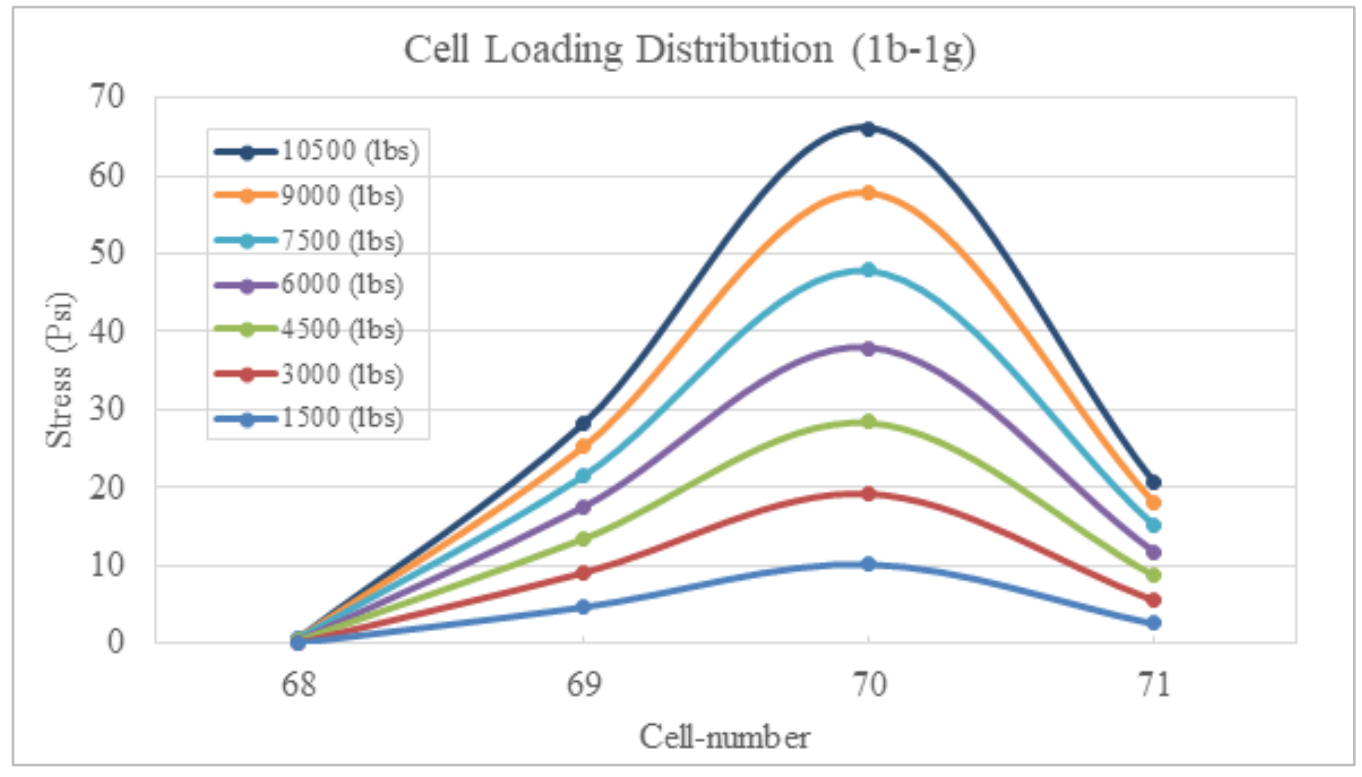

Figure 4-11 The result of vertical stress is applied various loads (Rose et al. 2018) 
Finite Element program, ABAQUS used to mode a three dimension of the half-track structure as shown in Figure 4-12. Results from numerical model are compared with the experimental observations. Eight-node brick element, which comprises a total of 55,677 elements are used in this model. Perfectly contact surface-to-surface and generating rough tangential with hard contact are considered for the interaction between surfaces of each layers. The boundary condition restrains the longitudinal and transversal directs as symmetric boundary conditions.

Furthermore, this simulation applied static load from $3000 \mathrm{lbs}$ to $10500 \mathrm{lbs}$ on top of the rail and the results are compared with experimental observations.

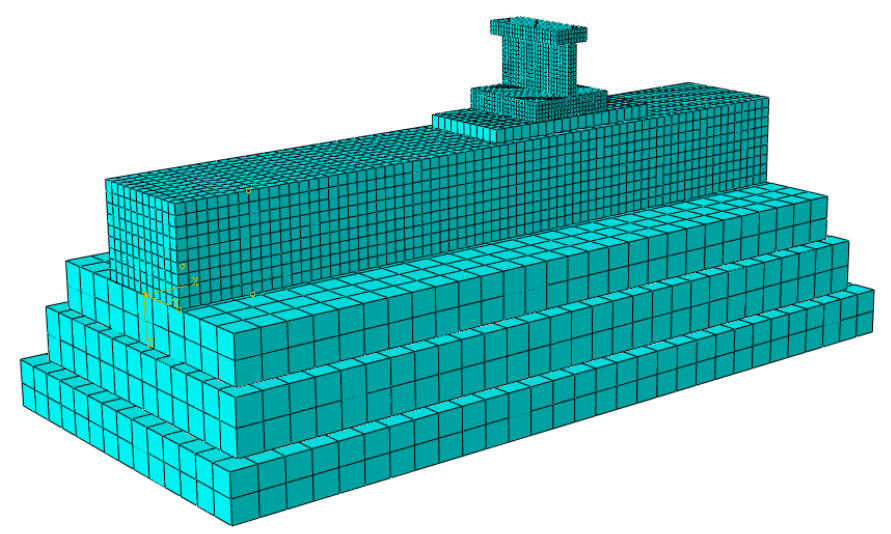

Figure 4-12 Mesh of half-track

The model simulates a half-track as same as the experiment components. Rail type 136 $\mathrm{lb} / \mathrm{yd}$ is simulated with the same dimensional as shown in Figure 4-13. Parameters of the rail, which are young modulus, density, and poisson's ratio, are equal to $210 \mathrm{GPa}$, $7,830 \mathrm{~kg} / \mathrm{m}^{2}$, and 0.3 , respectively. 


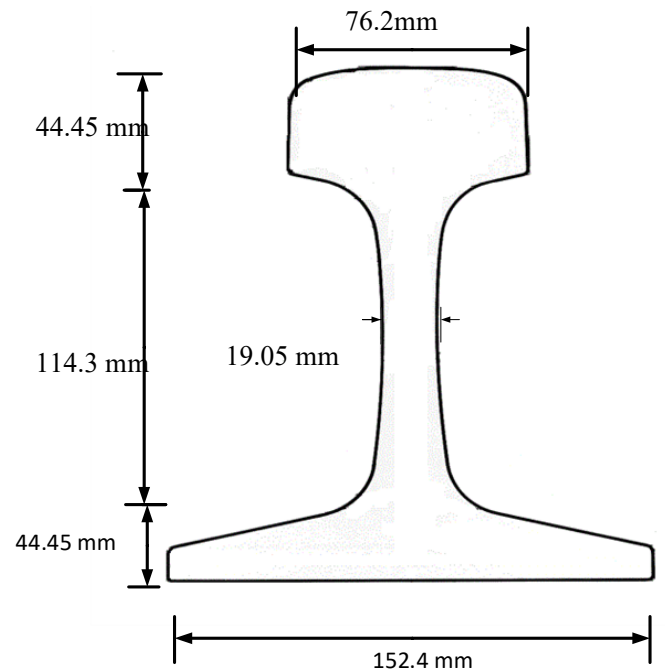

Figure 4-13 Dimension of rail type $136 \mathrm{lbs} / \mathrm{yd}$

Dimensional and parameter of other components are summarized in Table 4-1

Table 4- 1 Dimension and parameter of half-track structure.

\begin{tabular}{|l|c|c|c|c|c|c|}
\hline \multicolumn{1}{|c|}{ Components } & $\begin{array}{c}\text { Young } \\
\text { Modulus } \\
\mathrm{MPa}\end{array}$ & Density & $\mathrm{kg} / \mathrm{m} 3$ & & \multicolumn{3}{|c|}{ Dimension } \\
\cline { 5 - 7 } & Poisson ratio & & Wide (mm) & $\begin{array}{c}\text { Length } \\
\text { (mm) }\end{array}$ & $\begin{array}{c}\text { Depth } \\
\text { (mm) }\end{array}$ \\
\cline { 5 - 8 } \\
should) & 210,000 & 7,830 & 0.3 & 190.5 & 368.3 & 6.35 \\
Sleeper & 80 & 1200 & 0.3 & 228.6 & 1,397 & 177.8 \\
Upper ballast & 138 & 2100 & 0.3 & 558 & 1,397 & 88 \\
Lower Ballast & 138 & 2200 & 0.3 & 635 & $1,447.80$ & 150 \\
Subballast & 69 & 2150 & 0.3 & 711.2 & 1,524 & 88 \\
\hline
\end{tabular}

The result of this simulation is collected at the bottom of the tie to investigate the vertical stress under various applied loads, which are from $3000 \mathrm{lbs}$ to $10500 \mathrm{lbs}$, and comparing with the vertical stress from the experiment. 


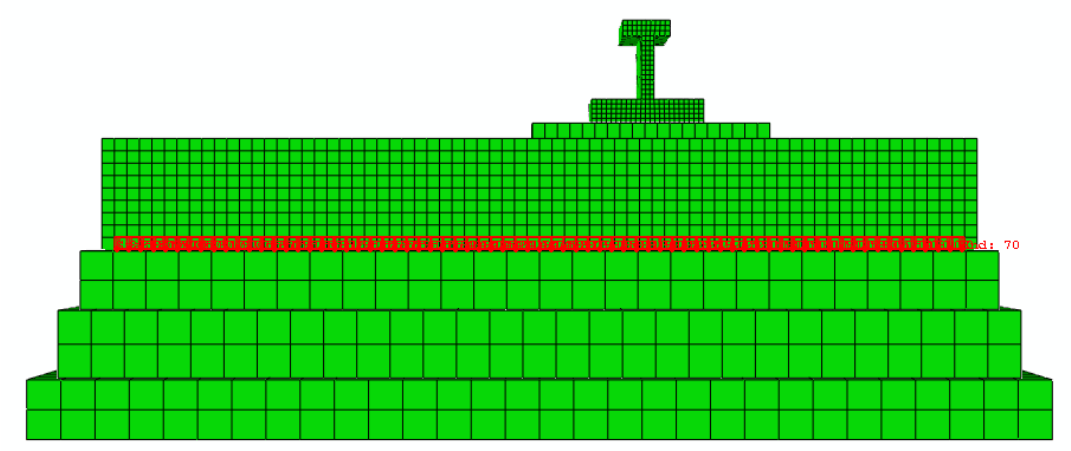

Figure 4-14 Consideration path of half-track structure

After analyses, applied static load on top of the rail shows the vertical stress distributed as the theory of 2:1 method, so the stress at the center of applied pressure has a highly concentration, as presented green color, before spreading to both sides with light color as illustrated in Figure 4-15.

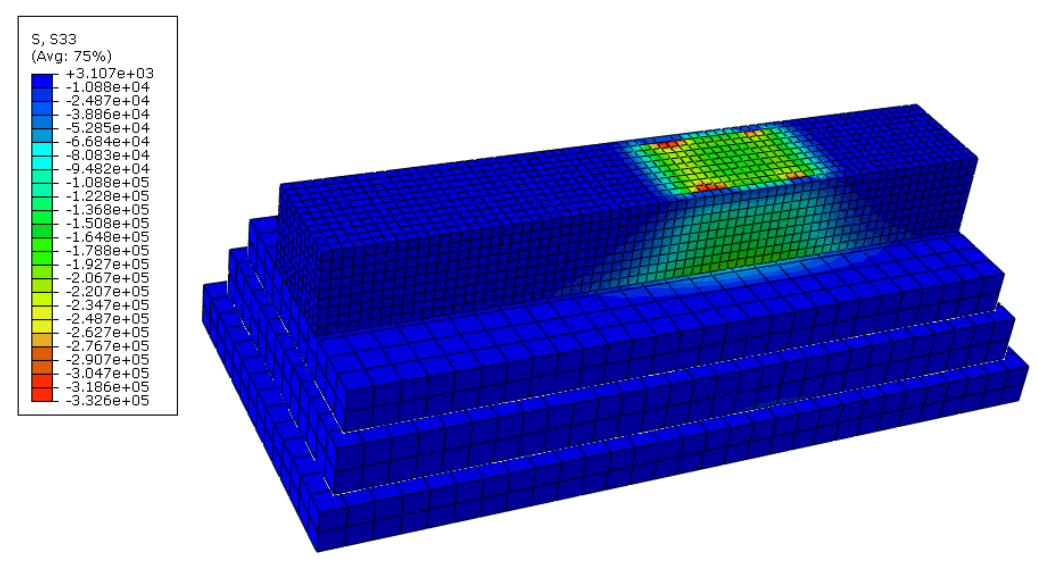

Figure 4-15 The vertical stress of half-track structure under applied load

The model presents the maximum vertical stress under applied static load is located under the rail, which is the same location as cell-number 70 , whereas the minimum vertical stress is approximately 0 Psi around the same location as cell-number 68 as shown in Figure 4-16. 


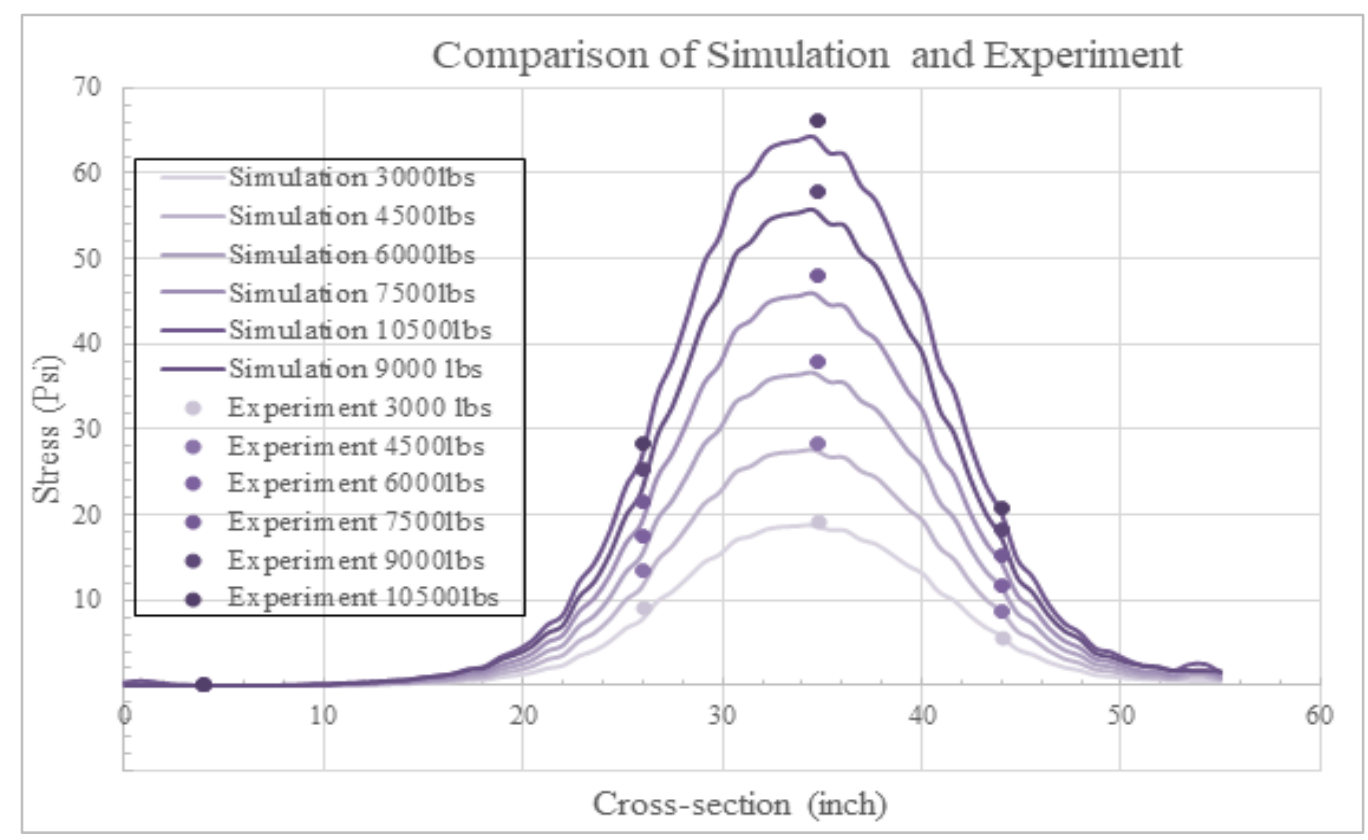

Figure 4-16 Comparison stress between experiment and analytical model.

Comparing the results between the present model and the experiment observations confirm the accuracy of the current model. The maximum vertical stresses are shown in Table 4-2.

Table 4- 2 Percent different between experiment and simulation

\begin{tabular}{|c|c|c|c|}
\hline Load (lbs) & $\begin{array}{c}\text { Analytical model } \\
\text { (Psi) }\end{array}$ & $\begin{array}{c}\text { Experiment } \\
\text { (Psi) }\end{array}$ & $\begin{array}{c}\text { Percent different } \\
(\%)\end{array}$ \\
\hline 3000 & 18.76 & 19.18 & 2.19 \\
4500 & 27.5 & 28.4 & 3.17 \\
6000 & 36.68 & 37.91 & 3.24 \\
7500 & 45.857 & 47.91 & 4.29 \\
9000 & 55.77 & 57.8 & 3.51 \\
10500 & 64.21 & 66.1 & 2.86 \\
\hline
\end{tabular}




\subsubsection{Sensitivty Study}

All parameters, particularly young's modulus, from those components highly affect the outcome of the track modulus.

To understand an influence of the track modulus due to the different parameters (track structure's components); the simulation is divided into five parts, which are part of rail, upper ballast layer, lower ballast layer, and subballast layer. Assuming that applied the static wheel load in this simulation is equal to $660 \mathrm{kPa}$, the dynamic wheel load is calculated using AREA formula considering train's speed, from $40 \mathrm{~km} / \mathrm{hr}$ to $330 \mathrm{~km} / \mathrm{hr}$. This model simulates a 3-D half-track with a shape of solid extrusion component as shown in Figure 4-17. Meshing with Eight-node brick element with reduced integration (C3D8R), which comprises a total of 47,589 elements, gives the great precision to display the Finite Element Method (FEM) analysis result. Interaction between surface of components generate rough tangential with hard normal contact. The boundary condition restrains the longitudinal and transversal directs as symmetric boundary conditions.

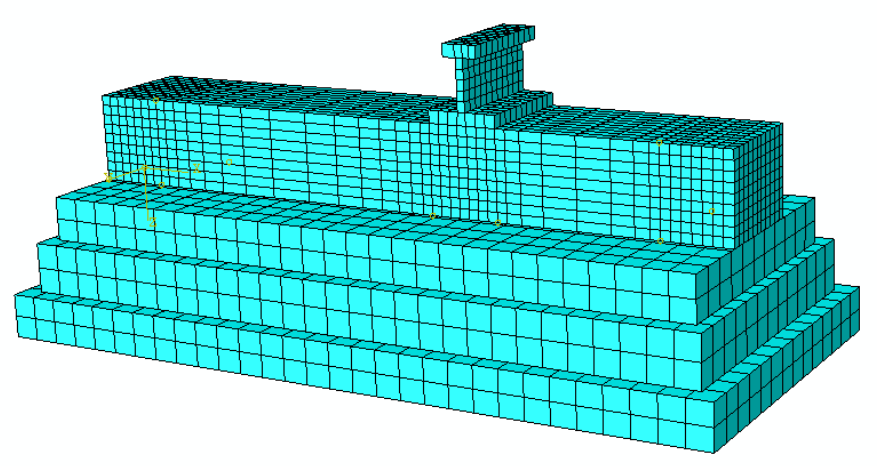

Figure 4-17 Mesh of simulation model in case of parametric study 
In this model, the young modulus, density, and moment of inertia of the rail are constant at $210 \mathrm{GPa}, 7830 \mathrm{~kg} / \mathrm{m}^{3}$, and $3.95 \times 10^{-5} \mathrm{~m}^{4}$, respectively. The rest of components, like sleeper, ballast, and subballast, are presented in Table 4-3.

Table 4- 3 Parameter and dimension

\begin{tabular}{|c|c|c|c|c|c|c|c|c|}
\hline \multirow[t]{2}{*}{ Components } & \multirow{2}{*}{$\begin{array}{c}\text { Lower } \\
\text { Bound } \\
\text { Mpa }\end{array}$} & \multirow{2}{*}{$\begin{array}{c}\text { Average } \\
\text { Mpa }\end{array}$} & \multirow{2}{*}{$\begin{array}{l}\text { Upper } \\
\text { Bound } \\
\text { Mpa }\end{array}$} & \multirow[t]{2}{*}{$\begin{array}{r}\text { Density } \\
\mathrm{kg} / \mathrm{m}^{3}\end{array}$} & \multirow{2}{*}{$\begin{array}{l}\text { Poisson } \\
\text { ratio }\end{array}$} & \multicolumn{3}{|c|}{ Dimension } \\
\hline & & & & & & $\begin{array}{c}\text { Wide } \\
(\mathrm{m})\end{array}$ & $\begin{array}{c}\text { Length } \\
(\mathrm{m})\end{array}$ & $\begin{array}{l}\text { Depth } \\
\text { (m) }\end{array}$ \\
\hline Sleeper & 70 & 80 & 100 & 1200 & 0.3 & 0.2286 & 1.397 & 0.1778 \\
\hline Upper ballast & 138 & 350 & 551 & 2100 & 0.3 & 0.558 & 1.397 & 0.088 \\
\hline Lower Ballast & 138 & 350 & 551 & 2200 & 0.3 & 0.635 & 1.4478 & 0.15 \\
\hline Subballast & 69 & 172 & 276 & 2150 & 0.3 & 0.7112 & 1.524 & 0.088 \\
\hline
\end{tabular}

A track modulus of parametric study is determined from the rail deflection using the Winkler's equation approach. The result from parametric comparison by applied train's velocity at $120 \mathrm{~km} / \mathrm{hr}$ shows that a track modulus significantly relates to a young modulus of track components, particularly substructure components. From all three substructures, the upper ballast highly affects the track modulus values.

In this case, the young modulus of upper ballast at $138 \mathrm{MPa}$ gives the lowest value of track modulus which is around $101.88 \mathrm{MN} / \mathrm{m} / \mathrm{m}$, while the highest value of track modulus is around $212.41 \mathrm{MN} / \mathrm{m} / \mathrm{m}$ when the young modulus of upper ballast is equal to $551 \mathrm{MPa}$.

The minimum young modulus of sleeper and subballast, both have similar value of young modulus. The result shows that young modulus of subballast at $69 \mathrm{MPa}$ presents 
a lower track modulus, which is around $135.56 \mathrm{MN} / \mathrm{m} / \mathrm{m}$. It can be concluded that properties of substructure, such as ballast, subballast, have more effect on trackbed modulus compared to the superstructure (rail and tie).

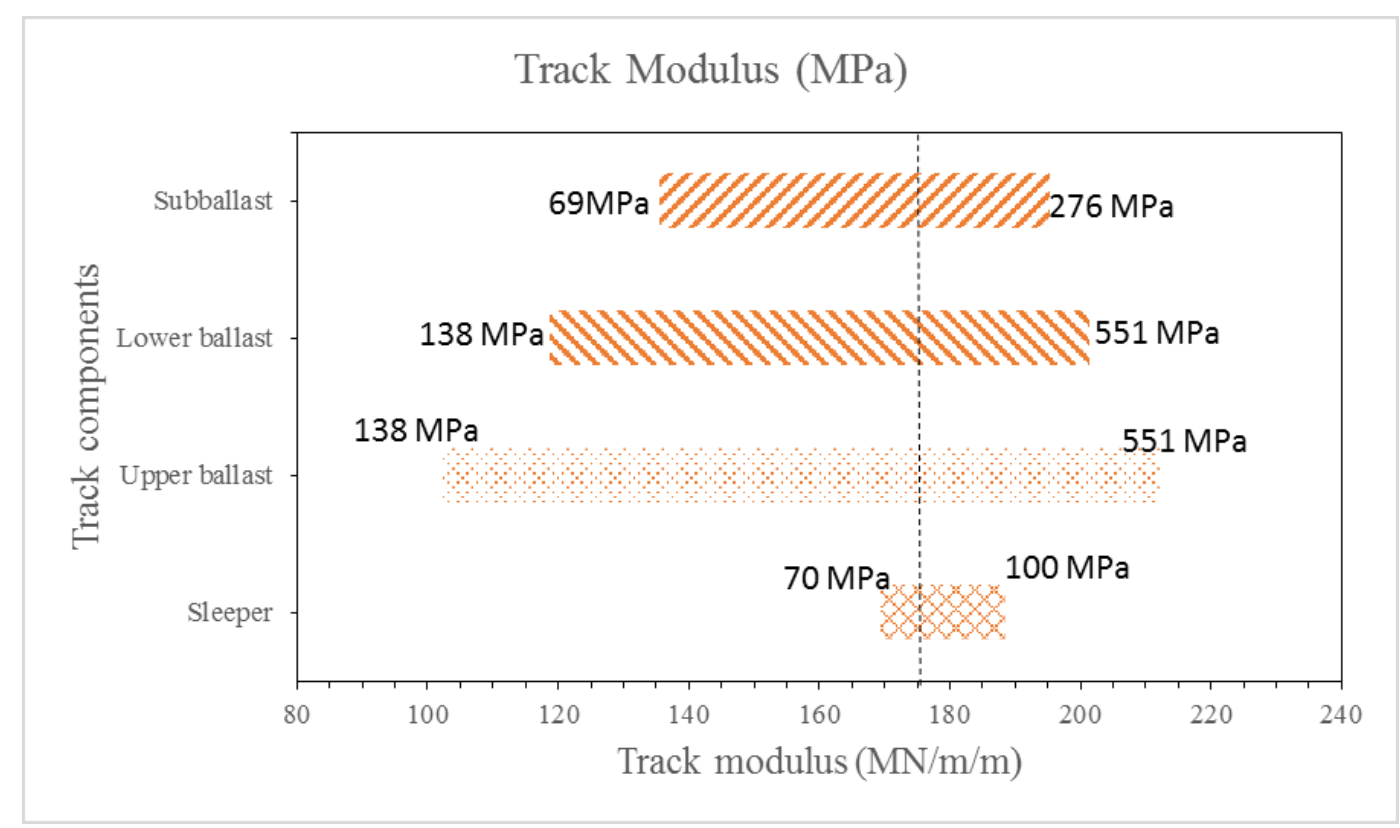

Figure 4-18 The range of track modulus due to various properties of track components

Furthermore, the track deformation due to various train's speeds shows that the track displacement is increased with train speed. Therefore, the attribution of track modulus shows that the reduction of the track modulus is related with an increase in axle load and displacements. In this simulation the constant of nominal track properties and eight different train's speeds, which are 40,90, 120, 140, 190, 235, 285, and $330 \mathrm{~km} / \mathrm{h}$ are considered

Applied the static load $(660 \mathrm{kPa})$ on the system produces the stress around $154.24 \mathrm{kPa}$ and displacement of the model is around $0.0883 \mathrm{~mm}$. In addition, applied various 
dynamic loads to the model shows that stress and displacement increase with increased of dynamic loads, as shown in Table 4-4.

Table 4- 4 Summary result of parametric study

\begin{tabular}{|c|c|c|c|c|}
\hline $\begin{array}{c}\text { Dynamic Load } \\
(\mathrm{kPa})\end{array}$ & $\begin{array}{c}\text { Speed } \\
(\mathrm{km} / \mathrm{h})\end{array}$ & Stress $(\mathrm{kPa})$ & $\begin{array}{c}\text { Displacement } \\
(\mathrm{mm} .)\end{array}$ & $\begin{array}{c}\text { Track Modulus } \\
(\mathrm{MN} / \mathrm{m} / \mathrm{m})\end{array}$ \\
\hline 700 & 40 & 163.591 & 0.0951 & 176.788 \\
750 & 90 & 175.286 & 0.1019 & 176.773 \\
780 & 120 & 182.314 & 0.1060 & 176.763 \\
800 & 140 & 186.983 & 0.1087 & 176.756 \\
850 & 190 & 198.681 & 0.1155 & 176.740 \\
900 & 235 & 210.38 & 0.1223 & 176.724 \\
950 & 285 & 222.081 & 0.1291 & 176.707 \\
1000 & 330 & 233.795 & 0.1359 & 176.678 \\
\hline
\end{tabular}

Although the result of stress and displacement are varying with increasing load, the track modulus is inversed with the increasing loads. Applied static wheel load to the system, the track modulus is equal to $176.83 \mathrm{MN} / \mathrm{m} / \mathrm{m}$ but the tack modulus is slightly decreased with increasing train speed, which is from $176.787 \mathrm{MN} / \mathrm{m} / \mathrm{m}$ at $40 \mathrm{~km} / \mathrm{h}$ to $176.678 \mathrm{MN} / \mathrm{m} / \mathrm{m}$ at $330 \mathrm{~km} / \mathrm{h}$.

This result satisfies the assumption that decreasing of track modulus is related with both increasing train speed and track displacement as shown Figure 4-19. 


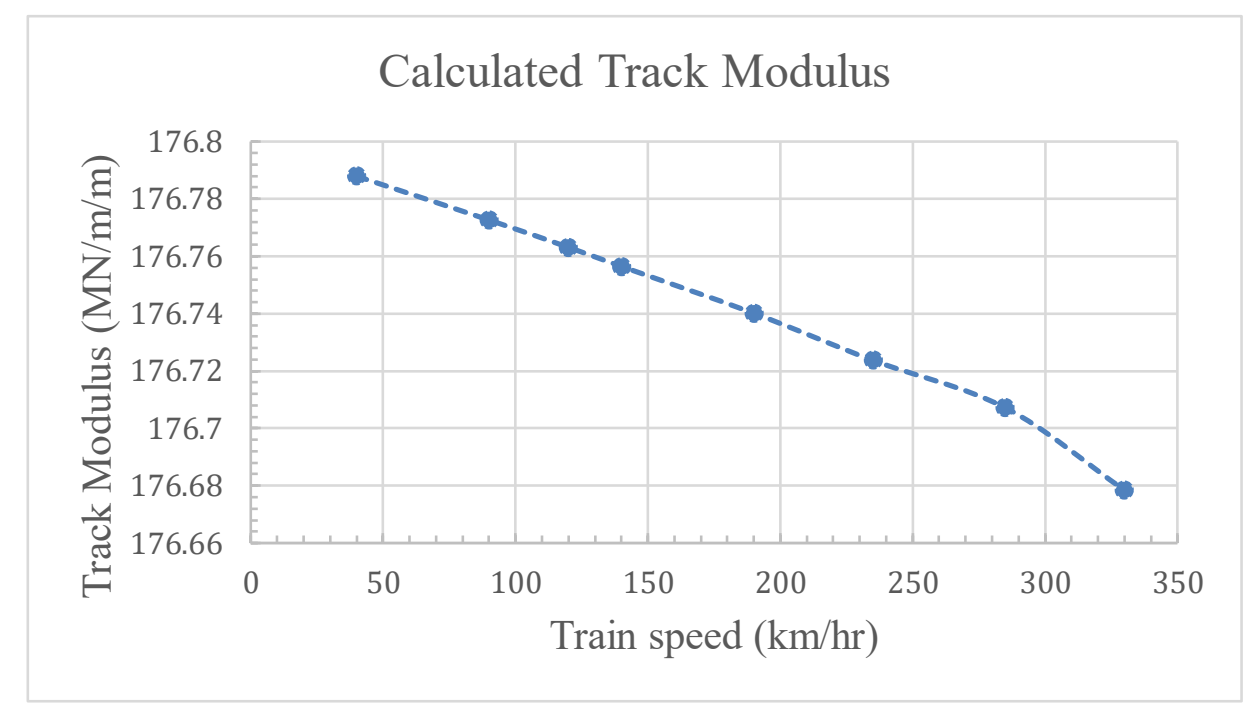

Figure 4-19 The range of track modulus due to change in the train's velocities.
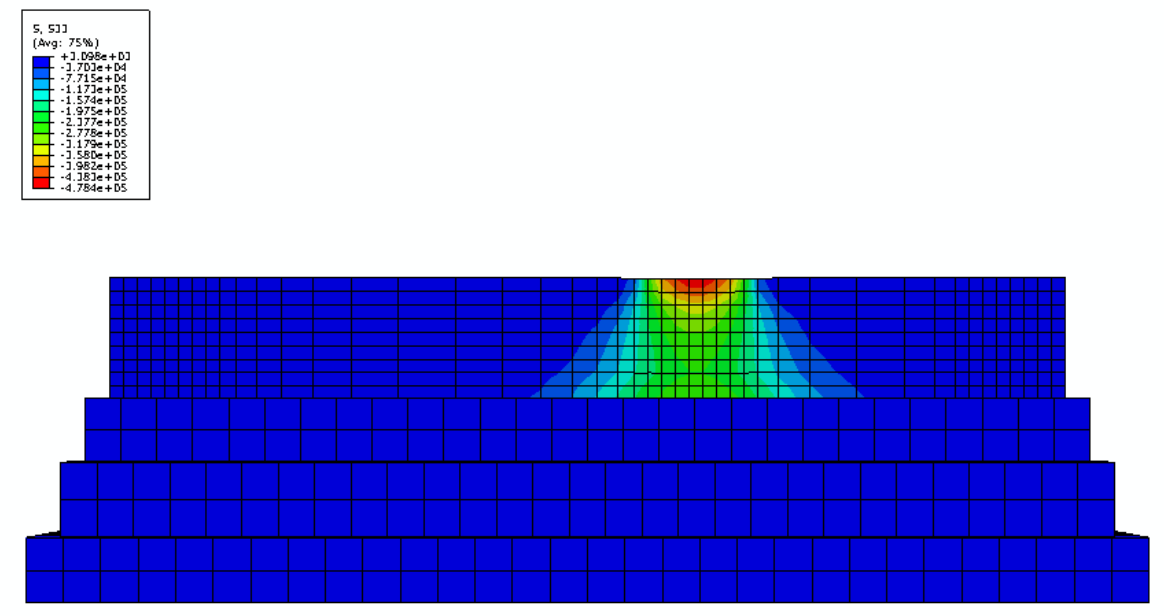

Figure 4-20 The vertical stress distribution at train's speed equal to $235 \mathrm{~km} / \mathrm{h}$

Figure 4-20 shows the vertical stress distribution in this case spreads similarly as the 2:1 method, which has been developed by Boussinesq, (1885). 


\section{CHAPTER 5 SENSITIVITY STUDY OF 3-D TRACKBED PERFORMANCE}

\subsection{Modeling Procedures in ABAQUS}

The ABAQUS program is a finite element that employs implicit integration scheme and explicit integration scheme to predict the mechanism behavior of a structure or an object. This software is able to model and analyze complex mechanism showing a visualization of the model in two-dimensional or three-dimensional. Thus, the procedure of the ABAQUS program is divided into different modules, which are part, property, Step, Mesh, and Visualization.

An analysis is started with creating the geometry of the model by sketching each part of the model into Part module and then defines material properties at property module. Step and mesh modules are related with regard to calculation method and accuracy of the result. For example, if the model is defined coarse elements, the calculation will use very short periods of time, illustrating an imprecise result. Using fines elements will give a very high accuracy result, but the calculation process will be time consuming. Finally, the result of analysis will illustrate at visualization module. The visualization 
module of ABAQUS program has a function to present the result as contour types, and it is easy to observe a mechanism behavior of the object after analysis.

\subsection{Trackbed Model with an HMA layer}

In general, thicknesses of design hot mixed asphalt installed under ballast layer varies from $10 \mathrm{~cm}$ to $20 \mathrm{~cm}$ or known as "underlayment design". Thus, this study simulates the track structure with different thicknesses of asphalt layer, which are 10, 12, 14, 15, 18 , and $20 \mathrm{~cm}$, with the additional thickness at $25 \mathrm{~cm}$ under the static load at $6.5 \mathrm{MPa}$. The current study also investigates the combination design of hot mixed asphalt layer at $15 \mathrm{~cm}$ in two different locations: (1) below subballast and (2) the asphalt layer above subballast. An effect of Hot Mixed Asphalt (HMA) with various thicknesses on stress and displacement of the trackbed are presented in this chapter. Later the results will show how the design method can improve the strength of the track structure. Figure 51 shows the geometry of the conventional trackbed.

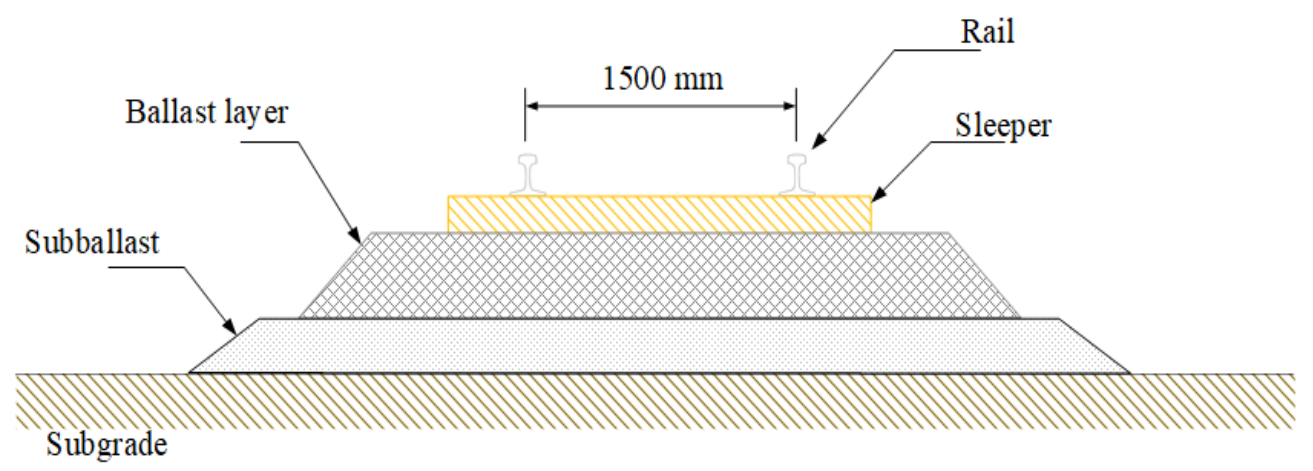

Figure 5-1 Cross-section of conventional track 


\subsubsection{Geometry}

The track components are simulated in three dimensions by following the design standard of American Railway Engineering and Maintenance-of-Way Association (AREMA). Dimension and parameter in this study use SI-unit for the consistency, and selecting shape of rail $115 \mathrm{lb} / \mathrm{yd}$ placing on sleepers that has a spacing from center to center around $50 \mathrm{~cm}$. The dimension of $115 \mathrm{RE}$ is shown in Figure 5-2.

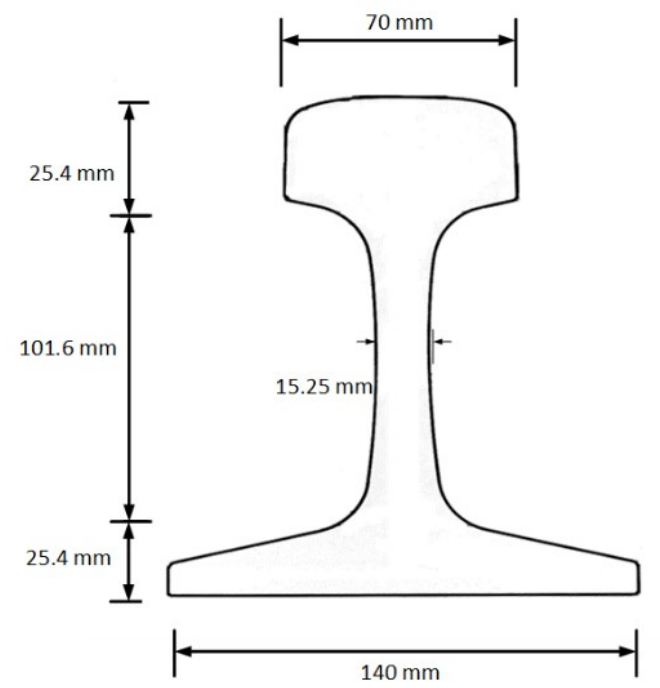

Figure 5-2 Dimension of rail type 115 RE

Other components of the track structure, like sleeper, ballast layer, subballast, and subgrade are presented in Table 5-1.

Table 5- 1 Dimension of components

\begin{tabular}{|l|r|r|r|}
\hline Components & Wide (mm) & $\begin{array}{c}\text { Long } \\
(\mathrm{mm})\end{array}$ & $\begin{array}{c}\text { Thickness } \\
(\mathrm{mm})\end{array}$ \\
\hline Sleeper (wooden) & 228.6 & 2500 & 177.8 \\
Ballast layer & 3200 & 10000 & 300 \\
Subballast layer & 4000 & 10609.6 & 150,300 \\
Asphalt layer & 4000 & 10609.6 & Various \\
Subgrade & 11000 & 112192 & 8000 \\
\hline
\end{tabular}


According to Table 5-1, the thickness of the asphalt layer is varying from $10 \mathrm{~cm}$ to 25 $\mathrm{cm}$. Thicknesses of the asphalt layer are considered to be $10,12,14,15,18,20$, and 25 $\mathrm{cm}$ in this study. Results are used to observe the correlation between a thickness of asphalt layer and an influence of applied static load, in stress and deflection.

In order to compare two locations between the asphalt layer above subballast and the asphalt layer below subballast, this research simulates a design of the track at Oklahoma City by following the research of Rose and Hensley, (1991). Thus, this model is simulated the thickness of ballast layer is equal to $20 \mathrm{~cm}$ and using the asphalt layer is equal to $15 \mathrm{~cm}$ to compare with the conventional track as shown in Figure 5-3.
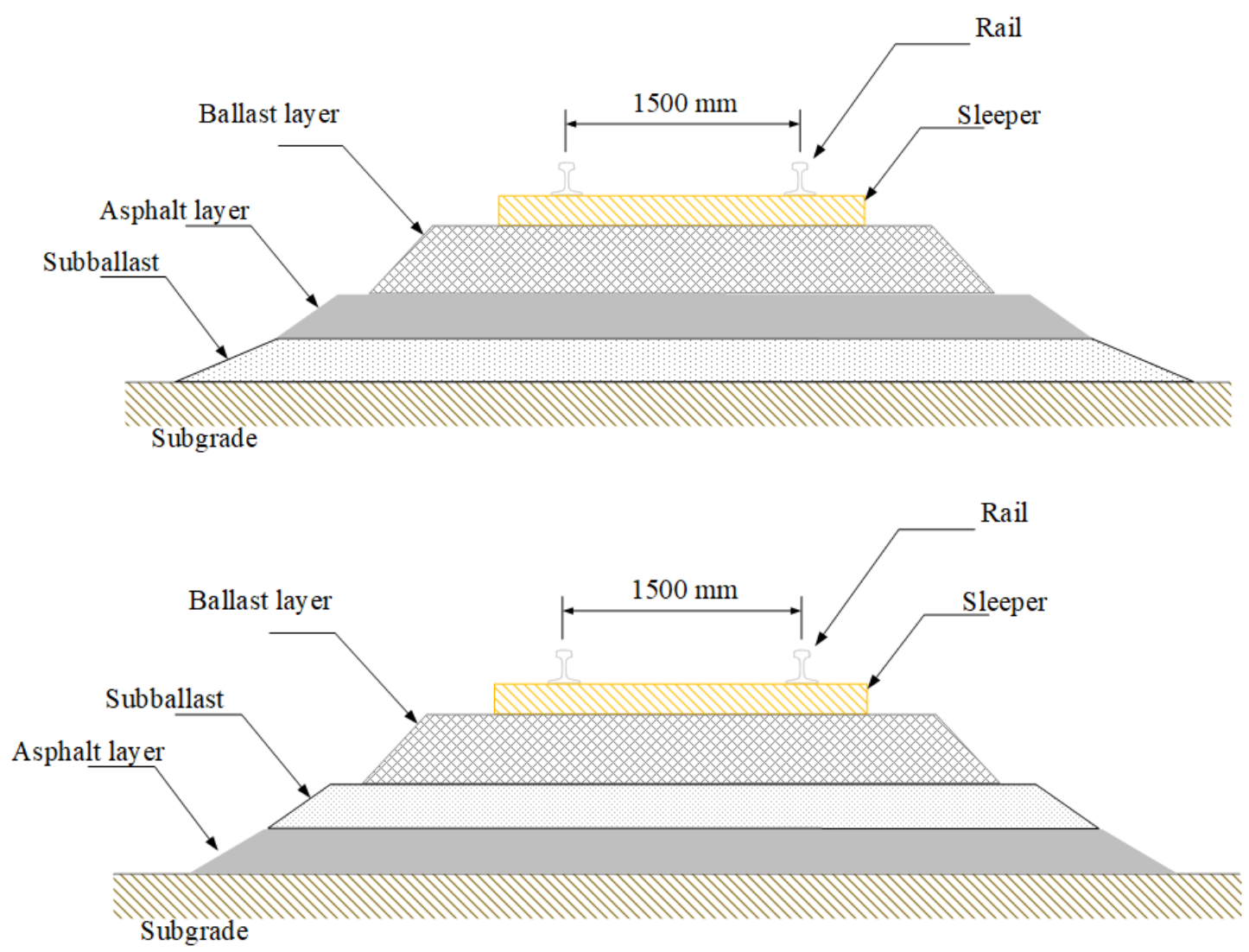

Figure 5-3 Cross-section of combination track design 


\subsubsection{Parameter}

Properties of the track components in this simulation, such as rail, wooden sleeper, ballast layer, subballast layer, and subgrade, uses an average from previous researches as shown in Table 5-2. The young modulus of asphalt binder, PG 64-22 usually is used as alternative subballast in the United States, varies with the weather from $6.27 \mathrm{GPa}$ to 30.33 GPa. In other words, young modulus of asphalt decreases with temperature. Young modulus of asphalt increases during the winter season. So, this simulation uses the average young modulus of asphalt in the United States around 18.96 GPa.

Table 5- 2 Parameter of track components

\begin{tabular}{|c|c|c|c|}
\hline $\begin{array}{c}\text { Track } \\
\text { components }\end{array}$ & $\begin{array}{c}\text { Density } \\
\left(\mathrm{kg} / \mathrm{m}^{2}\right)\end{array}$ & $\begin{array}{c}\text { Young } \\
\text { Modulus }(E)\end{array}$ & $\begin{array}{c}\text { Possion's } \\
\text { Ratio }(v)\end{array}$ \\
\hline Rail & 7830 & $210 \mathrm{GPa}$ & 0.3 \\
Sleeper & 1200 & $80 \mathrm{MPa}$ & 0.3 \\
Ballast & 2200 & $256 \mathrm{MPa}$ & 0.3 \\
Subballast & 1950 & $178 \mathrm{MPa}$ & 0.3 \\
Asphalt & 2400 & $18.96 \mathrm{GPa}$ & 0.3 \\
\hline
\end{tabular}


Meshing of this model uses Eight-node brick element, which comprises a total of 147,684 elements. The interaction between surfaces of five components perfectly contact surface-to-surface and generating rough tangential with hard contact. The boundary condition restrains the longitudinal and transversal directs as symmetric boundary conditions as shown in Figure 5-4.

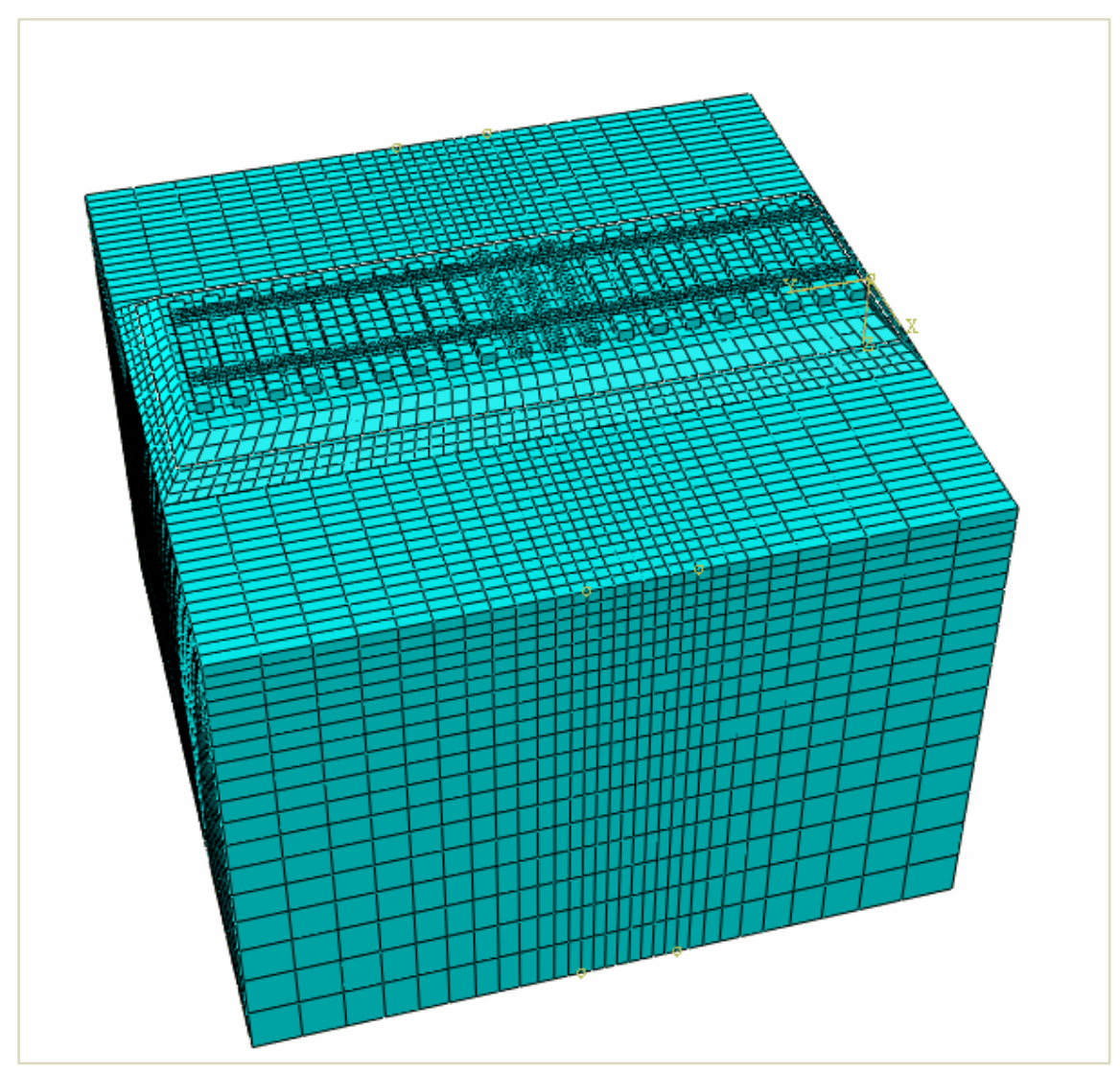

Figure 5-4 Meshing of simulation 
Collecting data by creating a path at the middle of the track structure at two locations, which are under tie and on the surface. These two locations showed maximum stress under the applied static load at 6.5 MPa as shown in Figure 5-5.

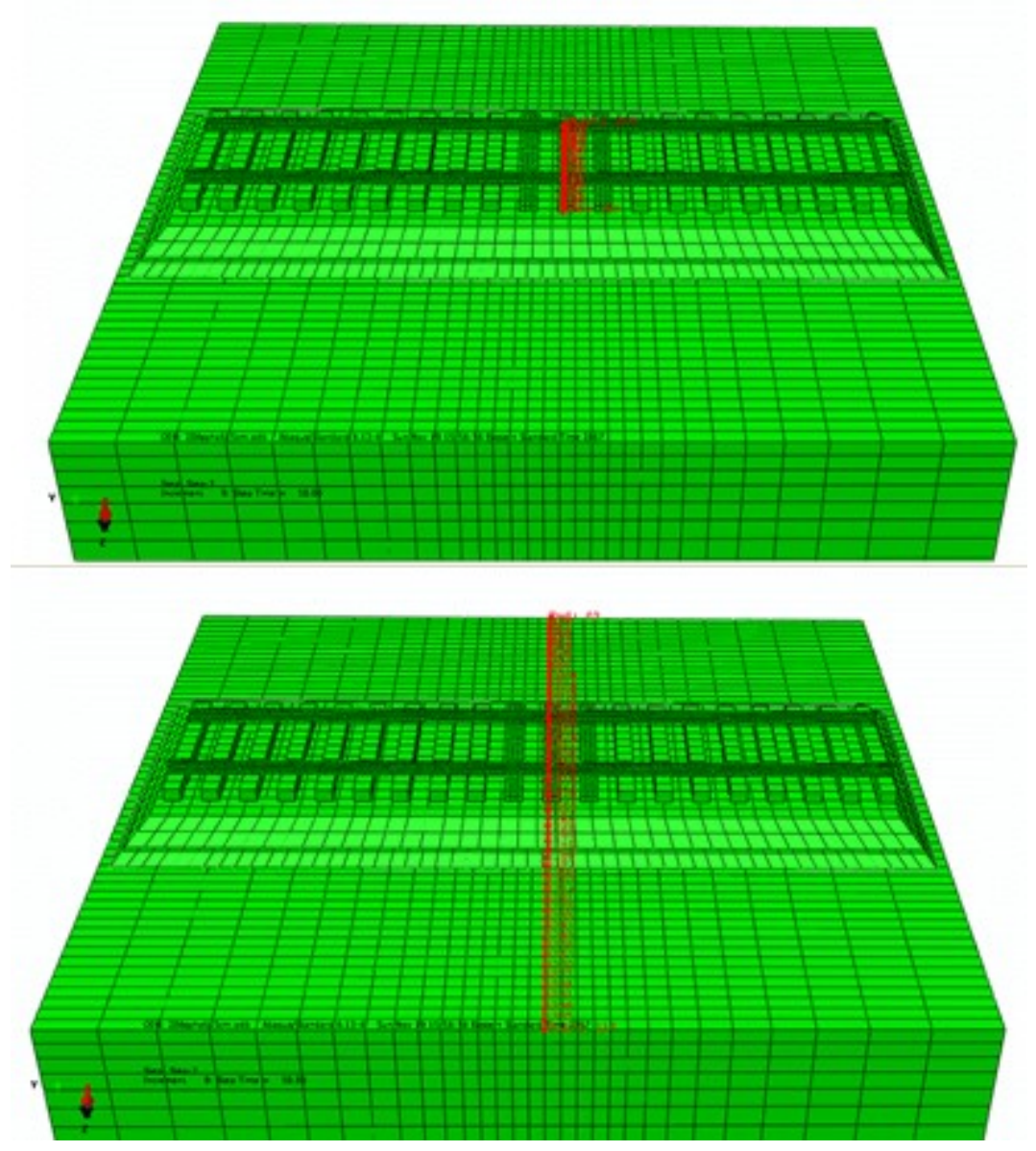

Figure 5-5 Consideration path of the model 


\subsection{Effect of the Tie under Applied Load}

The conventional track with $15 \mathrm{~cm}$ of granular subballast is a common design of the track structure. By applying the static load at $6.5 \mathrm{MPa}$ on the middle of the track, it shows that the maximum stress under the tie is around $211.83 \mathrm{kPa}$, while installing the asphalt layer as subballast with various thicknesses, such as $10 \mathrm{~cm}, 15 \mathrm{~cm}$, and $20 \mathrm{~cm}$, show the maximum stress around $179.361 \mathrm{kPa}, 180.13 \mathrm{kPa}$, and $183.07 \mathrm{kPa}$, respectively. As a result, the maximum stress of the tie under the static load at $6.5 \mathrm{MPa}$ is slightly increasing, but overall results are not significantly different from $15 \mathrm{~cm}$ of granular subballast.

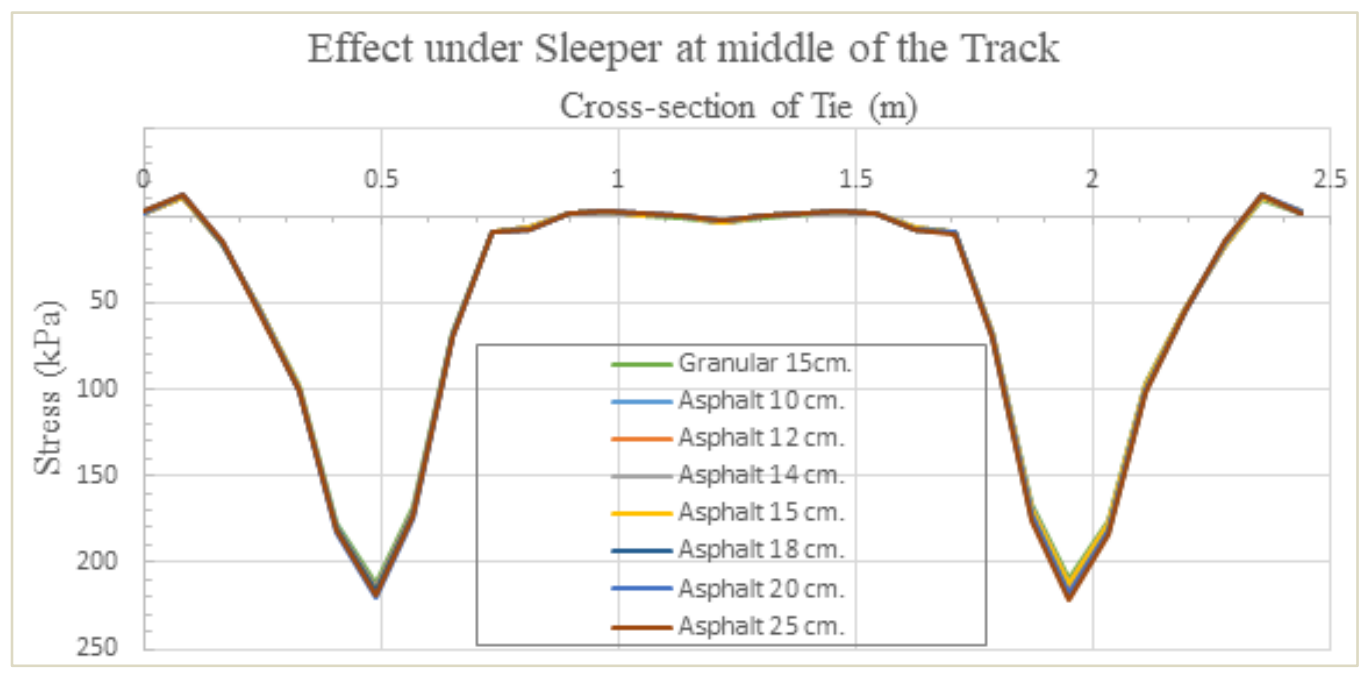

Figure 5-6 The vertical stress of tie under applied load

On the other hand, the displacement at the same tie under the static load at $6.5 \mathrm{MPa}$ shows that the conventional track with granular $15 \mathrm{~cm}$ deforms around $0.742 \mathrm{~mm}$. Whereas installing the asphalt layer as subballast, like $10 \mathrm{~cm}, 15 \mathrm{~cm}$, and $20 \mathrm{~cm}$, shows that the displacement is around $0.683 \mathrm{~mm}, 0.676 \mathrm{~mm}$, and $0.591 \mathrm{~mm}$, respectively. Therefore, installing alternative subballast, like the asphalt layer, reduces displacement 
of the track structure around $7.98 \%$ to $26.75 \%$, which depends on the thickness of the asphalt layer.

Comparison of the deformation under the static load between the different thicknesses of the asphalt layer, varying from $10 \mathrm{~cm}$ to $25 \mathrm{~cm}$, shows that the deformation of the tie reduces around $0.01 \mathrm{~mm}$, when the thickness of the asphalt layer is increased around 2 $\mathrm{cm}$ (See Figure 5-7 and 5-8).

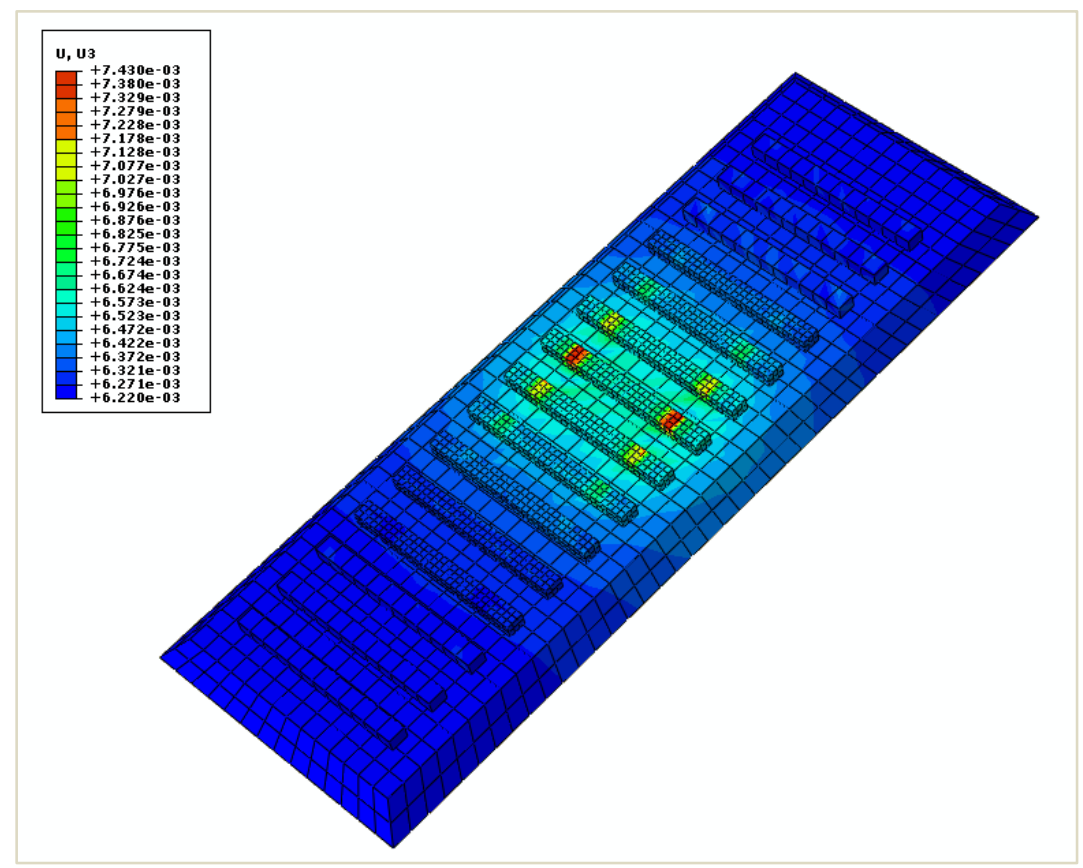

Figure 5-7 The vertical displacement of tie structure under applied load 


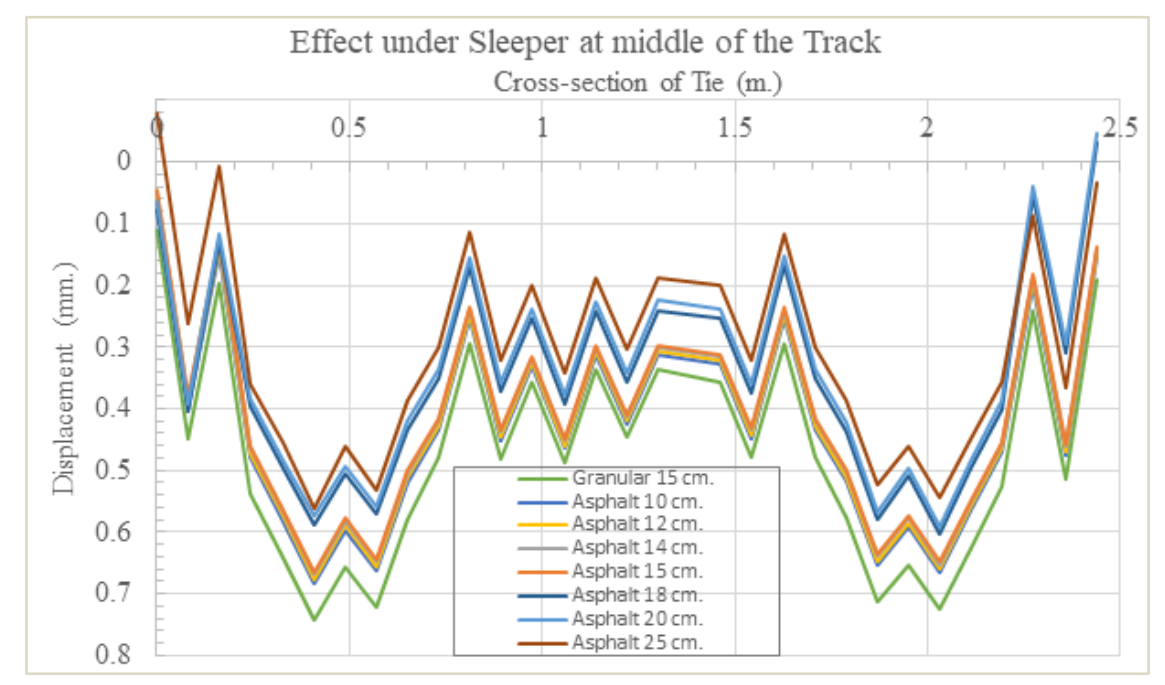

Figure 5-8 Comparison of vertical deflection of the tie

Furthermore, the vertical deflection of the track structure is reduced from $79.8 \%$ to

$26.75 \%$, which highly depends on the thickness of asphalt layer, as shown in Table 5-

3.

Table 5- 3 Summarized Percent of Protection

\begin{tabular}{|c|c|c|}
\hline $\begin{array}{c}\text { Asphalt thickness } \\
(\mathrm{cm} .)\end{array}$ & $\begin{array}{c}\text { Deformation } \\
(\mathrm{mm} .)\end{array}$ & Percent of Protection \\
\hline 10 & 0.683 & 7.98 \\
12 & 0.676 & 8.95 \\
14 & 0.670 & 9.82 \\
15 & 0.666 & 10.32 \\
18 & 0.587 & 20.90 \\
20 & 0.574 & 22.63 \\
25 & 0.544 & 26.75 \\
\hline
\end{tabular}




\subsection{Effect of the static load on the surface of subgrade}

This section presents a result of the static load at $6.5 \mathrm{MPa}$ on a subgrade surface of track structure in three different applications of track improvement, which are increasing granular subballat $15 \mathrm{~cm}$, installing various thickness of asphalt layer as subballast, and using the combination track design. The result presents an effect of applied static load in term of stress and deflection comparing with the conventional track design.

\subsubsection{Increasing the Thickness of the Subballast}

Subgrade is weakest layer on the track structure which should support a train's load. Therefore, this component can easily fail under the accumulative load. Therefore, many techniques, such as increased granular thickness, alternative subballast, and combination design, have been applied to reduce the stress and deformation of the subgrade.

The surface of subgrade is generally prevented by installing $15 \mathrm{~cm}$ of granular subballast. The deformation under the static load is around $0.434 \mathrm{~mm}$, and the maximum stress is around $15.78 \mathrm{kPa}$. The technique of increasing the granular subballast up to $30 \mathrm{~cm}$ can reduce impact from the static load. In this case, the deformation on the subgrade's surface is around $0.38 \mathrm{~mm}$ and the maximum stress is around $12.52 \mathrm{kPa}$ as shown in Figure 5-10. 

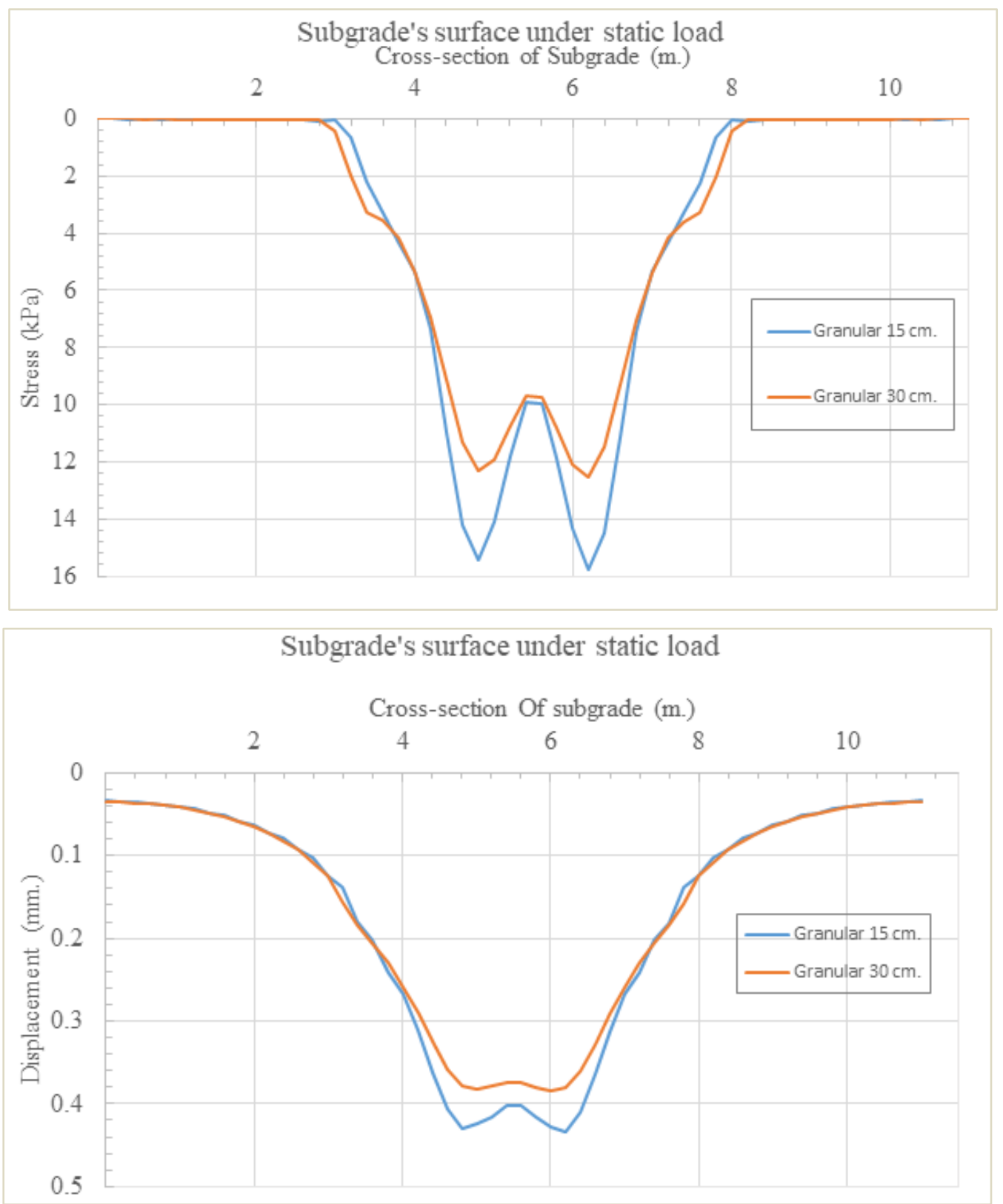

Figure 5-9 The vertical stress and the vertical displacement on subgrade's surface 


\subsubsection{Comparison Using Asphalt Layer and Conventional Track.}

Using the asphalt layer as subballast is another technique to reduce stress and displacement on the subgrade's surface. This study presents the maximum stress and the maximum deformation of using asphalt layers from $10 \mathrm{~cm}$ to $25 \mathrm{~cm}$ comparing with the $15 \mathrm{~cm}$ of granular subballast under the static load at $6.5 \mathrm{MPa}$.
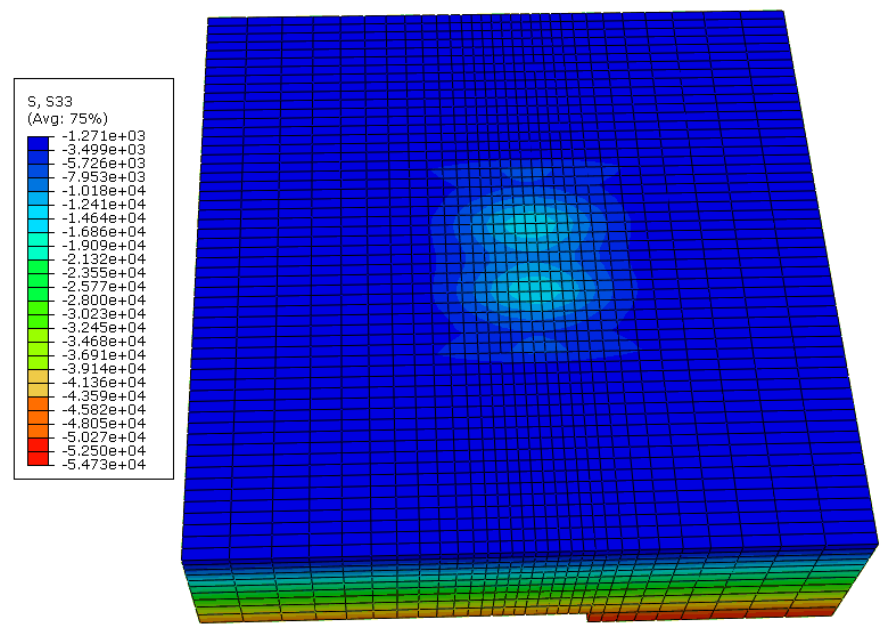

Figure 5-10 The result of vertical stress on subgrade's surface under applied load

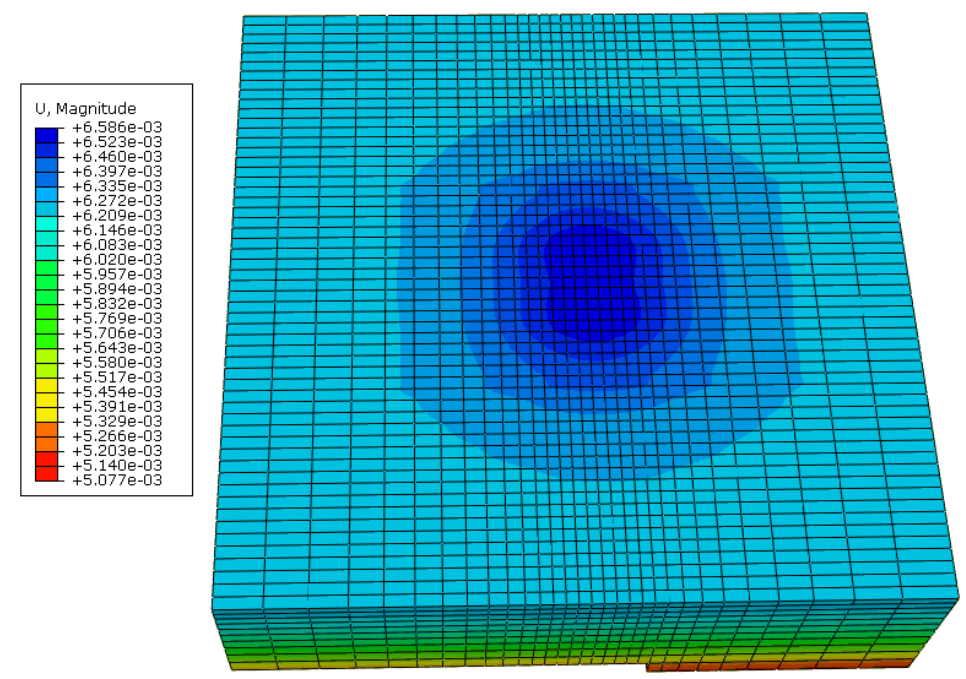

Figure 5-11 The result of vertical displacement on subgrade's surface under applied load 
The result of using asphalt layers with various thicknesses under the static load, shows that using the asphalt layer as subballast can reduce both stress and deformation on subgrade' surface. For example, the track structure with $10 \mathrm{~cm}$ of asphalt thickness deforms $0.411 \mathrm{~mm}$ and the maximum stress is around $14.22 \mathrm{kPa}$. And then, the stress and deformation decrease with the increase of thickness of asphalt layer. Using asphalt layer as subballast distributed the stress on all direction.

As Figure 5-12 shows, increasing the asphalt layer reduces the displacement and the stress. However, results show that using 18-cm-thickness for the asphalt the displacement and stress will be well distributed below the tie. Therefore, we can conclude that the $18 \mathrm{~cm}$ is the optimum asphalt thickness. Note, using asphalt layer might increase the stress on the corner of the ties. 

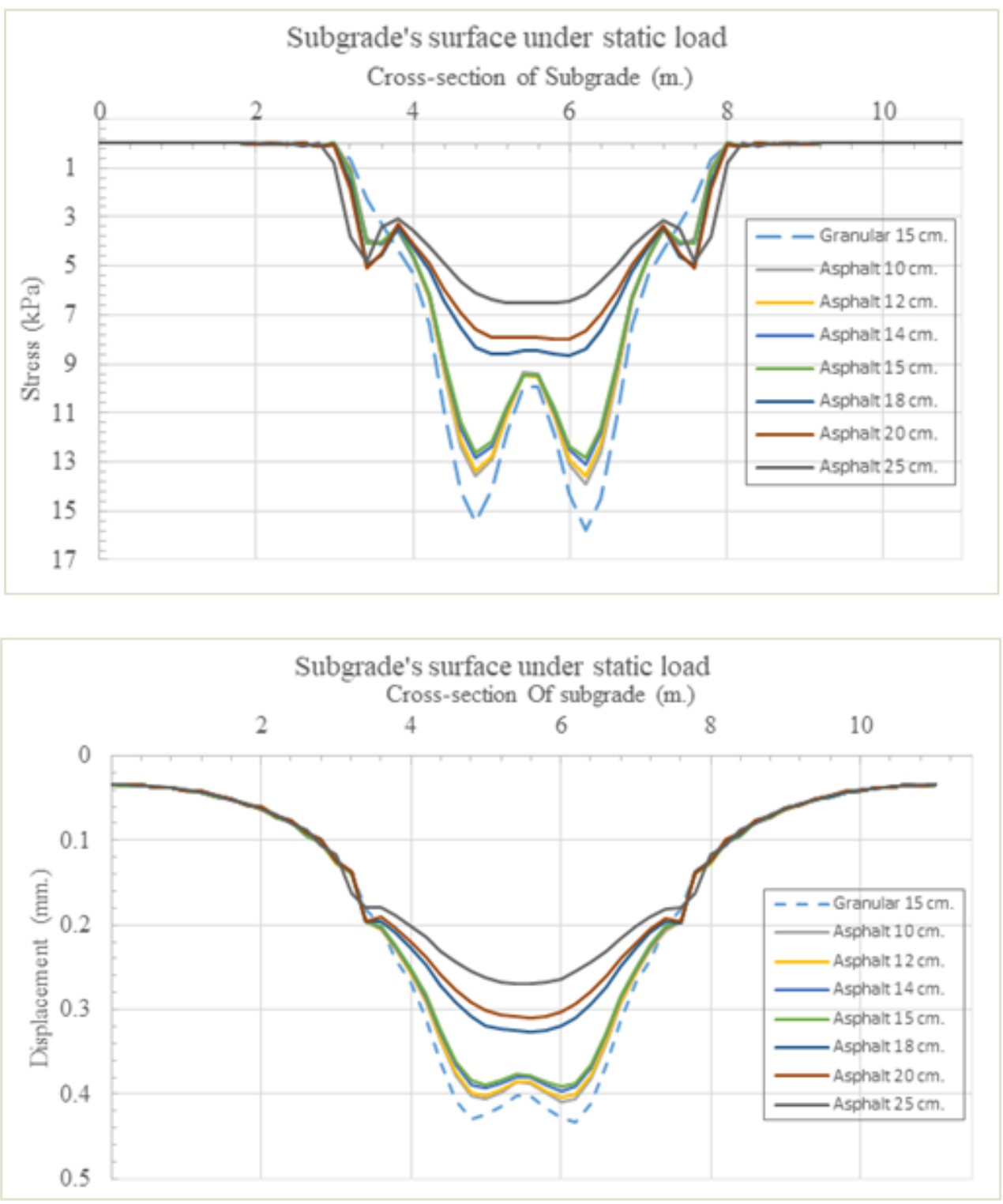

Figure 5-12 Effect of subgrade's surface under applied static 


\subsubsection{Comparison Using Combination Design and Conventional Track}

The combination track design uses granular subballast and the asphalt layer under ballast layer to increase the strength and to distribute stress to subgrade. In this case, 15 $\mathrm{cm}$ thickness of both layers that are granular subballast and asphalt layer were installed. For the ballast layer thickness has been reduced to $20 \mathrm{~cm}$ as the track structure at Oklahoma City. Furthermore, the analysis presents stress and displacement of the asphalt layer above subballast and the asphalt layer below subballast at two locations, which are under tie and subgrade's surface.

The tie of combination designs in case of installing asphalt above subballast layer shows the static load at $6.5 \mathrm{MPa}$ created the maximum displacement around $0.6728 \mathrm{~mm}$ and the maximum stress is around $178.45 \mathrm{kPa}$. Applying the same static load to the combination design by installing asphalt layer below subballast shows that the maximum displacement is around $0.6722 \mathrm{~mm}$ and the maximum stress is around 177.82 $\mathrm{kPa}$. 

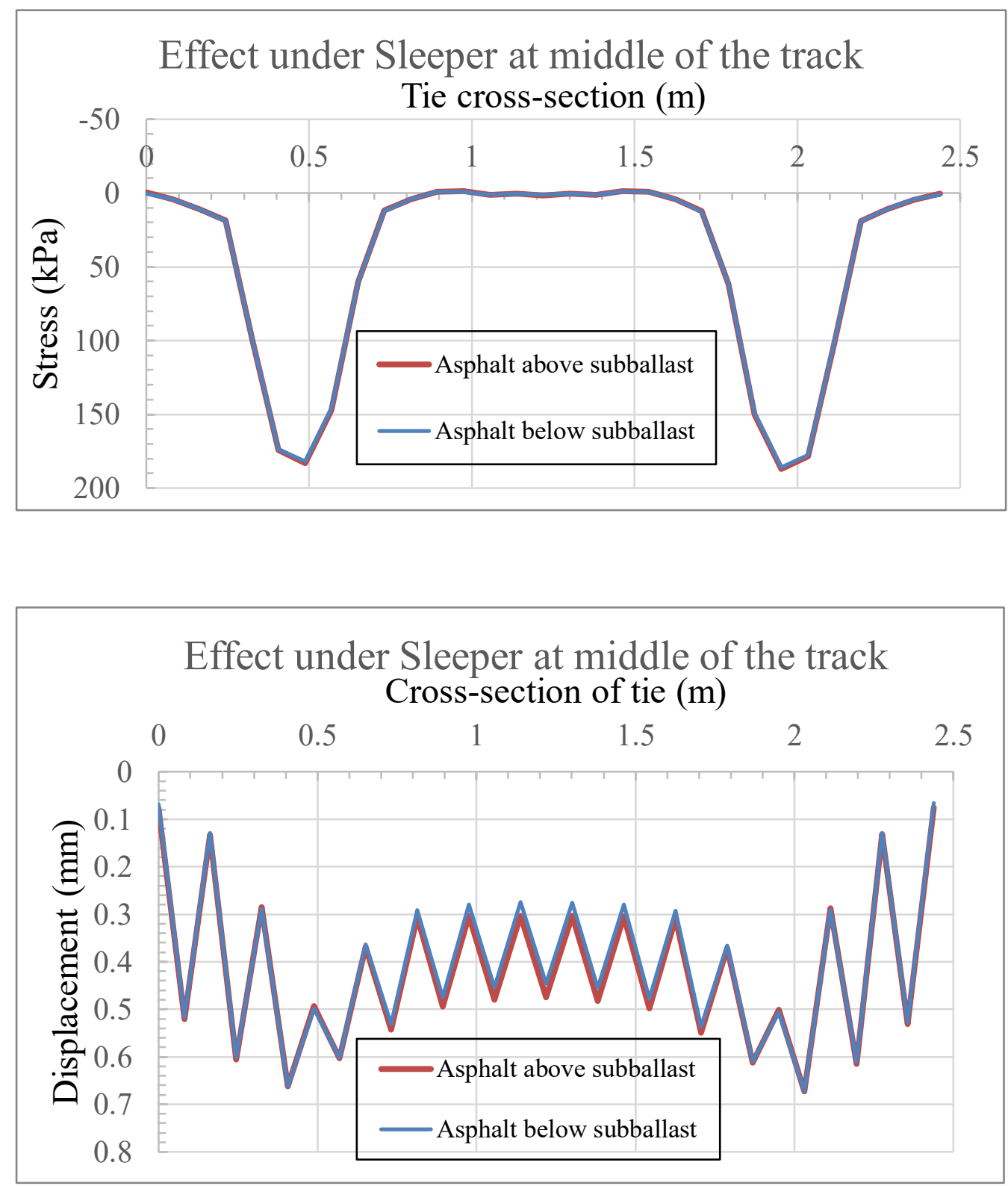

Figure 5-13 The vertical stress and vertical displacement under the tie

Considering the stress and displacement on subgrade's surface shows that installing the asphalt layer above subballast has the approximate displacement $0.387 \mathrm{~mm}$ and the stress approximate $12.67 \mathrm{kPa}$. While installing asphalt layer below subballast shows the displacement under the static load is around $0.372 \mathrm{~mm}$ and the maximum stress is around $12.13 \mathrm{kPa}$. Thus, the subgrade's surface of both designs under the static load shows the result of stress and displacement are not significantly different. Comparing 
an impact under applied static load at $6.5 \mathrm{MPa}$ between the combination track design and the conventional track design, the result shows that the maximum vertical stress and the maximum deflection are significantly decreased around $23.13 \%$, and $14.28 \%$ as shown in Figure 5-15.
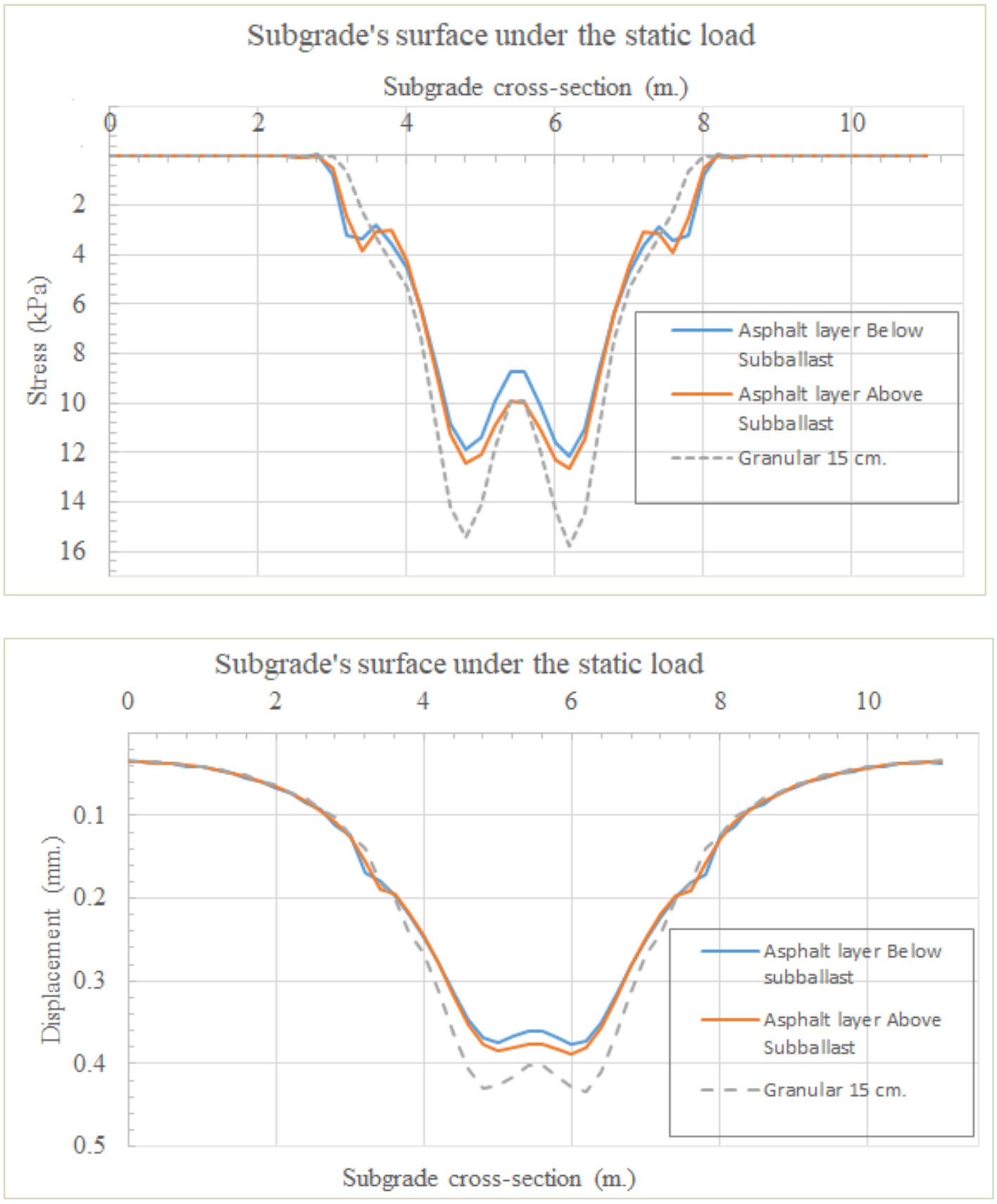

Figure 5-14 The vertical stress and the vertical displacement on subgrade's surface 
As a result, either the asphalt layer above subballast or the asphalt layer below subballast, both designs improve the track structure. However, using the asphalt layer above subballast is sufficient and economical rather than using the asphalt layer below subballast.

\subsection{Track Modulus}

Track Modulus, $k$, is a very important indicator to present a track performance and maintenance requirement, including safety and track quality. Low track modulus is observed from differential settlement and frequently need maintenance, whereas large track modulus shows the result of increasing the life of the track components and reducing a maintenance cycle.

Track modulus is determined by using the theory of Winkler, which is a correlation between the vertical deflection and the vertical contact load. In other words, track modulus is calculated from the vertical deflection $\left(w_{m}\right)$ and impacted from the wheel load, $P$. Therefore, the vertical deflection $(w)$ is equal to 0 at $\mathrm{x}$, the analytical expression from Eq. 3-3 can be rewritten as:

$$
w_{m}=\frac{P \beta}{2 k}=\frac{P \sqrt[4]{\frac{k}{4 E I}}}{2 k}
$$

Therefore, the track Modulus, $k$, is calculated as shown in Eq.5-2.

$$
k=\frac{1}{4} \sqrt[3]{\frac{P^{4}}{E I w^{4}}}
$$


Applied static load at $6.5 \mathrm{MPa}$ impacts on the track model, that uses $10 \mathrm{~cm}$ of the asphalt layer as subballast, creates the deflection of wood-tie track with $115 \mathrm{RE}$ around 0.683 $\mathrm{mm}$. In this case, flexural rigidity of the rail beam, $E I$, is equal to $8.295 \mathrm{MPa}$.

Thus, the track modulus is calculated as:

$$
\begin{gathered}
k=\frac{1}{4} \sqrt[3]{\frac{\left(6.5 \times 10^{6}\right)^{4}}{8.295 \times 10^{6} \times 0.000683}} \\
k=248.935 \mathrm{MN} / \mathrm{m}^{2}
\end{gathered}
$$

Using $10 \mathrm{~cm}$ of asphalt layer as subballast, the track modulus is equal to 248.935 $\mathrm{MN} / \mathrm{m}^{2}$. Track modulus of the rest of the track's designs are calculated by using the same equation. Figure 5-16 presents the variation of the track modulus at different conditions.

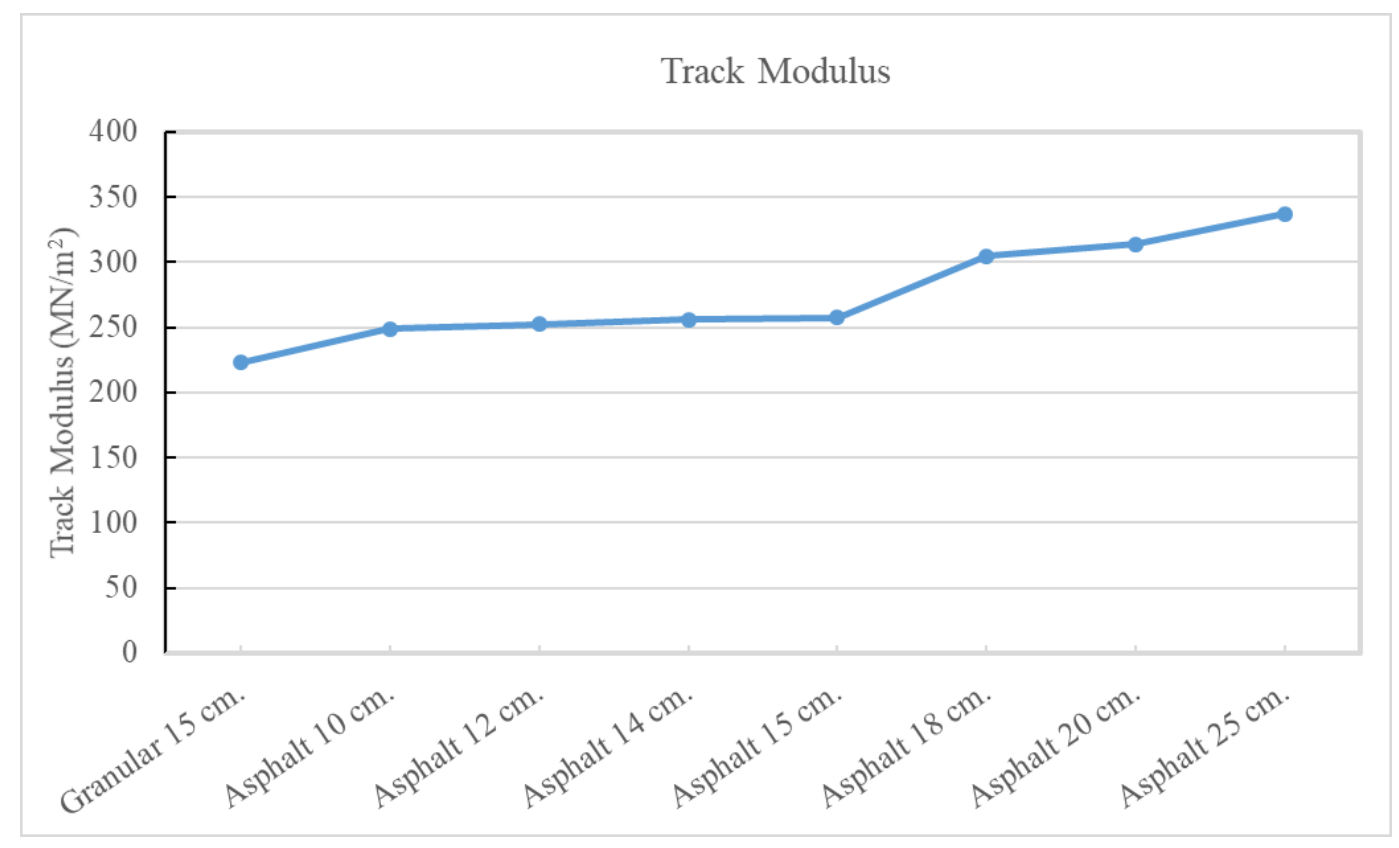

Figure 5-15 Comparison of track modulus between $15 \mathrm{~cm}$ of granular suballast and various asphalt layers 
According to Figure 5-16, the conventional track, that uses $15 \mathrm{~cm}$ of granular subballast, has the track modulus at around $222.81 \mathrm{MN} / \mathrm{m}^{2}$, whereas the track modulus, that uses $10 \mathrm{~cm}$ of the asphalt layer as subballast, is improved around $11.72 \%$. However, as it can be seen in the Figure 5-16, the big jump in the track modulus was when the asphalt layer changes from $15 \mathrm{~cm}$ to $18 \mathrm{~cm}$.

Table 5- 4 Summary of percent improving

\begin{tabular}{|c|c|c|}
\hline $\begin{array}{c}\text { Thickness of Asphalt } \\
(\mathrm{cm})\end{array}$ & $\begin{array}{c}\text { Track modulus } \\
\left(\mathrm{MN} / \mathrm{m}^{2}\right)\end{array}$ & Percent of improving \\
\hline 10 & 248.94 & 11.72 \\
12 & 252.49 & 13.32 \\
14 & 255.76 & 14.78 \\
15 & 257.64 & 15.63 \\
18 & 304.59 & 36.70 \\
20 & 313.73 & 40.80 \\
25 & 337.43 & 51.44 \\
\hline
\end{tabular}

In case of using $30 \mathrm{~cm}$ of granular subballast, the track modulus's value is around 244.58 MN/m², and it is improved around 9.76\%, when comparing with using $15 \mathrm{~cm}$ of granular subballast. 


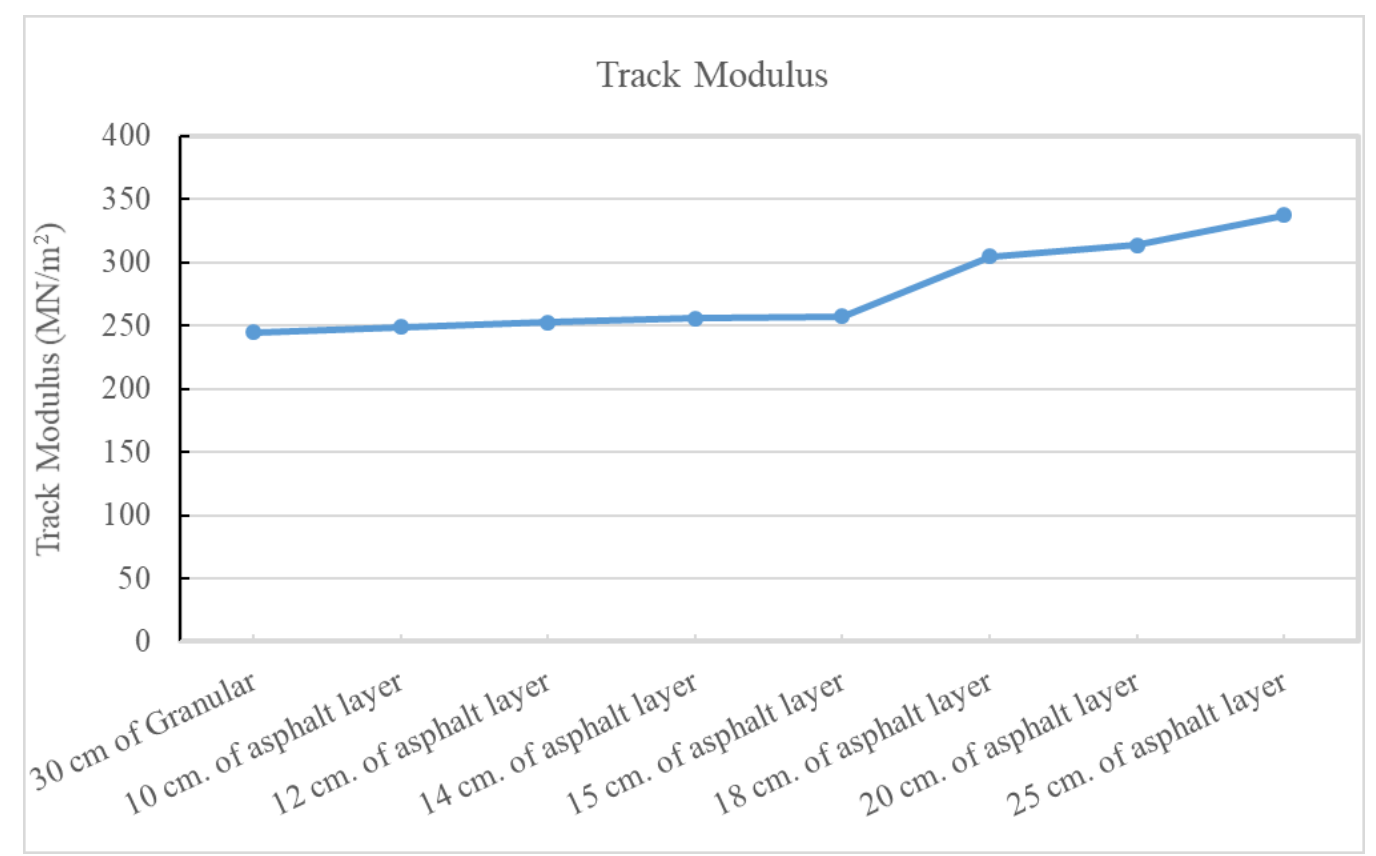

Figure 5-16 Comparison of track modulus between $30 \mathrm{~cm}$ of granular suballast and various asphalt layers

Overall, the track modulus is improved in all three methods. Increasing subballast thickness, using the asphalt layer as subballast, and using a combination track design.

Track modulus when the asphalt layer is placed below the subballast is around 259.69 $\mathrm{MN} / \mathrm{m}^{2}$, and Using the asphalt layer above subballast results $259.40 \mathrm{MN} / \mathrm{m}^{2}$. Therefore, placing asphalt layer above or below the subballast does not change the trackbed modulus.

Table 5- 5 Comparison the track modulus

\begin{tabular}{|l|c|}
\hline \multicolumn{1}{|c|}{ Design method } & $\begin{array}{c}\text { Track modulus } \\
\left(\mathrm{MN} / \mathrm{m}^{2}\right)\end{array}$ \\
\hline $15 \mathrm{~cm}$ of Granular & 222.82 \\
$30 \mathrm{~cm}$ of Granular & 244.59 \\
$15 \mathrm{~cm}$ of Asphalt & 257.64 \\
Asphalt above Subballast & 259.40 \\
Asphalt below Subballast & 259.69 \\
\hline
\end{tabular}




\section{CHAPTER 6 CONCLUSION AND FUTURE STUDY}

\subsection{Conclusion}

Although locomotives have been improved to carry heavy cargo or have high speed, many track routes have not been improved to support a modern locomotive. Railway tracks should provide reliable and safe support for the trains. Three methods have been used to improve trackbeds performance: (1) increasing subballast thickness, (2) using asphalt layer as subballast, and (3) combination of asphalt and subballast. To analyze the performance of the trackbed, stress and displacement under tie and on subgrade surface have been studied.

The finite element program has been used to simulate the trackbed. Firstly, the model was validated through analytical, and experimental measurements. For the first step, shallow foundation on sandy soil was modeled in ABAQUS and the bearing capacity was compared with the theoretical value (Terzaghi equation). The bearing capacity values for different dilation angles were consistent with the results published in literature. For the second, step the experiment performed at the University of Kentucky was simulated using ABAQUS. Stress distributions predicted below the tie for different 
static loadings were consistent with the experimental observations. After validating the finite element model, the validated model is used to predict the optimum asphalt layer thickness and to study the effect of train speed and ballast, subballast, and asphalt thickness on track modulus. Results showed that increasing the asphalt layer from 10 $\mathrm{cm}$ to $25 \mathrm{~cm}$ does not have significant effect on stress distribution below the tie. However, using the combination trackbed (both Asphalt layer and subballst layer) can reduce the stress under the tie by $18 \%$. Results obtained in this study showed increasing the asphalt thickness from $10 \mathrm{~cm}$ to $25 \mathrm{~cm}$ reduces the deflection under tie by $20 \%$.

Stress and displacements on the subgrade surface are also key parameters to design trackbeds. The results from this study show that the vertical stress and the vertical deflection are reduced by $55 \%$ and $37 \%$, respectively, when the thickness of the asphalt layer is increased from $10 \mathrm{~cm}$ to $25 \mathrm{~cm}$. It is interesting to note that increasing the thickness of the asphalt layer to $18 \mathrm{~cm}$ to $25 \mathrm{~cm}$ results in well distributed stress and uniform displacement above the subgrade.

Besides, using the theory of the Winkler (the correlation between the maximum vertical displacement and the applied load) the track modulus for all the combinations were calculated. The calculation's result shows that the track modulus for all cases increase compared to the conventional track (15 $\mathrm{cm}$ of granular subballast). Increasing the asphalt thickness from $15 \mathrm{~cm}$ to $18 \mathrm{~cm}$ increases the track modulus by $18 \%$. Results also showed that increasing the train speed slightly reduces the track modulus by $20 \%$. 
Finally, the validated model is used to study where the asphalt layer should be placed. Results in this study show there is not a significant change in maximum vertical stress, vertical deflection, and the trackbed modulus by placing the asphalt layer below or above the subballast. However, it is easier to place the asphalt layer above the subballast for the construction and therefore it will be more cost efficient.

\subsection{Future Study}

Failure of a track structure has been influenced by some conditions such as loading condition, and environmental condition. Loading condition comes from a heavy freight, or high-speed trains. The extra loading induces immediate settlement, fatigue failure, and shear failure to a whole track structure. The performance of the trackbeds under heavy loads must then be studied. Future research should also perform to predict the effects of environmental conditions on track systems. To accurately model these environmental issues, daily ambient temperature varation, water content, and swellshrinkage of the soil must be considered in the model. Appropriate drainage and viable design for the railroad crossing should be suggested. For some specific locations such as California with high traffic demand, the railway system under the earthquake loading should be analyzed. 


\section{REFERENCES}

Brough, M., Stirling, A., Ghataora, G., and Madelin, K. (2003). "Evaluation of railway trackbed and formation: a case study." NDT \& E International, 36(3), $145-156$.

Buonanno, A. (2000). "The use of bituminous mix subballast in the Italian state railways." 2nd Eurasphalt \& Eurobitume, 1001-1011.

Burrow, M. peter, Ghataora, G. S., and Evdorides, H. (2011). "Railway Foundation Design principles." Journal of Civil Engineering and Architecture, 5(3), 224232.

Cai, Z., Raymond, G. P., and Bathurst, R. J. (1994). "Estimate of static Track Modulus Using Elastic Foundation Models.” Transportation Research Record 1470, 6572 .

Cardona, D. R., Benedetto, H. D., Sauzeat, C., Nguyen, Q., Calon, N., and Robinet, A. (n.d.). "Linear Thermo-Viscoelastic Behaviour of Bituminous Mixtures used for Railway Trackbeds." Proceedings of the Second International Conference on Railway Technology: Research, Development and Maintenance.

Chandra, S., and Agarwal, M. M. (2007). Railway Engineering. Oxford University Press, India.

Chen, B., Chen, G., and Su, X. (n.d.). "Analysis and Evaluation of Ground Vibration Response Induced by Rapid Rail Transit." Geotechnical Engineering for Disaster Mitigation and Rehabilitation, 284-293.

Clarks, D. Rose, J. G., Liu, G. (2018). "Development of a laboratory test method for measuring trackbed pressure at the tie/ballast interface." 97 Annual Meeting Transportation Research Board, January 7-11, Washington, D.C.

Cook, R. D., Malkus, D. S., Plesha, M. E., and Witt, R. J. (2002). Concepts and Application of finite element analysis. Wiley, Dabvers, MA.

D’Andrea, A., Loprencipe, G., and Xhixha, E. (2012). "Vibration Induced by Rail Traffic: Evaluation of Attenuation Properties in a Bituminous Sub-ballast Layer." Procedia - Social and Behavioral Sciences, 53, 245-255.

Das, B. M. (2009). Shallow foundations: bearing capacity and settlement, 2nd ed. CRC Press, Boca Raton, Fla.

Fang, M., Cerdas, S. F., and Qiu, Y. (2013). "Numerical determination for optimal location of sub-track asphalt layer in high-speed rails." Journal of Modern Transportation, 21(2), 103-110. 
Ferreira, T. M., and Teixeira, P. F. (2012). "Rail Track Performance with Different Subballast Solutions: Traffic and Environmental Effects on Subgrade Service Life.” Journal of Transportation Engineering, 138(12), 1541-1550.

Fu, Q., and Zheng, C. (2014). "Three-Dimensional Dynamic Analyses of TrackEmbankment-Ground System Subjected to High Speed Train Loads.” The Scientific World Journal, 2014, 1-19.

Galvín, P., Romero, A., and Domínguez, J. (2010). "Fully three-dimensional analysis of high-speed train-track-soil-structure dynamic interaction." Journal of Sound and Vibration, 329(24), 5147-5163.

Huang, H. (2012). “Track performance modeling under mixed traffic.” 2012 Joint Rail Conference, 147-152.

Huang, H., Shen, S., and Tutumluer, E. (2010). "Moving load on track with Asphalt trackbed." Vehicle System Dynamics, 48(6), 737-749.

Huang, Y. H., Lin, C., and Deng, X. (1984). "Hot mix asphalt for railroad trackbedsstructural analysis and design." Association of Asphalt Paving Technologists, 475-494.

Hudson, A., Watson, G., Pen, L. L., and Powrie, W. (2016). "Remediation of Mud Pumping on a Ballasted Railway Track." Procedia Engineering, 143, 10431050 .

Indraratna, B., Lackenby, J., and Christie, D. (2005). "Effect of confining pressure on the degradation of ballast under cyclic loading." Géotechnique, 55(4), 325328.

Indraratna, B., Nimbalkar, S. S., and Tennakoon, N. (2010). "The Behaviour of Ballasted Track Foundations: Track Drainage and Geosynthetic Reinforcement." GeoFlorida 2010.

Indraratna, B., Nimbalkar, S., Christie, D., Rujikiatkamjorn, C., and Vinod, J. (2010). "Field Assessment of the Performance of a Ballasted Rail Track with and without Geosynthetics." Geotechnical and Geoenvironmental Engineering, 136(7), 907-917.

Kalliainen, A., Kolisoja, P., and Nurmikolu, A. (2016). "3D Finite Element Model as a Tool for Analyzing the Structural Behavior of a Railway Track." Procedia Engineering, 143, 820-827.

Labuz, J. F., and Zang, A. (2012). “Mohr-Coulomb Failure Criterion.” Rock Mechanics and Rock Engineering, 45(6), 975-979. 
Lei, X., and Rose, J. (2008). "Numerical Investigation of Vibration Reduction of Ballast Track with Asphalt Trackbed over Soft Subgrade." Journal of Vibration and Control, 14(12), 1885-1902.

Leshchinsky, B., and Ling, H. I. (2013). "Numerical modeling of behavior of railway ballasted structure with geocell confinement." Geotextiles and Geomembranes, 36, 33-43.

Li, D. (2000). "Deformations and Remedies for Soft Railroad Subgrades Subjected to Heavy Axle Loads." Advances in Transportation and Geoenvironmental Systems Using Geosynthetics.

Li, D., and Selig, E. T. (1995). "Evaluation of Railway Subgrade

Problems." Transportation research Record, (1489), 17-25.

Li, D., and Selig, E. T. (1998). "Method for Railroad Track Foundation Design. I:

Development." Journal of Geotechnical and Geoenvironmental Engineering, 124(4), 316-322.

Li, D., and Selig, E. T. (1998). "Method for Railroad Track Foundation Design. II: Applications.” Journal of Geotechnical and Geoenvironmental Engineering, 124(4), 323-329.

Milne, D., Pen, L. L., Thompson, D., and Powrie, W. (2017). "Properties of train load frequencies and their applications." Journal of Sound and Vibration, 397, $123-140$.

Mino, G. D., Liberto, M. D., Maggiore, C., and Noto, S. (2012). “A Dynamic Model of Ballasted Rail Track with Bituminous Sub-Ballast Layer." Procedia Social and Behavioral Sciences, 53, 366-378.

Momoya, Y., Sekine, E., and Tatsuoka, F. (2005). "Deformation Characteristics of Railway Roadbed and Subgrade under moving-wheel load." Japanese Geotechnical Society, 45(4), 99-118.

Raymond, G. P. (1985). Analysis of track support and determination of track modulus.

Roghani, A., Macciotta, R., and Hendry, M. T. (2017). "Quantifying the Effectiveness of Methods Used to Improve Railway Track Performance over Soft Subgrades: Methodology and Case Study.” Journal of Transportation Engineering, Part A: Systems, 143(9), 04017043.

Rose, J. G., and Bryson, L. S. (2009). "Perpetual Pavements 2009.” Hot Mix Asphalt Railway Trackbeds: Trackbed Materials, Performance Evaluations, and Significant Implications, Ohio. 
Rose, J. G., and Hensley, M. J. (1991). "Performance of Hot Mix Asphalt railway Trackbeds." Transportation Research Record, (1300), 35-44.

Salgado, R. (2008). The Engineering of Foundations. McGrawHill.

Shahraki, M., Sadaghiani, M., Witt, K., and Meier, T. (2014). "Model quality investigations of induced moving loads of high-speed trains." Numerical Methods in Geotechnical Engineering, 1169-1173.

Shahraki, M., Warnakulasooriya, C., and Witt, K. J. (2015). "Numerical study of transition zone between ballasted and ballastless railway track." Transportation Geotechnics, 3, 58-67.

Wang, J. C., Zeng, X., and Mullen, R. L. (2005). “Three-Dimensional Finite Element Simulations of Ground Vibration Generated by High-Speed Trains and Engineering Countermeasures." Journal of Vibration and Control, 11(12), 1437-1453.

Yang, L. A., Powrie, W., and Priest, J. A. (2009). "Dynamic Stress Analysis of a Ballasted Railway Track Bed during Train Passage." Journal of Geotechnical and Geoenvironmental Engineering, 135(5), 680-689.

Zakeri, J. A., and Xia, H. (2008). "Sensitivity analysis of track parameters on traintrack dynamic interaction." Journal of Mechanical Science and Technology, 22(7), 1299-1304. 


\section{CURRICULUM VITA}

NAME:

ADDRESS:

EMAIL ADDRESS:

\section{EDUCATION \&}

RAINING:
Thammapot Wattanapanalai

Department of Civil and Environmental Engineering University of Louisville

Louisville, KY, 40292

t0watt04@louisville.edu

B.E. Civil Engineering

King Mongkut's University of Technology Thonburi Bangkok, Thailand (2008)

B.Sc. Civil and Environmental Engineering University of Kentucky

Lexington, KY (2014)

M.Sc. Business Administration

Kentucky State University

Frankfort, KY (2016)

M.Sc. Civil and Environmental Engineering University of Louisville

Louisville, KY (2018) 